University of Louisville

ThinkIR: The University of Louisville's Institutional Repository

Electronic Theses and Dissertations

$12-2003$

\title{
Oxygen toxicity and mitochondrial metabolism.
}

Jian Li 1974-

University of Louisville

Follow this and additional works at: https://ir.library.louisville.edu/etd

\section{Recommended Citation}

Li, Jian 1974-, "Oxygen toxicity and mitochondrial metabolism." (2003). Electronic Theses and Dissertations. Paper 822.

https://doi.org/10.18297/etd/822

This Doctoral Dissertation is brought to you for free and open access by ThinkIR: The University of Louisville's Institutional Repository. It has been accepted for inclusion in Electronic Theses and Dissertations by an authorized administrator of ThinkIR: The University of Louisville's Institutional Repository. This title appears here courtesy of the author, who has retained all other copyrights. For more information, please contact thinkir@louisville.edu. 


\title{
OXYGEN TOXICITY AND MITOCHONDRIAL METABOLISM
}

\author{
By \\ Jian Li \\ M.D., Tianjin Medical University, 1997 \\ M.S., Peking Union Medical College, 2000 \\ M.S., University of Louisville, 2002
}

\begin{abstract}
A Dissertation
Submitted to the Faculty of the

Graduate School of the University of Louisville in Partial Fulfillment of the Requirements for the Degree of

Doctor of Philosophy

Department of Pharmacology and Toxicology

University of Louisville

Louisville, Kentucky
\end{abstract}

December 2003 


\title{
OXYGEN TOXICITY AND MITOCHONDRIAL METABOLISM
}

\author{
By \\ Jian Li \\ M.D., Tianjin Medical University, 1997 \\ M.S., Peking Union Medical College, 2000 \\ M.S., University of Louisville, 2002 \\ A Dissertation Approved on
}

November 14, 2003

by the following Dissertation Committee:

Dissertation Director 


\section{ACKNOWLEDGEMENTS}

I wish to acknowledge Dr. John W. Eaton, for his valuable counsel and comprehensive leadership throughout this project. I would like to express my sincere gratitude to my graduate committee members, Drs. William M. Pierce, Jr., David W. Hein, Robert D. Gray, and Paul N. Epstein, for their guidance and advice in preparing this dissertation. I would also like to express my thanks to the Department of Pharmacology and Toxicology faculty, staff and graduate students for their collegiality and friendship. Finally, I would like to thank my parents and my fiancé, Eugen C. Campian, for their understanding and support. 


\section{ABSTRACT \\ OXYGEN TOXICITY AND MITOCHONDRIAL METABOLISM}

Jian Li

November 14, 2003

Oxygen is critical to aerobic metabolism, but hyperoxia is cytostatic and cytocidal. The precise mechanisms involved in hyperoxic cell injury remain incompletely understood although there is substantial support for the possibility that hyperoxia increases the 'leak' of electrons from the mitochondrial electron transport chain and the resulting increased generation of reactive oxygen species (ROS) might explain the toxic effects of high oxygen. To evaluate the possible role of mitochondria in oxygen toxicity, we used cloned HeLa cells having no functional mitochondria ( $\rho^{\circ}$ cells) as a model. In contrast to wild-type HeLa cells, $\rho^{\circ}$ cells survive and grow in $80 \% \mathrm{O}_{2}$ but are equally susceptible to oxidant-mediated killing. Two other strategies which diminish mitochondrial ROS generation (exposure of cultures to either carbonyl cyanide mchlorophenylhydrazone [CCCP] or chloramphenicol) also increase tolerance of wild-type HeLa cells to hyperoxia. Thus, three different maneuvers which minimize mitochondrial ROS production improve cell survival and growth under hyperoxia. This suggests that mitochondrial ROS production is primarily responsible for hyperoxic damage. Results of experiments with an oxygen tolerant strain of HeLa cells, which proliferates even under $80 \% \mathrm{O}_{2}$, termed 'HeLa- 80 ', lend further support to this general concept. In this oxygen tolerant cell line, antioxidant defenses are similar to the parent line of HeLa cells. In 
addition, these two cell lines are equally susceptible to killing by hydrogen peroxide and t-butyl hydroperoxide. However, under both $20 \%$ and $80 \% \mathrm{O}_{2}$, intracellular ROS production is $>2$-fold higher in HeLa-20 cells compared to HeLa- 80 cells as assessed by (1) dihydrodicholorfluorescein oxidation, (2) dihydroethidium oxidation, (3) hyperoxiamediated suppression of aconitase activity and (4) mitochondrial protein carbonyl content. Diminished ROS production may be related to the fact that the oxygen-tolerant HeLa-80 cells have significantly higher cytochrome $c$ oxidase (COX) activity ( $\sim 2.0$ fold) than HeLa-20, and preferential blockade of this terminal complex of mitchondrial electron transport by treatment with n-methyl protoporphyrin, which selectively diminishes synthesis of heme-aa 3 in COX, abrogates the tolerance of HeLa- 80 cells to hyperoxia and increases ROS production in HeLa-80 cells under hyperoxia. In the oxygen tolerant HeLa cells, the elevated COX activity may be due to a $>2$-fold increase in $\mathrm{COX} \mathrm{Vb}$ (a regulatory subunit of $\mathrm{COX}$ ) whereas expression levels of three other $\mathrm{COX}$ subunits (COX I, II and IV) are very close to wild-type. Finally, preliminary results indicate a similar over-expression of COX activity in a unique strain of oxygen tolerant rats. Overall, our results suggest that it is possible to make cells tolerant of hyperoxia either by depletion of electron-rich intermediates (in the oxygen tolerant HeLa cells or wild-type cells treated with $\mathrm{CCCP}$ ) or by blockade of respiration $\left(\mathrm{rho}^{\circ}\right.$ and chloramphenicol-treated cells). These observations may serve to guide new pharmaceutical strategies to diminish tissue damage in patients exposed to hyperoxia and to lessen the mitochondrial production of cytotoxic ROS by cellular mitochondria in other clinical situations. 


\section{TABLE OF CONTENTS}

\section{PAGE}

ACKNOWLEDGEMENTS .....................................................

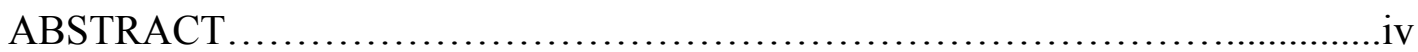

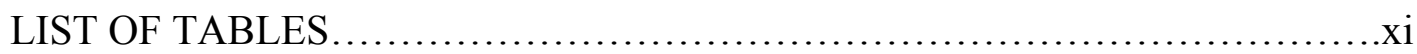

LIST OF FIGURES..................................................

\section{INTRODUCTION}

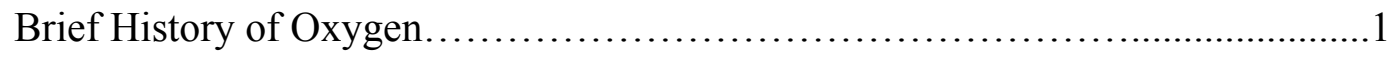

Therapeutic Applications of Oxygen: Success with Toxic Side-Effects............2

An Unexpected Toxicity of Hyperoxia: the Tragedy of Retrolental Fibroplasia.....2

Early Reports of Oxygen Toxicity and the Basis of Oxygen Toxicity.............

Theories Regarding the Mechanism of Oxygen Toxicity.......................4

Oxygen Tolerance....................................................6

Oxygen Tolerance In Eukaryotic Cells.................................... 7

ROS and Oxygen Toxicity...........................................

Mitochondrial Electron Transport....................................... 10

What is the Source of Increased ROS Generation During Hyperoxic Exposure?...11

Where is the Site of ROS Formation in Mitochondria?....................................... 14

Q Cycle............................................................. 14

Cytochrome c Oxidase................................................17 
Metabolic Control of Respiration by COX

COX Activity is Selectively Inhibited by Heme Deficiency.....................20

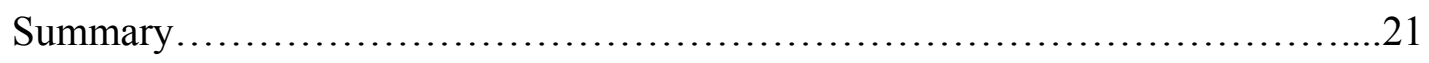

\section{MATERIALS AND METHODS}

Cell Culture......................................................... 23

Establishment of $\rho^{\circ}$ Cells...............................................28

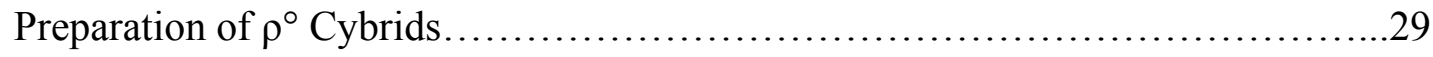

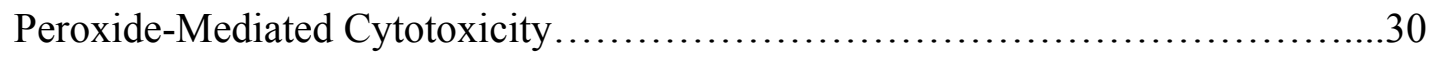

Estimation of Reactive Oxygen Species (ROS) Production....................... 31

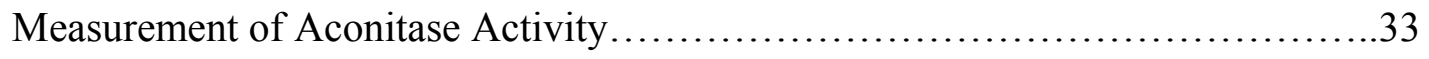

Estimation of Mitochondrial Protein Carbonyls...................................34

Determination of the Source of Intracellular ROS Generation.................... 35

Determinations of $\mathrm{O}_{2}$ Consumption, Glucose Utilization and Lactate Production under

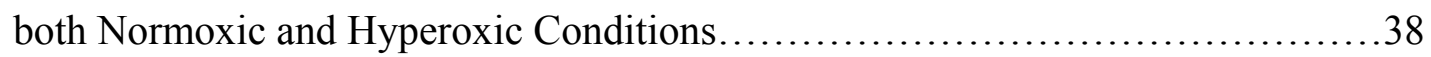

Assays of the Activities of Respiratory Chain Components......................39

Preparation of Purified Mitochondria from Fresh Rat Liver.....................43

Preparation of Mitochondria from Cultured Cells $\ldots \ldots \ldots \ldots \ldots \ldots \ldots \ldots \ldots \ldots \ldots . . .44$

Enzymatic Detection of the Lysosomal Marker Enzyme, $\beta$-Galactosidase..........45

JC-1 Staining as an Indicator of Mitochondrial Membrane Potential -

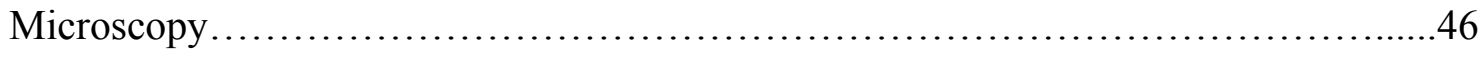

JC-1 Accumulation as an Indicator of Mitochondrial Membrane Potential -

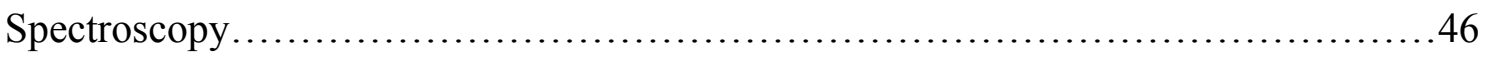

Measurement of Heme Oxygenase Enzyme Activity.........................46 
Electrophoretic Procedures and Western Blotting. .47

Real-Time Reverse Transcript Polymerase Chain Reaction (RT-PCR).............52

Small Interference RNA (SiRNA) Transfection................................55

\section{RESULTS AND DISCUSSION}

Part I. ROS Produced by Mitochondria are Causally Related to Hyperoxic Cell

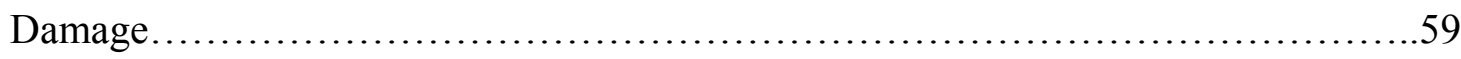
A. $\rho^{\circ}$ cells have a growth and survival advantage in hyperoxia 60
B. $\rho^{\circ}$ cybrids exhibit wild-type sensitivity to hyperoxia.........................65
C. $\rho^{\circ}$ cells are not resistant to oxidant killing.................................68
D. Differences in intracellular ROS generation in wild-type vs. $\rho^{0}$ cells............70
E. Pharmacologic suppression of mitochondrial ROS production also permits the survival and growth of wild-type HeLa cells under hyperoxia.....................73

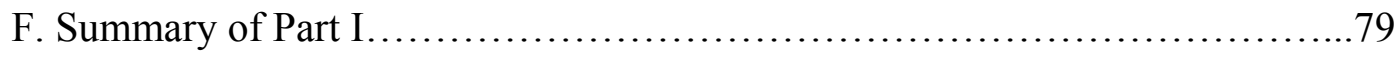

Part II: Investigations of a Unique Line of Oxygen-Tolerant HeLa Cells..............81

A. HeLa-80 cells grow and survive in hyperoxia............................... 81

B. HeLa-20 and HeLa- 80 cells do not differ in susceptibility to oxidant killing...88

C. Oxygen tolerant HeLa-80 cells exhibit decreased ROS production under both

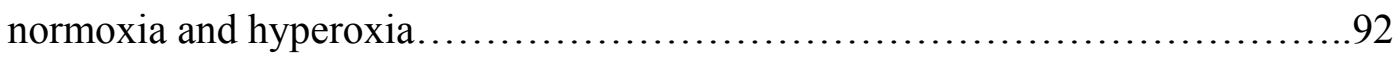

D. Additional evidence that oxygen tolerant HeLa- 80 cells generate less ROS under both normoxia and hyperoxia............................................ 97 E. Mitochondrial respiration inhibitors modulate ROS production by both HeLa-20

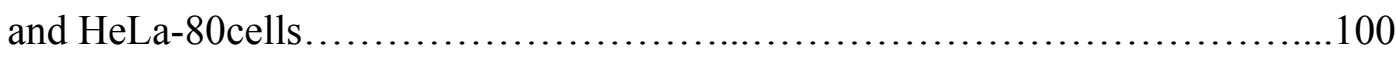

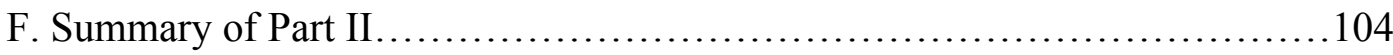


Part III: Why Do the Mitochondria in HeLa-80 Cells Generate ROS?. .105

A. HeLa-80 cells are more metabolically efficient .......................... 105

B. Cytochrome c oxidase (COX) activity is elevated in HeLa-80 cells............110

C. There are no corresponding differences in the activities of complexes I-III in HeLa20 vs. HeLa-80 cells.

D. Preferential inhibition of cytochrome c oxidase activity in HeLa-80 cells abrogates their oxygen tolerance

E. HeLa-80 cells show a highly significant increase in 'respiratory potential' ....123

F. Summary of part III.....................................................

Part IV. Molecular Basis for the Increased COX Activity in HeLa-80 Cells.........126

A. Subunit Vb of COX is over-expressed in HeLa-80 cells.....................127

B. COX Vb mRNA levels are similar in HeLa-20 and HeLa-80 cells...............129

C. Suppression of COX Vb expression via Small - interference RNA (SiRNA) in HeLa-80 cells

D. Summary of Part IV

Part V: Oxygen Tolerant Rats and HeLa-80 Cells: A Common Mechanism?............135

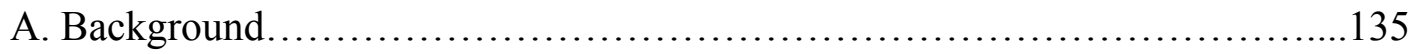

B. Pulmonary fibroblasts from oxygen tolerant rats are more sensitive to peroxidemediated killing........................................................ 136

C. In the oxygen tolerant rats, mitochondrial COX activity is amplified...........138

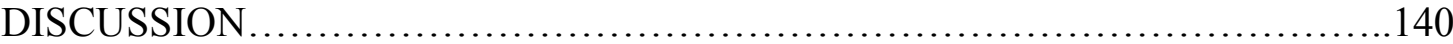

The Cytostatic and Cytocidal Effects of Hyperoxia are Associated with Enhanced Intracellular ROS Production 143 
The Origins of Hyperoxia-Mediated ROS Generation......................... 144

The Importance of Antioxidant Status in Oxygen Toxicity......................145

Oxygen Tolerant HeLa Cells Have Normal Antioxidant Defenses................147

Mitochondrial Metabolism is the Focal Point of Hyperoxic Cell Injury............148

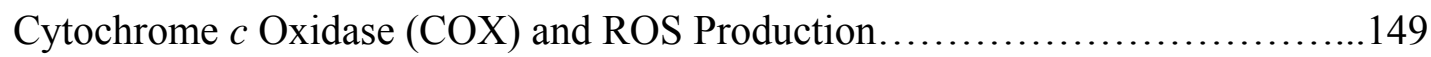

The Possibility That Increased COX Vb Expression Plays A Major Role in Higher

COX Activity of HeLa-80 Cells........................................... 151

Oxygen Tolerance in HeLa Cells and Rats: A Common Mechanism?....................152

The Possibility That Oxygen Tolerance Arises from Enhanced Anti-Apoptotic

Mechanisms............................................................ 154

Do Hyperoxia and Radiation Damage Cells through A Common Mechanism?....155

SUMMARY AND CONCLUSIONS ........................................ 157

FUTURE INVESTIGATIONS........................................ 159

REFERENCES ........................................................... 161

APPENDICES ...................................................... 186

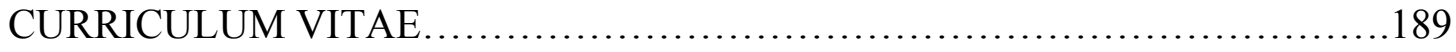




\section{LIST OF TABLES}

TABLE

PAGE

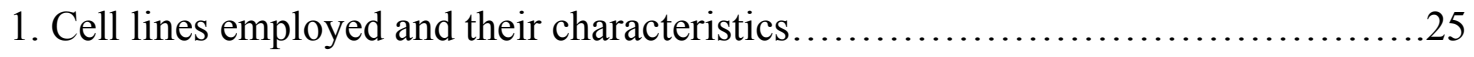

2. Sense and antisense primers used for quantitative RT-PCR analysis.............58

3. Cytochrome c oxidase activity and $\mathrm{O}_{2}$ consumption in wild-type and respiration-

deficient HeLa cells....................................................62

4. Adenine nucleotide related intermediates in HeLa cells........................109 


\section{LIST OF FIGURES}

FIGURE

PAGE

1. Study model: oxygen tolerant HeLa-80 cells.................................. 8

2. Mitochondrial electron transport chain.......................................

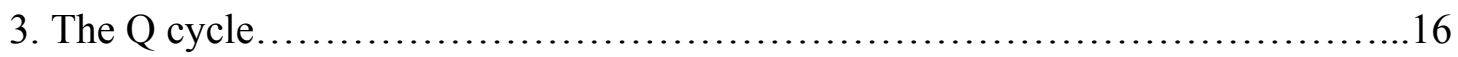

4. Mitochondrial electron transport and sites of action of various inhibitors............37

5. Growth characteristics of wild-type and $\rho^{\circ} \mathrm{HeLa}$ cells in normoxic and hyperoxic

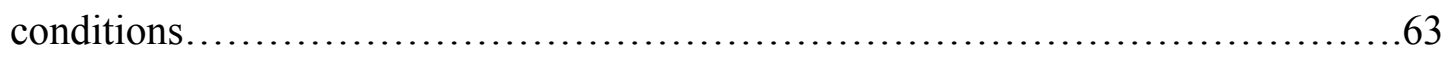

6. Growth characteristics of $\rho^{\circ}$ HeLa cells and cybrids in hyperoxic conditions......66

7. Mitochondrial ROS generation in wild-type, $\rho^{\circ}$ and cybrid HeLa cells............67

8. Susceptibility of wild-type, $\rho^{\circ}$ and cybrid HeLa cells to oxidant-mediated cell

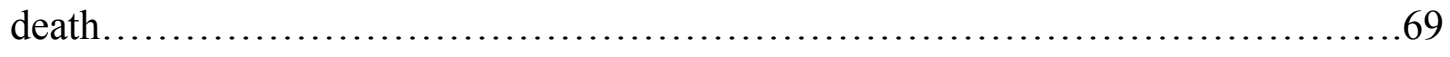

9. Wild-type, but not $\rho^{\circ}$, HeLa cells show hyperoxia-dependent inhibition of aconitase

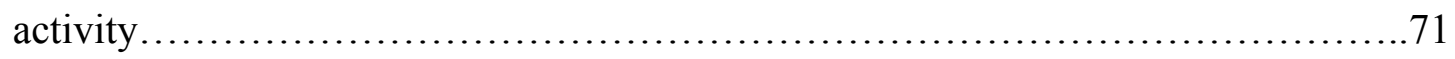

10. Wild-type, but not $\rho^{0}$, HeLa cells show hyperoxia-dependent increased mitochondrial protein carbonyl formation.

11. The protonophoric uncoupler, $\mathrm{CCCP}$, decreases ROS production and enhances the survival of HeLa cells under hyperoxia. .74 
12. Inhibition of mitochondrial protein synthesis with chloramphenicol decreases ROS production and increases survival of HeLa cells under hyperoxia.

13. Growth characteristics of wild-type HeLa-20 and oxygen tolerant HeLa- 80 cells in normoxic and hyperoxic conditions .83

14. Changes in mitochondrial membrane potential (reflected by JC-1 staining) in the absence and presence of $10 \mu \mathrm{M}$ CCCP. .86

15. HeLa-20 and HeLa-80 cells were grown under $80 \%$ Oxygen for 10 days

16. Total heme oxygenase activities measured in HeLa-20, HeLa-80 and rho ${ }^{\circ} \mathrm{HeLa}-20$ cell lines

17. Bcl-2 levels in HeLa-20, HeLa-80, rho0-HeLa20 and the corresponding cybrids .90

18. Susceptibility of wild-type HeLa-20 and oxygen tolerant HeLa-80 cells to oxidantmediated cell death.

19. Mitochondrial ROS generation in wild-type HeLa-20 and oxygen tolerant HeLa-80 cells. ...

20. Mitochondrial ROS generation in wild-type HeLa-20 and oxygen tolerant HeLa-80 cells under both normoxic and hyperoxic conditions.

21. Wild-type HeLa-20, but not oxygen tolerant HeLa-80 cells, show hyperoxiadependent inhibition of aconitase activity .98

22. Wild-type HeLa-20, but not oxygen tolerant HeLa-80 cells, show hyperoxiadependent increased mitochondrial protein carbonyl formation. .99 
23. Inhibitors of complexes I and II decrease ROS production in both HeLa-20 and HeLa-80 cells 101

24. The mitochondrial inhibitor, antimycin A, increases ROS production in both HeLa-20 and HeLa-80 cells. 103

25. Glucose consumption by HeLa cells were measured over a 24-hr period under both normoxic and hyperoxic conditions .106

26. Lactate production by HeLa cells over a 24-hr period under both normoxic and hyperoxic conditions 107

27. Cytochrome c oxidase activity in HeLa-20 and HeLa-80 cells.

28. Complex I (NADH reductase) activity in HeLa-20 and HeLa-80 cells....

29. Complex II (succinate reductase) activity in HeLa-20 and HeLa-80 cells....

30. Complex III (cytochrome $c$ reductase) activity in HeLa-20 and HeLa-80 cells...116

31. N-methyl protoporphyrin (NMP) preferentially blocks COX activity...

32. N-methyl protoporphyrin (NMP) preferentially decreases COX subunit II

33. ROS production by HeLa- 80 cells grown in the continuous presence of $5 \mu \mathrm{M} \mathrm{N}$ methyl protoporphyrin (NMP) for different periods

34. COX suppression abrogates the oxygen tolerance of HeLa-80 cells....

35. Oxygen consumption by HeLa-20 and HeLa- 80 cells in the absence and presence of $20 \mu \mathrm{M}$ CCCP

36. Western blot analysis of COX subunit expression in HeLa-20 and HeLa-80 cells.128 37. Similar mRNA levels of COX Vb in HeLa-20 and HeLa-80 cells detected by real time RT-PCR 
38. Significantly decreased COX Vb proteins in siRNA transfected HeLa-80 cells by Western blot

39. Significantly decreased mRNA level for COX Vb in siRNA transfected HeLa- 80

cells as detected by real time RT-PCR

40. Primary pulmonary fibroblasts cultured from oxygen tolerant rats are more sensitive to peroxide-mediated killing

41. Hepatic mitochondrial COX activity in control and oxygen tolerant rats 139

42. Schematic representation of our tentative conclusions. 


\section{INTRODUCTION}

\section{Brief History of Oxygen}

Centuries ago, it was known that air was composed of more than one component. The behavior of oxygen and nitrogen as components of air led to the advancement of the phlogiston theory of combustion, which tortured chemists for a century. Oxygen was produced by several chemists prior to its 'formal' discovery in 1774 by Joseph Priestley and Carl Wilhelm Scheele. Both produced oxygen by heating mercuric oxide $(\mathrm{HgO})$, generating 'dephlogisticated air' (Priestly) or 'fire air' (Scheele). Antoine Lavoisier, who coined the term 'oxygen' from 'oxus' (gr. acid) and 'gennan' (gr. generate) did so out of the mistaken impression that this substance was required for the formation of all acids.

Oxygen, a diatomic gas $\left(\mathrm{O}_{2}\right)$ at standard temperature and pressure, makes up approximately $21 \%$ of the earth's atmosphere. Oxygen is both highly reactive (able to combine with most elements) and required for respiration, the major source of metabolic energy for most aerobic organisms. Unfortunately, as reviewed below, prolonged exposure to pure oxygen can be toxic, having both pulmonary and (when administered hyperbarically) neurological effects. Pulmonary effects include edema, loss of lung capacity and damage to lung tissues. More acute neurological effects of exposure to very high oxygen pressures include loss of vision, convulsions and coma. 


\section{Therapeutic Applications of Oxygen: Success with Toxic Side-Effects}

Oxygen supplementation is certainly not a new concept as a therapeutic modality for treating the sick. The use of hyperbaric air began in 1662 when Henshaw, a European physician, used it to treat respiratory ailments and to 'cool the fires of the heart'. After the discovery of oxygen in 1774, air was enriched with oxygen and even more benefits were claimed, all unfounded. At the end of the 1800's, Paul Bert discovered that oxygen was poisonous at high pressure. Despite this, interest in the medical use of hyperoxia and hyperbaric air persisted and, in 1918, Orval Cunningham, an American physician, was very successful in the treatment of pneumonia by hyperbaric air. Around this time, Dr. Edgar End also obtained good results in treatment of victims of carbon monoxide poisoning with hyperbaric oxygen therapy. Following two decades of relative inactivity in research on hyperoxia/hyperbaria, Boerema and Brummelkamp, two American surgeons, in the late 1950 's, used a hyperbaric oxygen chamber during cardiovascular surgery and for the therapy of gas gangrene. This marked the beginning of the modern era of hyperbaric oxygen therapy. However, as reviewed below, this was not without major mishap.

\section{Unexpected Toxicity of Hyperoxia: the Tragedy of Retrolental Fibroplasia}

Around 1940, hyperoxia came to be used extensively to support respiratory function, especially in newborn infants with pulmonary insufficiency. Shortly thereafter, the first description of retrolental fibroplasia (RLF) was published in 1942. Over the next decade, thousands of babies became blind before the outbreak of this previously rare disease was firmly attributed to the use of supplemental oxygen. The first suggestion that 
oxygen might cause retrolental fibroplasia was made by Kate Campbell (Campbell, 1951) and the first controlled trial suggesting that too much oxygen could damage the eyes of preterm babies appeared in 1952 (Patz et al., 1952). In that year, the first large landmark trial in neonatal medicine confirmed that although oxygen was a 'good thing' it was quite possible to have 'too much of a good thing' (Kinsey et al., 1956). In further support of this, it was found that preterm infants receiving $70 \%$ oxygen for $4-7$ weeks frequently developed RLF whereas those receiving $<40 \%$ oxygen for $1-2$ weeks were spared the disease (Patz et al., 1952; Crosse and Evans, 1952). About this time realization dawned that high oxygen might affect the lung as well as the eye (Carpenter et al., 1973).

\section{Early Reports of Oxygen Toxicity and the Basis of Oxygen Toxicity}

A general precept of toxicology is that anything is toxic at a high enough concentration (Paracelsus, 1493-1541). Without question, this is true of oxygen (Knight, 1998). Oxygen has often been referred to as 'a double-edged sword'; although it is critical for life, many essential intracellular reactions which require oxygen result in the formation of free radicals.

Shortly after the discovery of oxygen, Lavosier reported that oxygen inhalation had poisonous effects (Binger et al., 1927). Oxygen toxicity was first described in laboratory animals by Bert in 1878 who found that high concentrations of oxygen caused convulsions and death in sparrows, some laboratory animals, insects and even earthworms. Twenty years later, Smith showed that increased oxygen tensions cause severe pulmonary congestion with pneumonia-like changes in mice, rats and guinea pigs 
(Smith et al., 1899). Later, in 1927, Binger also reported that concentrations greater than $70 \%$ oxygen were poisonous to dogs, rabbits, guinea pigs, and mice (Binger et al., 1927). In 1945, Comoroe and colleagues reported the toxic effects of inhalation of high concentrations of oxygen in normal men both at sea level and at a simulated altitude of 18,000 feet above sea level (Comoroe et al., 1945).

Despite the above evidence of pulmonary oxygen toxicity and the clear example of RLF, it was not until the mid 1960's that lung damage from hyperoxia was definitely recognized. Nash (Nash et al., 1967) reported a close relationship between the concentration and duration of inspired oxygen before death and pulmonary pathologies at autopsy. One year later, the formation of pulmonary hyaline membranes in adults was reported to result from treatment with hyperoxia (Soloway et al., 1968). These and many other observations left no doubt that, especially with regard to the lung, hyperoxia was "too much of a good thing".

\section{Theories Regarding the Mechanism of Oxygen Toxicity}

Although the first experiment regarding a free radical reaction was reported in 1894 (Fenton et al., 1894), the involvement of free radicals (or, more properly, reactive oxygen species) in oxygen toxicity was not suspected until Gerchman proposed that damage caused by both hyperoxia and X-irradiation might have a common basis - the formation of free radicals (Gerschman, 1954). Indeed, oxygen and gamma radiation exert synergistic effects; in the presence of oxygen, the dose of gamma irradiation needed to kill cells is about one-third of the dose needed for an equal effect under anoxic conditions 
(the so-called 'oxygen enhancement ratio') (Alper and Howard-Flanders, 1956; Dewey, 1960). This probably is because only about one-third of the damage caused by $\mathrm{x}$ irradiation is due to a direct hit on DNA whilst the remainder of the damage arises from the production of reactive oxygen species (which then secondarily damage DNA).

Despite the early and prescient suggestion by Gerschman that oxygen toxicity might have a free radical basis, the importance of free radicals in biological systems was not generally accepted until the discovery of superoxide dismutase in 1969 (McCord and Fridovich, 1969). Free radicals are now widely considered to be very important in many (perhaps too many) pathological processes such as aging, atherosclerosis, cancer, cardiac myopathy, cataractogenesis, diabetes mellitus, immune system disorders, ischemia/reperfusion injury, liver diseases, kidney diseases, lung diseases, neurodegenerative disorders, nutritional deficiencies, radiation injury and skin disorders (Knight, 1998). This list definitely includes hyperoxic injury to cells and organs which clearly involves reactive oxygen production promoted by hyperoxia (Jamieson, 1989).

The present (albeit vague) theory of oxygen toxicity is that during hyperoxic exposure reactive species (ROS) are produced at a rate which exceeds the detoxification capacity of cellular antioxidant defenses (Jamieson, 1989). The amount of hyperoxia required to cause cellular damage and the time course of these changes vary from species to species and from individual to individual within the same species. Age, nutritional status, presence of underlying diseases, and certain drugs may influence the development of oxygen toxicity. There is currently no reliably effective drug for preventing or 
delaying the development of oxygen toxicity in humans but, as described below, instances of oxygen tolerance have been described.

\section{Oxygen Tolerance}

Some evidence for the involvement of ROS in hyperoxic damage derives from studies of oxygen tolerant animals. For example, a number of earlier investigations clearly show that very young animals are more tolerant to hyperoxia than are their older counterparts (Clark and Lamberts, 1971), yet the age-dependent factor(s) involved in this tolerance remain unknown. Furthermore, it has been known for many years that tolerance to hyperoxia can be induced in some species, mainly rats, by various means such as intermittent exposure to hyperoxia or prior exposure to raised but sublethal concentrations of oxygen (Clark and Lamberts, 1971). Interestingly, similar tolerizing effects have been demonstrated using injections of endotoxin or cytokines such as IL-1 and tumor necrosis factor-alpha (TNF- $\alpha$ ) (Frank and Roberts, 1978b; 1978a; Frank et al., 1978; Tsan et al., 1991a; 1991b; 1991c; 1992a; 1992b). The protective effects of these pre-treatment regimens have been ascribed variously to the induction of particular antioxidant enzymes (e.g., Mn-SOD), changes in nitric oxide production, diminished neutrophil recruitment and modulation of alveolar macrophage activity (Capellier et al., 1998a; 1998b) . For example, following bacterial endotoxin pre-treatment, adult rats exposed to $95-98 \% \mathrm{O}_{2}$ demonstrated increased activities of pulmonary SOD, catalase and glutathione peroxidase (Frank and Roberts, 1978b). We should note, however, that, although increases in antioxidant enzyme activities have been correlated with increased oxygen tolerance, the responses associated with tolerance have been cell type- and animal 
species-dependent (Deneke and Fanburg, 1980; Deneke and Fanburg, 1982), suggesting that each particular cell system may have its own characteristic survival strategy to oxygen stress (Gille et al., 1988). Nonetheless, these earlier findings raised the concept that increased or over-expressed antioxidant activity might confer oxygen tolerance.

\section{Oxygen Tolerance In Eukaryotic Cells}

Interestingly, cultured cells also can be used as in vitro models of oxygen toxicity and tolerance. An oxygen-tolerant line of HeLa cells was previously developed by Dr. Hans Joenje (Joenje et al., 1985) by continuous culture of wild-type cells with stepwise increases of $\mathrm{pO}_{2}$ over a prolonged period of time (approximately 21 months). The selection process is shown in Figure 1. These HeLa cells (termed 'HeLa-80') can survive and proliferate under $80 \% \mathrm{O}_{2}$, an oxygen concentration that is lethal to the original cell line and most other cell types. Importantly, this oxygen tolerance is a stable genetic characteristic. Long-term culture of HeLa-80 cells under normoxic conditions does not affect tolerance to subsequent exposure to hyperoxia. This selection for genetic variant(s) was probably aided by the notorious genetic instability of HeLa cells. HeLa cells are genetically heterogeneous (McCord, 1969) and this heterogeneity may be enhanced under hyperoxic conditions due to the mutagenic effects of hyperoxia (Gille and Joenje, 1989; Joenje, 1983). 


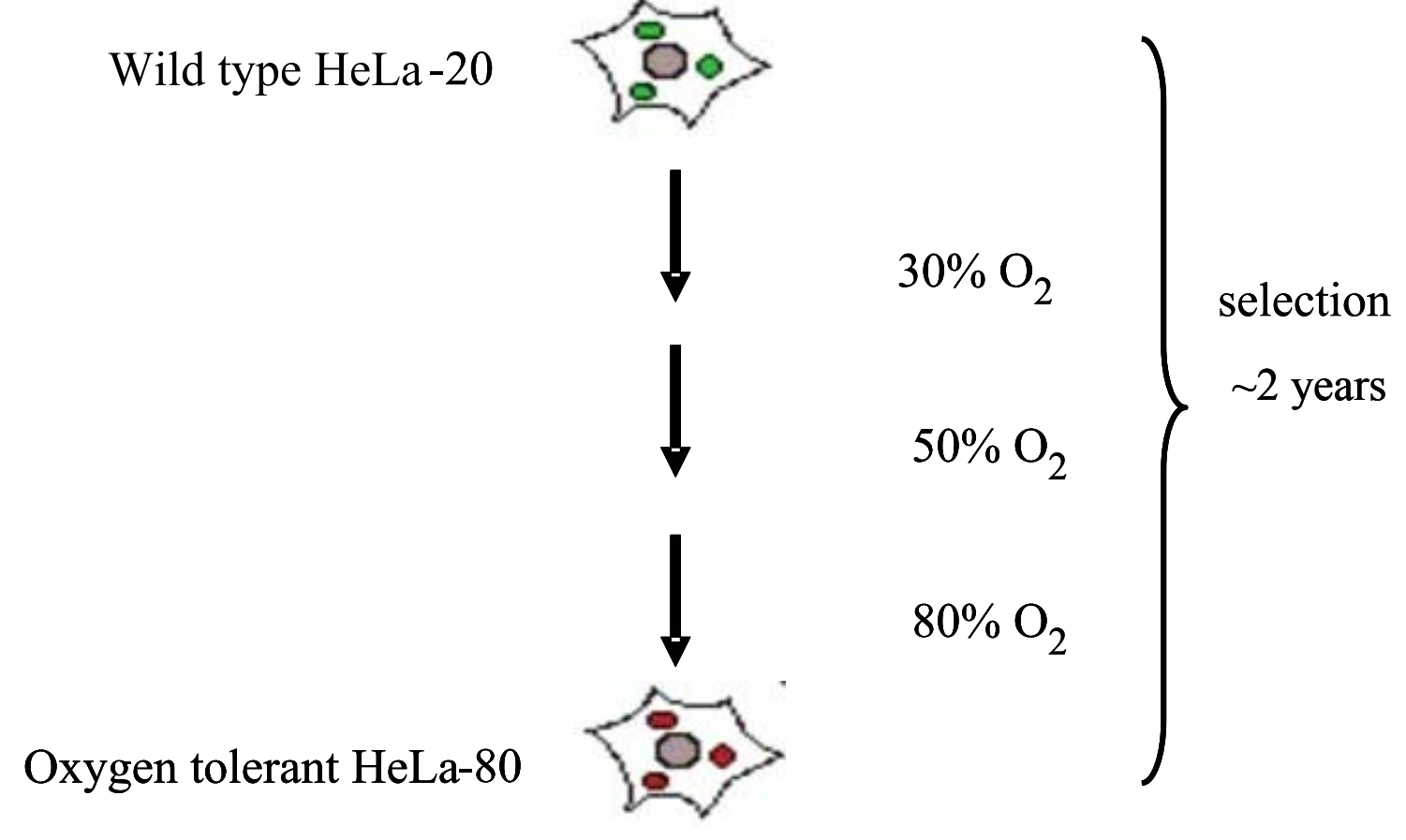

Figure 1. Study model: oxygen tolerant HeLa-80 cells. 
Despite many decades of work on the question, it is still not known how hyperoxia causes damage to cells and tissues. Nonetheless, it is commonly believed that free radicals play a key role in the pathophysiology of oxygen toxicity and cellular damage is probably mediated by increased production of ROS (Gerschman et al., 1954). This excessive production of ROS likely derives from the mitochondria which, under conditions of high oxygen, exhibit increased electron leak from the electron transport chain (Chance et al., 1979; Gerschman et al., 1954).

Based on the free radical theory of oxygen toxicity, it might be anticipated that physiologic mechanisms of this unusual oxygen tolerance might arise from (1) decreased intracellular generation of ROS, (2) increased levels of antioxidant defense enzymes, (3) an increased repair/turnover rate of damaged cell components, or (4) some combination of these. A major goal of the present research was to attempt to dissect these possibilities.

\section{$\underline{\text { ROS and Oxygen Toxicity }}$}

If enhanced ROS production is, in fact, at the root of oxygen toxicity, then there are at least two major ways in which cells might avoid oxygen toxicity: hypertrophied antioxidant defense systems or lesser production of ROS. Important antioxidant defenses include glutathione and related enzymes (glutathione reductase, glutathione peroxidase, thioredoxin/thioredoxin reductase, peroxiredoxins), ascorbic acid, vitamin E, catalase, superoxide dismutases (both the cytoplasmic $\mathrm{Cu} / \mathrm{Zn} \mathrm{SOD}$ and the mitochondrial $\mathrm{Mn}$ SOD), and control of intracellular transition metals by proteins such as metallothionine and ferritin (Scott et al, 1997). However, in the case of the oxygen tolerant HeLa cells 
under study, it appears that the activities of all defenses against ROS measured thus far are normal (i.e., nearly identical to those in the wild-type Hela-20 cells) (Joenje et al., 1985e). This has two major implications. First, it indicates that the tolerance of these cells to high oxygen is probably not due to hypertrophied defenses against ROS. Second, many of these antioxidant enzymes are known to be induced by ROS. The fact that these enzymes display normal activities even in HeLa-80 cells exposed to high oxygen suggests that these cells somehow manage to avoid exaggerated ROS production even when exposed to high partial pressures of oxygen (Joenje et al., 1985d; Gille et al., 1988).

\section{$\underline{\text { Mitochondrial Electron Transport }}$}

The apparent lack of any changes in antioxidant defenses in the HeLa-80 cells directed our attention to the mitochondrial electron transport chain (Figure 2). Reducing species such as $\mathrm{NADH}$ and $\mathrm{FADH}_{2}$ are generated in the cytosol from glycolysis and in the mitochondrial matrix from the tricarboxylic acid cycle. Mitochondria generate ATP from reduced electron carriers via oxidative phosphorylation. The energy carried by the reduced electron carriers is released gradually by passing electrons along the components of the electron transport chain and is used to create a proton gradient across the inner mitochondrial membrane. The electron transport chain consists of four inner membraneassociated complexes, ubiquinone and cytochrome $c$. Complex I (ubiquinone oxidoreductase) accepts electrons from NADH and transfers them to ubiquinone. Ubiquinone also can accept electrons from complex II and other $\mathrm{FADH}_{2}$ containing dehydrogenases. Electrons are further transferred from reduced ubiquinone to complex III, then to cytochrome $c$, complex IV (COX) and finally to molecular $\mathrm{O}_{2}$ (which is fully 
reduced to $\mathrm{H}_{2} \mathrm{O}$ ). The proton gradient created by the electrons passing through complexes I, III and IV is used to power ATP synthase (complex V).

\section{What is the Source of Increased ROS Generation During Hyperoxic Exposure?}

Energy production by mitochondria is essential for a multitude of cellular functions, including intermediary metabolism, ion regulation and other active transport processes, cell mobility and cell proliferation. In most cells, the vast majority of energy (about 95\%) is derived from oxidative phosphorylation. But even under well-coupled (normoxic) conditions, as much as $1-2 \%$ of the reducing equivalents escape the respiratory chain, initially as superoxide $\left(\mathrm{O}_{2}{ }^{-}\right)$and, thence, hydrogen peroxide $\left(\mathrm{H}_{2} \mathrm{O}_{2}\right)$ (Chance et al., 1979). In vivo, particularly in tissues not exposed to atmospheric oxygen, the proportion of oxygen converted $\mathrm{O}_{2}^{-}$is likely to be smaller since the intramichondrial $\mathrm{pO}_{2}$ is between 3 and $30 \mu \mathrm{M}$ (Genova et al., 2001; Alvarez et al., 2003). Because ROS generation is a continuous process, mitochondria and extra-mitochondrial compartments possess efficient antioxidant systems (as described above). Under hyperoxic conditions, or in the presence of defective antioxidant systems (as might, for example, be the case for premature infants), mitochondria can generate excess ROS and cell damage may ensue. 


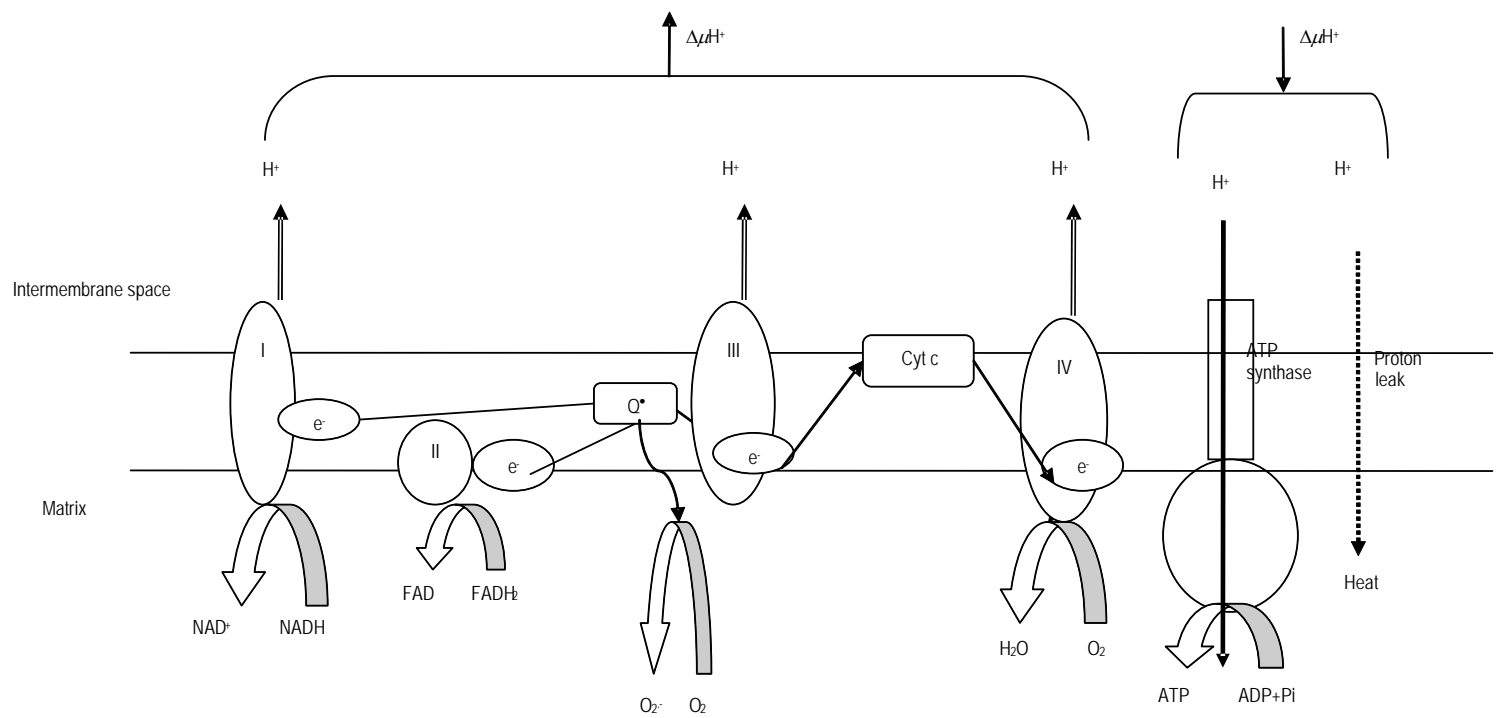

Figure 2. Mitochondrial electron transport chain.

Note the formation of ubisemiquinone (Q') between complexes II and III, thought by many investigators to be the major source of superoxide formation. 
ROS have been implicated in cell dysfunction and death associated with hyperoxia (Hengartner, 2000). It is likely that metabolically-generated ROS (primarily $\mathrm{O}_{2}{ }^{-}$and $\mathrm{H}_{2} \mathrm{O}_{2}$ ) are not particularly injurious because $\mathrm{H}_{2} \mathrm{O}_{2}$ reacts slowly with most targets and $\mathrm{O}_{2}{ }^{-}$, although capable of inactivating certain enzymes (especially those with ironsulfur clusters in the active site), is actually a reducing agent. The dismutation of $\mathrm{O}_{2}^{-}$ occurs in stages; $\mathrm{O}_{2}^{-}$must first combine with a proton to yield the hydroperoxyl radical, $\mathrm{HO}_{2}$, which is more reactive than $\mathrm{O}_{2}{ }^{-}$(Bielski, 1979). Formation of $\mathrm{HO}_{2}$ is favored at $\mathrm{pH}$ values lower than "physiological", but the phagocytic vacuole operates at an acid $\mathrm{pH}$ and the pericellular $\mathrm{pH}$ of macrophages has been reported to be 6 or less (Etherington, 1979). Although $\mathrm{HO}_{2}$ can act as a direct oxidant, the majority of damage from metabolic ROS may involve radical generation catalyzed by transition metals such as iron and copper. In the presence of $\mathrm{O}_{2}{ }^{-}$and $\mathrm{H}_{2} \mathrm{O}_{2}$, these metals can produce the dread, highly-reactive hydroxyl radical (HO) via Fenton-type chemistry or, in the case of iron, related ferryl/perferryl species.

Even under normal conditions, ROS are important agents of cell damage and, in extremis, apoptotic and necrotic cell death. Exogenously added ROS such as $\mathrm{H}_{2} \mathrm{O}_{2}$ and tert-butyl hydroperoxide induce either form of cell death depending on concentration (Brunk et al., 2001; Antunes et al., 2001). Furthermore, quinone compounds such as menadione can undergo redox cycling, leading to the production of excessive amounts of $\mathrm{O}_{2}{ }^{-}$and $\mathrm{H}_{2} \mathrm{O}_{2}$, which will cause cell death (Gutierrez et al., 1982). Even in the absence of such xenobiotics, increased endogenous ROS production has been implicated in the etiology of a great many neurodegenerative disorders (such as Alzheimer's disease, 
Down's syndrome, and familial amyotrophic lateral sclerosis), inflammatory and cardiovascular diseases (Amstad et al., 2001).

\section{Where is the Site of ROS Formation in Mitochondria?}

Assuming that hyperoxic cell damage does arise from exaggerated mitochondrial ROS production, the site of electron leak from the electron transport chain becomes an important question. Although this is still an area of some controversy, most experts agree that ubisemiquinone, present at both complex I and complex III, is a likely candidate. Several studies have reported that complex III is the main site of ROS production under normal metabolic conditions, especially in heart and lung mitochondria (Finkel et al., 2000; Goijman et al., 1985; Turrens et al., 1982; Turrens, 1997; Turrens, 2003). Ubiquinones are very hydrophobic (bearing usually 6 to 10 isoprene units) and can undergo both one- and two-electron reduction. The one-electron reduction intermediate (just like that formed in the case of menadione mentioned above) is called ubisemiquinone. The fully reduced (2e-) form is called ubiquinol or dihydroubiquinone.

\section{Q Cycle}

In the so-called Q cycle, electrons from ubiquinol are donated to complex III, one electron reducing an iron-sulfur (FeS) protein and the second reducing cytochrome $b$. The FeS protein is a lower-energy carrier, while cytochrome $b$ is a higher energy carrier, able to pass electrons back to ubiquinone (forming ubisemiquinone). Also, in this process, protons are relocated; ubiquinol passes the electrons to the FeS protein and cytochrome b, translocating two protons. One of the electrons (the one on the FeS protein) is passed on 
to cytochrome $c$ and down the electron transport chain. Thus, for each electron from complex I, two protons are translocated (Figure 3) (Birch-Machin et al., 2001).

The redox-cycling of quinones has been used in cancer therapy. Some quinonecontaining anti-tumor agents are enzymatically reduced leading to the formation of either the (ROS-generating) semiquinone or the hydroquinone. The semiquinone can donate its extra electron to $\mathrm{O}_{2}$ with the formation of $\mathrm{O}_{2}{ }^{-}$and the original quinone. In contrast, the two-electron reduced hydroquinone is usually stable and may be excreted or otherwise detoxified without causing secondary damage. However, in some cases, such as aziridine quinones, the hydroquinone can be oxidized one electron at a time, resulting in the production of $\mathrm{O}_{2}{ }^{-}$, the semiquinone and the parental quinone. So, in brief summary, redox cycling xenobiotics can kill cells by effecting the one electron reduction of oxygen to $\mathrm{O}_{2}^{-}$ in reactions which probably involve transition metal-catalyzed production of highly reactive ROS such as $\mathrm{HO}$. These reactions probably explain some of the anti-cancer effects of redox-cycling quinones although the semiquinone intermediate also may be involved in alkylation reactions. 


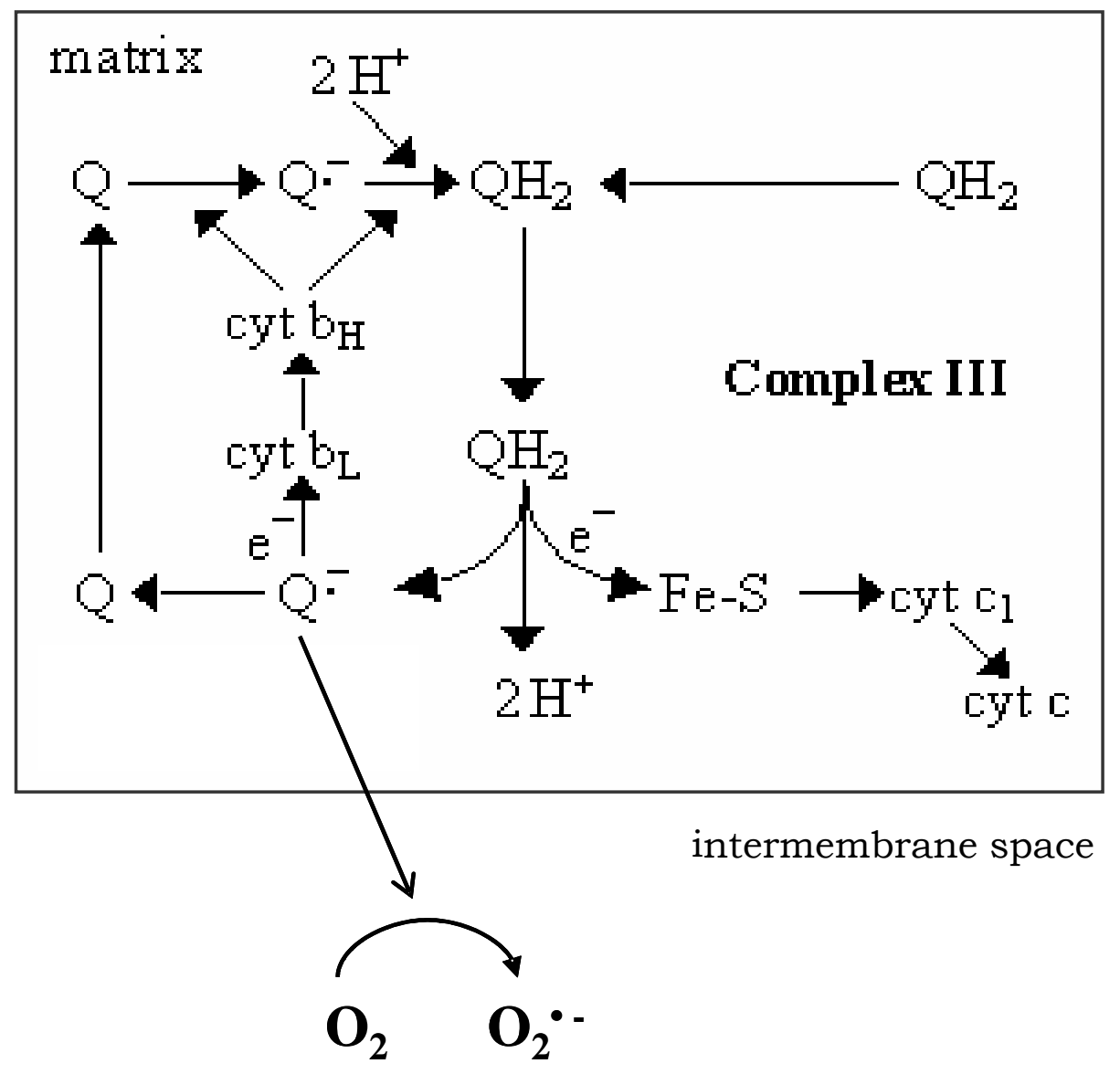

Figure 3. The Q cycle. In the $\mathrm{Q}$ cycle, ubisemiquinone $\left(\mathrm{Q}^{*}\right)$ is associated with complex III, the electron donor for superoxide formation in a reaction, presumably dependent on the partial pressure of oxygen. 
Overall, semiquinones are the dangerous species whereas two-electron reduced products such as ubiquinol can have antioxidant effects, interrupting $\mathrm{O}_{2}{ }^{-}$-initiated chain reactions and lipid peroxidation. In the particular case of mitochondria and ubiquinone, inhibition of complex III by antimycin A in isolated liver mitochondria results in the accumulation of ubisemiquinone with greatly increased $\mathrm{O}_{2}^{-}$production (Zhang et al., 2001). As mentioned above, one way in which cells might avoid damage from spontaneously generated ROS (whether under normal or high $\mathrm{O}_{2}$ conditions) might involve diminished production of these species by mitochondrial ubisemiquinone. However, how could cells manage to have lower steady-state concentrations of ubisemiquinone and still survive? In fact, there is an example from Caenorhabditis elegans. In this $\sim 900$ cell worm, a mutant (clk) has been found which is associated with increased longevity and impaired synthesis of coenzyme Q10. Replenishment of normal coenzyme Q10 levels leads to decreased longevity, probably associated with increased leak of electrons from the electron transport chain (Branicky et al., 2000; Wong et al., 1995).

\section{Cytochrome $c$ Oxidase}

In the results reported below, cytochrome c oxidase (COX) is an important factor in the explanation of why HeLa-80 cells have an oxygen-tolerant phenotype. COX is the terminal enzyme of the mitochondrial electron transport chain, which consists of four complexes (I-IV), all in the inner membrane of the mitochondria. Complex I (NADH:ubiquinone oxidoreductase) and complex II (succinate:ubiquinone oxidoreductase) oxidize mitochondrial NADH and succinate, respectively, to form 
ubiquinol. Ubiquinol is then oxidized to ubiquinone by complex III (ubiquinol:cytochrome $c$ oxidoreductase), which reduces cytochrome $c$. Cytochrome $c$ then delivers electrons to complex IV, COX. It catalyzes the reduction of dioxygen $\left(\mathrm{O}_{2}\right)$ to water and indirectly harnesses the free energy of the reaction to phosphorylate ADP to ATP. COX consists of 13 subunits in mammalian cells. The three catalytic subunits, COX I, II and III, are coded by the mitochondrial DNA and are synthesized within mitochondria. Heme $\mathrm{a}$, heme $\mathrm{a}_{3}$ and $\mathrm{Cu}_{\mathrm{b}}$ are ligated to subunit $\mathrm{I}$, while $\mathrm{Cu}_{\mathrm{a}}$ is ligated to subunit II which is also the binding site for cytochrome $c$ (Regan et al., 1998; Yoshikawa, 1999).The remaining 10 subunits of the mammalian enzyme, namely, IV, Va, Vb, VIa, VIb, VIc, VIIa, VIIb, VIIc and VIII, are encoded by the nuclear genome, synthesized in the cytosol and imported into mitochondria (Capaldi, 1990; Taanman, 1997; Vijayasarathy et al., 1998). Some of the nuclear-encoded subunits in mammals are regulated developmentally and occur as tissue specific isoforms (Bonne et al., 1993; Taanman et al., 1993). Although the nuclear-encoded COX subunits, such as COX IV, $\mathrm{Vb}$, VIa and VIb, have been shown to enhance the catalytic efficiency of the enzyme (Anthony et al., 1993; Weishaupt and Kadenbach, 1992), the precise role of many nuclear-encoded subunits in the mammalian enzyme complex remains unknown.

The function of COX is closely linked to both oxygen availability and heme, a prosthetic group. It has been shown that both oxygen and heme act as physiological modulators and regulate the expression of the enzyme complex in yeast (Poyton and Dagsgaard, 2000). COX subunit $\mathrm{V}$ is expressed as two distinct isoforms, $\mathrm{Va}$ and $\mathrm{Vb}$, which are regulated by heme and $\mathrm{O}_{2}$ in yeast (Burke and Poyton, 1998). In mammalian 
systems, however, the differential expression of nuclear-encoded subunits in response to different physiological factors has not been investigated in detail.

\section{Metabolic Control of Respiration by COX}

As reviewed by Kadenbach and Arnold (1999), the first mechanism of respiratory control is based on the mitochondrial proton motive force, $\Delta p$ (Bell et al., 1992), which is generally assumed to represent the energy-rich intermediate of oxidative phosphorylation. However, in eukaryotes, $\Delta p$ is not the only parameter controlling the rate of respiration. A second mechanism of respiratory control-intramitochondrial ATP/ADP ratio-via binding of the nucleotides to subunit IV of COX (Steenaart and Shore, 1997), contributes to maintainance of a constant and relatively low mitochondrial membrane potential, $\Delta \psi$ (the major component of $\Delta p$ ). The second mechanism of respiratory control requires that COX plays the rate limiting step in mitochondrial respiration. Whether COX is the rate limiting step of cell respiration, although COX catalyzes the only irreversible reaction $\left(\mathrm{O}_{2} \rightarrow \mathrm{H}_{2} \mathrm{O}\right)$ in the respiratory chain has been debated. Some old publications reported that COX capacity was 5-7 fold in excess of that required to support the endogenous respiration of isolated mitochondria (Letellier et al., 1993; Letellier et al., 1994; Wanders et al., 1981). However, under these experimental conditions, there was a significant alteration of the environment due to the possible loss of essential metabolites and to the absence of cytosolic substrates and coenzymes when the metabolic control analysis was carried out in the isolated mitochondria instead of the intact cells. 
Recently, studies of the metabolic control of respiration in intact cells revealed a tight control of cell respiration by COX, exceeding its capacity above the endogenous respiratory activity only by 7-25\% (Villani et al., 1998; Villani and Attardi, 1997). Erecinska and Wilson also came to similar conclusions. They proposed that an equilibrium exists between the reactions of NADH oxidation and cytochrome $c$ reduction in mitochondria, but that COX represents an irreversible and rate-limiting reaction (Erecinska and Wilson, 1982). Kadenbach proposed that the different control strength of COX measured in isolated mitochondria vs. intact cells might be due to uncoupling of the second mechanism of respiratory control during isolation of mitochondria (Kadenbach and Arnold, 1999).

The metabolic control of respiration by COX is important to maintain a physiological low mitochondrial $\Delta \psi$ of $100-130 \mathrm{mV}$ in vivo (Wan et al., 1993). The control of respiration by $\Delta p$ alone would allow $\Delta \psi$ to rise to very high levels, around 160$220 \mathrm{mV}$ (Hafner and Brand, 1988). High $\Delta \psi$ values will have adverse consequences, including increased $\mathrm{O}_{2}^{-}$formation. (Boveris and Chance, 1973; Korshunov et al., 1997; Liu, 1997) .

\section{COX Activity is Selectively Inhibited by Heme Deficiency}

When administered to mice, certain inhibitors of heme biosynthesis (e.g., succinyl acetone and cobalt chloride) can cause a 50\% reduction in mitochondrial genomeencoded COX I and II mRNAs and nuclear genome encoded COX Vb mRNA (Vijayasarathy et al., 1999). Important to the present investigations, heme deficiency, 
relatively selective for the type of heme in a subunit of $\mathrm{COX}$ also can be induced by $\mathrm{n}$ methyl protoporphyrin (NMP), selectively interrupting the assembly of COX (Atamna et al., 2001). Some studies suggested that heme deficiency might regulate not only mammalian COX gene expression but also catalytic activity of the enzyme by affecting its stability or composition (Vijayasarathy et al., 2003).

Heme deficiency occurs in iron deficiency (Ackrell et al., 1984), in porphyria patients and with advanced age (Bitar and Shapiro, 1987; Scotto et al., 1983), especially under conditions of stress (Freedman, 1987). This may be because the activity of ferrochelatase, which catalyzes metallation of protoporphyrin IX at the terminal step of heme biosynthesis, declines in the livers of old rats, as does COX activity (Boffoli et al., 1994). Similar, but perhaps more marked, changes also are observed in Alzheimer's disease patients (Ojaimi et al., 1999a; 1999b).

\section{$\underline{\text { Summary }}$}

As reviewed above, despite decades of work the nature of hyperoxic damage to cells remains incompletely understood. So also are the mechanisms by which cells might achieve an oxygen tolerant state. With this latter in mind, we elected to proceed with investigations of the oxygen tolerant HeLa- 80 cell line previously established by Dr. Hans Joenje. We hoped that these cells might yield valuable clues as to the nature of hyperoxic damage and ways in which this damage might be avoided. As reported below, we have generated nearly conclusive evidence that the majority of hyperoxic cell damage derives from enhanced mitochondrial ROS formation. Furthermore, successful adaption 
to hyperoxia - at least from the example of the HeLa 80 cells - would appear to depend on changes which limit mitochondrial ROS generation rather than enhancement of cellular antioxidant defenses. Overall, we believe that knowledge of the mechanism(s) permitting these cells to be tolerant of hyperoxia may be extremely valuable - not only for understanding the nature of oxygen damage itself but also to the understanding of basic cellular oxidative stress and antioxidant balance which are critical in many disease processes. Furthermore, the results of these investigations may be helpful in the future design of therapeutic modalities to limit oxygen toxicity in clinical situations. 


\section{MATERIALS AND METHODS}

\section{$\underline{\text { Cell Culture }}$}

Cells and reagents:

A wild-type strain of HeLa-20 cells (which grow under $20 \%$ oxygen) and an oxygen tolerant strain of HeLa-80 cells (which can grow under $80 \%$ oxygen) were generously provided by Dr. Hans Joenje (Institute of Human Genetics, Free University, Amsterdam, The Netherlands.). Carbonyl cyanide m-chlorophenylhydrazone (CCCP), ethidium bromide (EB), bovine heart cytochrome c, chloramphenicol, guanidine, bilirubin, porcine heart isocitrate dehydrogenase, sodium citrate, $\beta$-NADH, $\mathrm{MnCl}_{2}, 2,4-$ dinitrophenylhydrazine (DNP), trichloroacetic acid (TCA), sucrose, potassium phosphate, ethylenediaminetetraacetic acid (EDTA), tris (hydroxymethyl)aminomethane hydrochloride (Tris-HCl), ethyl acetate and streptomycin sulfate were purchased from Sigma Chemical Co. (St. Louis, MO). N-methyl protoporphyrin (NMP) and heme were from Porphyrin Products (Logan UT). Heparin was obtained from Bristol-Myers Squibb Company (Princeton, NJ). Dulbecco's Modified Eagle's Medium (DMEM), Ham's F-10 medium, phosphate buffered saline (PBS), HEPES, glutamine, penicillin, trypsin-EDTA and some lots of FBS were obtained from GIBCO LifeTechnologies (Grand Island, NY). Dihydrodicholorfluorescein (DCF) and dihydroethidium were purchased from Molecular Probes (Eugene, OR). Percoll was from Amersham Pharmacia Biotech. Polyethylene 
glycol 2000 (PEG) was obtained from Fluka (Milwaukee, WI). For $\rho^{0}$ HeLa:platelet fusions (see below), a $45 \%$ PEG solution ( $\mathrm{w} / \mathrm{v})$ was prepared at $65^{\circ} \mathrm{C}$ in Hanks' balanced salt solution (HBSS), subsequently sterilized by $0.22 \mu \mathrm{m}$ Millipore filtration and held at $37^{\circ} \mathrm{C}$ until needed. 


\begin{tabular}{|c|l|c|}
\hline Cell type & Characteristics & Culture medium \\
\hline HeLa-20 & wild-type HeLa cells & DMEM \\
\hline HeLa-80 & oxygen-tolerant HeLa cells & DMEM \\
\hline$\rho^{\circ}$ HeLa-20 & HeLa cells lacking mtDNA & $\begin{array}{l}\text { Enriched DMEM }(4 \\
\text { pyruvate and } 50 \mu \mathrm{g} / \mathrm{ml}\end{array}$ \\
\hline$\rho^{\circ}$ HeLa-20 & $\rho^{\circ}$ HeLa-20 with $100 \mu \mathrm{g} / \mathrm{ml}$ \\
cybrids & reconstituted mitochondria & DMEM \\
\hline
\end{tabular}

Table 1. Cell lines employed and their characteristics. 
General conditions of cell culture:

HeLa cells were routinely cultured in DMEM supplemented with $1 \mathrm{mM}$ glutamine and $10 \%(\mathrm{v} / \mathrm{v})$ heat-inactivated FBS under $20 \% \mathrm{O}_{2}$ (normoxia) or $80 \% \mathrm{O}_{2}$ (hyperoxia) with $5 \% \mathrm{CO}_{2}$ at $37^{\circ} \mathrm{C}$. For routine passage, cells were washed with PBS and lifted with $0.05 \%$ trypsin, $0.02 \%$ EDTA in PBS. Stock cultures were grown in polystyrene T-75 culture flasks in a Forma Scientific incubator under an atmosphere of $20 \% \mathrm{O}_{2}, 5 \% \mathrm{CO}_{2}$. Exposure to hyperoxia was performed with cells grown in 10-cm dishes under an atmosphere of $80 \% \mathrm{O}_{2}, 15 \% \mathrm{~N}_{2}$ and $5 \% \mathrm{CO}_{2}$ contained in a specially designed gas-tight modular incubator chamber (Billups-Rothenberg, Inc., CA). The sealed chamber was placed in a standard tissue culture incubator and the gas was replenished every $48 \mathrm{hr}$. Because the respiration-deficient $\rho^{\circ}$ cells require special supplements to the medium, all test cells were cultured in 'enriched DMEM' (see below) under both normoxic and hyperoxic conditions. The survival and growth of cells were assessed over a period of 10 days by counting cell numbers in marked sectors of the culture dishes using light microscopy.

It is important to note that the oxygen tolerance of HeLa- 80 cells is a stable characteristic. Even after these cells have been continuously passed in normoxic culture for more than two months they retain their resistance to $80 \% \mathrm{O}_{2}$ when re-exposed. However, being aware that the characteristics of cultured cells can 'drift' under conditions of continuous culture, we prepared $>70$ stabilates of each cell line, stored in liquid nitrogen. In the experiments reported here, cultures were replenished from these stabilates every 30 days and the oxygen tolerance of each new culture was checked. 
Cell culture in the presence of CCCP and chloramphenicol:

As an alternative way of suppressing mitochondrial respiration and ROS production, HeLa cells (initial density $\sim 5 \times 10^{4}$ per $10 \mathrm{~cm}$ dish) were treated with $1 \mu \mathrm{M}$ CCCP or $50 \mu \mathrm{g} / \mathrm{ml}$ chloramphenicol. CCCP, a protonophoric uncoupler of oxidative phosphorylation, causes a loss of mitochondrial membrane potential (Kessler, 1976), increases respiration and, paradoxically, decreases ROS production. Chloramphenicol selectively inhibits mitochondrial protein synthesis (Deanin, 1973) and decreases both respiration and mitochondrial ROS generation. Cells were cultured in CCCP or chloramphenicol under $20 \% \mathrm{O}_{2}$ for 2 days prior to exposure to $80 \% \mathrm{O}_{2}$ and control cultures were carried out under $20 \% \mathrm{O}_{2}$ to detect possible drug effects on cell growth.

Cell culture in the presence of n-methyl protoporphyrin (NMP):

At appropriate concentrations, the porphyrin derivative, NMP, selectively decreases the activity of COX (Atamna et al., 2001) through partial inhibition of ferrochelatase (Gamble et al., 2000; Tangeras, 1986). HeLa cells (initial density $\sim 5 \times 10^{4}$ per 10 -cm dish) were treated with $5 \mu \mathrm{M}$ NMP for 9 days under both normoxia and hyperoxia. The medium was changed every 4 days. A previous study using this dose of NMP to inhibit ferrochelatase showed that the enzymatic activity decreases to $\sim 15 \%$ of control (Tangeras, 1986). Ferrochelatase, the terminal enzyme in the heme biosynthetic pathway, catalyzes the insertion of iron (II) into protoporphyrin IX. Twelve hours after plating, the cells were treated with NMP in complete medium under normoxic conditions for $24 \mathrm{hr}$ prior to exposure to $80 \% \mathrm{O}_{2}$. Control cultures were maintained under $20 \% \mathrm{O}_{2}$ to detect possible drug effects on cell growth. 


\section{Establishment of $\rho^{\circ}$ Cells}

To deplete wild-type HeLa cells of mitochondrial DNA (mtDNA), cells were cultured in the presence of $400 \mathrm{ng} / \mathrm{ml} \mathrm{EB}$ for 8 months. For this, the standard DMEM medium was supplemented with $4 \mathrm{mg} / \mathrm{ml}$ glucose, $100 \mu \mathrm{g} / \mathrm{ml}$ pyruvate and $50 \mu \mathrm{g} / \mathrm{ml}$ uridine ('enriched DMEM') to compensate for (1) respiratory incompetence, (2) pyridine nucleotide redox imbalance and (3) pyrimidine/purine auxotrophy arising from mitochondrial dysfunction. $\rho^{\circ}$ clones were isolated using limiting dilution cloning and grown for at least 3 weeks in enriched DMEM in the absence of EB to ensure stable $\rho^{\circ}$ status. The $\rho^{\mathrm{o}}$ state was assured by (i) estimation of mitochondrial membrane potential (JC-1 staining), (ii) absent 200 bp PCR product for mtDNA, (iii) low-absent $\mathrm{O}_{2}$ consumption and (iv) deficient COX activity. For estimation of mitochondrial membrane potential, JC-1 was added to the cell culture for $30 \mathrm{~min}$ at $37^{\circ} \mathrm{C}$, at a final concentration of $5 \mu \mathrm{M}$. The cells were then washed 3 times in HBSS and examined by fluorescence microscopy. In order to estimate residual mtDNA, total DNA was isolated from cells using a DNA isolation kit (QIAGEN Inc., Valencia, CA) according to the manufacturer's instructions. PCR was performed using mtDNA primers (sense CCCCACAAACCCCATTACTAAACCCA; antisense TTTCATCATGCGGAGATGTTGGA TGG) (Ayala-Torres et al., 2000). The 200 bp PCR product was resolved by $0.8 \%$ agarose gel electrophoresis and the EB-stained DNA was quantified using a Molecular Dynamics Image System (Molecular Dynamics, Sunnyvale, CA). 


\section{Preparation of $\rho^{\circ}$ Cybrids}

Obtaining platelets from human blood:

In order to re-introduce functional mitochondria into HeLa $\rho^{\circ}$ cells, $20 \mathrm{ml}$ of heparinized venous blood was obtained from a healthy volunteer. The platelets were isolated by differential centrifugation as described by Mann et al. (Mann et al., 1992). The following procedures were performed at room temperature, unless otherwise specified and manipulations were carried out in a sterile hood, using sterile reagents and pipettes. The volume of blood was determined and the blood was transferred to a sterile 50-ml screw-capped polypropylene tube, and one-ninth volume of $0.1 \mathrm{M}$ sodium citrate and $0.15 \mathrm{M} \mathrm{NaCl}$ were added. The cell suspension was mixed by inversion and centrifuged the at $200 \mathrm{xg}$ for $20 \mathrm{~min}$ at $4^{\circ} \mathrm{C}$. The platelet-rich plasma was collected, leaving behind at least $3 \mathrm{~mm}$ of plasma above the red blood cell layer to avoid erythrocyte contamination. The platelet concentration in the plasma was determined at this point by counting in a hemocytometer in a phase-contrast microscope. The plateletrich plasma was then centrifuged in a sterile $15-\mathrm{ml}$ polypropylene tube at $1500 \mathrm{xg}$ for 20 $\min$ at $4{ }^{\circ} \mathrm{C}$ and the pellet containing the platelets was suspended in about $2 \mathrm{ml}$ physiological saline. Following trituration using a small bore pipette, physiological saline was added to a final volume of $11 \mathrm{ml}$.

Preparation of reconstituted cybrids of transformed $\rho^{\circ} \mathrm{HeLa}$ cells:

For restoration of functional mitochondria, fusion of normal human platelets with $\rho^{0}$ HeLa lines was performed by a modification (Higuchi et al., 1997) of the method of Chomyn et al. (Chomyn et al., 1994). The platelet suspension, prepared as described 
above (containing $<1 \%$ of other cell types), was centrifuged for $30 \mathrm{~min}$ at $2,000 \mathrm{xg}$ at $4^{\circ} \mathrm{C}$. The pellet was resuspended in $10 \mathrm{ml}$ PBS and centrifuged for $15 \mathrm{~min}$ at $1,500 \mathrm{xg}$ at $4^{\circ} \mathrm{C} .1 \times 10^{7}$ washed platelets were added to a $2 \mathrm{ml}$ suspension of $\rho^{\circ} \mathrm{HeLa}$ cells $\left(5 \times 10^{5}\right.$ in DMEM). The mixed cells were sedimented by centrifugation at $180 \mathrm{xg}$ for $10 \mathrm{~min}$ at room temperature. Following aspiration of the supernatant, $0.1 \mathrm{ml}$ of a PEG solution (45\% w/v PEG 2000 in HBSS) was added and the cells were gently resuspended. After 1 min incubation at $37^{\circ} \mathrm{C}, 10 \mathrm{ml}$ of enriched DMEM was added slowly, the cells were centrifuged for $5 \mathrm{~min}$ at $150 \mathrm{xg}$, suspended in $2 \mathrm{ml}$ enriched DMEM and cultured for 57 days. The medium was then changed to selective medium (regular DMEM with $10 \%$ FBS but lacking supplemental glucose, uridine and pyruvate) which only permits the growth of cells containing functional mitochondria. Three weeks later, subcloning was performed by limiting dilution and tests for mitochondrial function were conducted as described above.

\section{Peroxide-Mediated Cytotoxicity}

To determine whether changes in mitochondrial function might have secondary effects on cellular resistance to exogenous oxidants, the cytotoxic effects of both $\mathrm{H}_{2} \mathrm{O}_{2}$ and t-butyl hydroperoxide were measured. For these experiments, HeLa-20 and HeLa-80 cells, $\rho^{\circ} \mathrm{HeLa}$ cells and cybrids were grown in 48 -well plates (initial density $\sim 2 \times 10^{4}$ cells per well in $0.5 \mathrm{ml}$ of enriched DMEM) for three days. When cells were $90 \%$ confluent, the medium was replaced with $1.0 \mathrm{ml}$ of HBSS and the cells were exposed to the indicated concentrations of $\mathrm{H}_{2} \mathrm{O}_{2}$ or t-butyl hydroperoxide for $2 \mathrm{hr}$ at $37^{\circ} \mathrm{C}$. HBSS was used for these tests to avoid the confounding effect of varying contamination of FBS 
with catalase. The HBSS was then replaced with enriched DMEM. Following $10 \mathrm{hr}$ culture under normal conditions $\left(20 \% \mathrm{O}_{2} / 5 \% \mathrm{CO}_{2}\right.$ at $\left.37^{\circ} \mathrm{C}\right)$, Alamar Blue was added and, after a $4 \mathrm{hr}$ incubation, fluorescence of the reduced dye was measured at ex530 $\mathrm{nm}$ and em590 nm (Nikolaychik et al., 1996; Nociari et al., 1998; Page et al., 1993) using a spectrofluorometric plate reader (Molecular Devices Corp., Sunnyvale, CA). Cell viability was calculated as the ratio of surviving cells to the original cell population.

\section{Estimation of Reactive Oxygen Species (ROS) Production}

The generation of ROS was evaluated under atmospheres of both $20 \%$ and $80 \%$ $\mathrm{O}_{2}$. The tests under normoxic conditions assessed the oxidation of two probes: DCF-DA (added to cells bathed in Hanks' balanced salt solution (HBSS) and dihydroethidium (cells in complete culture medium). Two distinct probes were employed to ensure that the same proportionate differences were evident. The more long-term incubations of cells under hyperoxic conditions required that we use dihydroethidium exclusively because cells are not viable long-term in HBSS and because some time is needed for full equilibration of the cells with the atmospheric oxygen levels ( $\sim 3 \mathrm{hr}$; Stevens, 1992).

For a number of reasons, we believe that DCF-DA is an optimal probe for shortterm measurements of steady-state intracellular ROS generation (Amstad et al., 2001). Other probes such as dihydrorhodamine were not used because they report on two processes: the initial oxidation of the probe and the subsequent concentration of the oxidized product (rhodamine) by the mitochondria. Inasmuch as we had reason to think 
that these cells might differ in mitochondrial function and membrane potential, the use of such a probe would have been inappropriate.

The non-fluorescent DCF-DA precursor enters cells by passive diffusion whereupon the two acetate groups are esterolytically cleaved. Within the cell, the probe can be oxidized in a reaction which requires $\mathrm{H}_{2} \mathrm{O}_{2}$ and a peroxidase or pseudoperoxidase such as cytochrome $c$ or redox-active Fe. Upon oxidation, the probe is converted to highly fluorescent 2',7'-dichlorofluorescin (DCF). Although DCF, once formed, can diffuse out of the cell, in our conditions the medium is not changed and therefore, all of the DCF formed is measured. To assess ROS production with this probe, cells were plated onto 48 -well plates at an initial density of $2 \times 10^{4}$ cells per well. After cells were $>90 \%$ confluent, they were washed 3 times with HBSS or/and treated with various inhibitors of respiration in $0.5 \mathrm{ml} \mathrm{HBSS}$ for 5 min. Following the addition of $10 \mu \mathrm{M}$ DCF-DA (final concentration), the appearance of DCF fluorescence was followed continuously using a heated plate reading spectroflurometer (Molecular Devices Corp., Sunnyvale, CA), typically for $1 \mathrm{hr}$, with product detection at ex486 nm and em530 nm. Following the experiment, cell protein was measured in each well using the bicinchoninic acid reaction (Smith et al., 1985) (Pierce, Rockford, IL) and the relative fluorescence was corrected for variations in cell protein between wells.

Alternatively, the generation of ROS was evaluated under both $20 \% \mathrm{O}_{2}$ and $80 \%$ $\mathrm{O}_{2}$ using the oxidation of dihydroethidium (Bindokas et al., 1996). Cells were plated onto 48-well plates at an initial density of $2 \times 10^{4}$ cells per well. When cells were $>90 \%$ 
confluent, 3-4 days later, fresh medium containing $100 \mu \mathrm{M}$ dihydroethidium with or without $10 \mu \mathrm{M}$ of the protonophoric uncoupler, CCCP, was added. ROS generation was estimated after $4 \mathrm{hr}$ incubation with dihydroethidium under $20 \%$ or $80 \% \mathrm{O}_{2}$. In comparison with DCF-DA, dihydrotethidium permits estimates of ROS formation over longer periods of time in complete culture medium and the product, ethidium, is held within the cell via intercalation into DNA. We should note, however, that the latter event is eventually toxic to cells, limiting experiments to a maximum of $8 \mathrm{hr}$. After incubation with dihydroethidium, cells were washed 3 times with HBSS and ethidium fluorescence was detected at ex520 nm and em610 nm. Again, the relative fluorescence was corrected for variations in cell protein between individual wells.

\section{Measurement of Aconitase Activity}

Aconitase is inactivated by oxidative destabilization of a $4 \mathrm{Fe}: 4 \mathrm{~S}$ cuboid cluster in the active site. The loss of a single iron causes inactivation of the enzyme (and converts it into a DNA-binding protein called IRP-1 which controls various aspects of cellular iron metabolism). Therefore, changes in the activity of this particular enzyme serve as an intracellular 'detector' of endogenous ROS production. Cells $\left(\sim 5 \times 10^{6}\right)$ were detached with trypsin/EDTA and washed with HBSS (1,000 xg x $10 \mathrm{~min})$. The cells were suspended in $1 \mathrm{ml}$ of $50 \mathrm{mM}$ Tris- $\mathrm{HCl}, \mathrm{pH} 7.4$, containing $0.6 \mathrm{mM} \mathrm{MnCl}_{2}$ and disrupted by ten $1 \mathrm{~s}$ bursts from a microtip sonic oscillator (Fisher Scientific, Pittsburgh, PA). The lysate was transferred to a chilled 1.5-ml Eppendorf tube. $\mathrm{MnCl}_{2}$ was included in the lysis buffer to limit the inactivation of aconitase by $\mathrm{O}_{2}{ }^{-}$during extract preparation (Gardner and Fridovich, 1991). Cell extracts were clarified by centrifugation for $10 \mathrm{~min}$ at 2,000 xg 
and the supernatants were promptly assayed for aconitase activity, following the linear absorbance change at $340 \mathrm{~nm}$ at $25^{\circ} \mathrm{C}$ in a $1.0-\mathrm{ml}$ reaction mixture containing $50 \mathrm{mM}$ Tris- $\mathrm{HCl}\left(\mathrm{pH}\right.$ 7.4), $5 \mathrm{mM}$ sodium citrate, $0.6 \mathrm{mM} \mathrm{MnCl}_{2}, 0.2 \mathrm{mM}$ NADP, 2 units of isocitrate dehydrogenase, and $50 \mu \mathrm{g}$ of extract protein. One milliunit of aconitase activity was defined as the amount catalyzing the formation of $1 \mathrm{nmol}$ of isocitrate per min. An initial lag in NADPH formation was seen in samples with low aconitase activity, which presumably reflects the delayed accumulation of cis-aconitase (Gardner et al., 1994; Kerbs and Holzach, 1952). In these cases, the linear rates during the latter half of a 60min assay were used for the determinations of aconitase activity. Results were corrected for measured protein concentrations.

\section{Estimation of Mitochondrial Protein Carbonyls}

Mitochondria were prepared by differential centrifugation using a modification of a previously described procedure (Arriaga et al., 2002; Fuller et al., 2002). Briefly, cells were washed twice with cold mitochondrial isolation buffer $(250 \mathrm{mM}$ sucrose, $10 \mathrm{mM}$ Tris-HCl, $\mathrm{pH} 7.8,1 \mathrm{mM}$ EDTA, $\mathrm{pH} 8.0$ ). The cells were diluted in this isolation buffer to $8 \times 10^{6}$ cells $/ \mathrm{ml}$ and disrupted by nitrogen cavitation at $4{ }^{\circ} \mathrm{C}$ using an ice-cooled cell disruption bomb (Parr Instrument Co., Moline, IL). Following removal of large debris by centzifugation at $500 \mathrm{xg}$ for $10 \mathrm{~min}$ at $4^{\circ} \mathrm{C}$, the supernatants were centrifuged at 14,000 $\mathrm{xg}$ for $20 \mathrm{~min}$ at $4^{\circ} \mathrm{C}$ to obtain crude mitochondrial pellets. The total carbonyl content of mitochondrial proteins was determined by reaction with 2,4-dinitrophenylhydrazine (DNP) using a slight modification of the method of Levine et al. (1990). Briefly, the mitochondria pellets containing $\sim 300 \mu \mathrm{g}$ of protein were incubated with $500 \mu 1$ of $10 \mathrm{mM}$ 
DNP in $2 \mathrm{M} \mathrm{HCl}$ at room temperature for $1 \mathrm{hr}$ with intermittent mixing. Following addition of $500 \mu \mathrm{l}$ of $20 \%(\mathrm{w} / \mathrm{v})$ ice-cold trichloroacetic acid (TCA), the samples were centrifuged at 11,000 $\mathrm{xg}$ for $3 \mathrm{~min}$. The supernatant was discarded and the pellets were washed 3 times with $1 \mathrm{ml}$ ethanol:ethyl acetate (1:1) to remove unreacted DNP. The protein pellet was redissolved in $0.6 \mathrm{ml}$ of $6 \mathrm{M}$ guanidine with $20 \mathrm{mM} \mathrm{K}_{2} \mathrm{HPO}_{4}(\mathrm{pH}$ adjusted to 2.3 with $20 \% \mathrm{TCA}$ ) at $37^{\circ} \mathrm{C}$ and any insoluble material was removed by centrifugation at $11,000 \mathrm{xg}$ for $3 \mathrm{~min}$. The carbonyl content in the supernatant was measured spectrophotometrically at $375 \mathrm{~nm}$. Results were calculated using a molar absorbance coefficient of $22,000 \mathrm{M}^{-1} \mathrm{~cm}^{-1}$ and normalized for protein concentration.

\section{Determination of the Source of Intracellular ROS Generation}

We used particular inhibitors of the mitochondrial electron transport chain to determine whether the majority of intracellular ROS production was associated with mitochondrial metabolism and, if possible, to attempt to identify the major site(s) of ROS generation. This was done through the use of inhibitors of specific complexes such as the complex I inhibitor rotenone (ROT), complex II inhibitor thenoyltrifluoroacetone (TTFA), complex III inhibitor antimycin A (AA), and the uncoupler CCCP, all of which have been used previously to investigate mitochondrial ROS generation (see Figure 3). We should note at the outset that some of these inhibitors can actually enhance ROS generation by increasing the levels of electron-rich intermediates in the chain. It is generally accepted that complexes I and III (both of which generate ubisemiquinone) are the sites of most abundant electron leak (i.e., $\mathrm{O}_{2}{ }^{-}$formation). However, the relationship between electron leak from these mitochondrial electron transport complexes and 
hyperoxic cell injury remains unclear. A summary of the sites of inhibitor action is shown in Figure 4 below. 


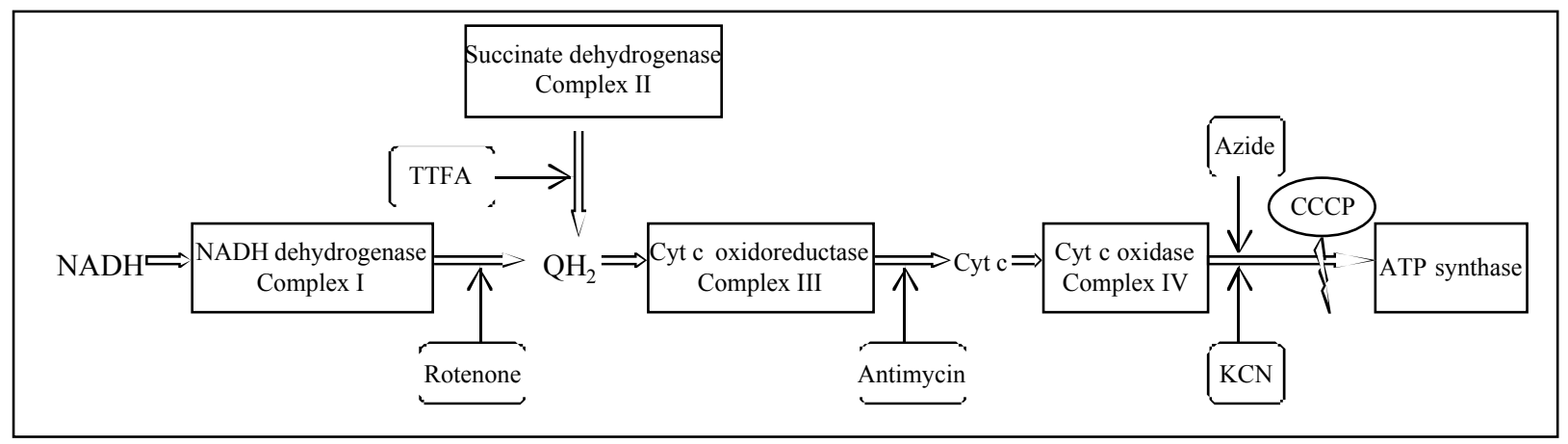

Figure 4. Mitochondrial electron transport and sites of action of various inhibitors. 


\section{Determinations of $\mathrm{O}_{2}$ Consumption, Glucose Utilization and Lactate Production under}

\section{Both Normoxic and Hyperoxic Conditions}

These parameters were measured in wild-type HeLa-20 and oxygen-tolerant HeLa-80 cell lines to provide some idea of the overall energy metabolism and oxygen consumption in hopes that the results might provide further information regarding which metabolic pathway(s) might be involved in the unique oxygen tolerance of the HeLa-80 cells.

Oxygen consumption:

HeLa cell cultures were washed with PBS, detached with trypsin/EDTA and washed (1,000 xg x $10 \mathrm{~min})$ in complete culture medium. Oxygen consumption was measured using a Gilson Oxygraph with a Clark electrode (Yellow Springs Instrument Co., Yellow Springs, OH). Respiration rates were measured using $3-5 \times 10^{6}$ cells suspended in a total volume of $3.0 \mathrm{ml}$ of DMEM containing 10\% FBS and supplemented with $17 \mathrm{mM}$ glutamate at $37^{\circ} \mathrm{C}$. A starting $\mathrm{O}_{2}$ concentration of $240 \mu \mathrm{M}$ was assumed based on $\mathrm{O}_{2}$ solubility at sea level at $37^{\circ} \mathrm{C}$ (Chappell, 1964).

Lactate production:

Under standard culture conditions, the cells were incubated for varying periods of time up to $24 \mathrm{hr}$ and lactic acid accumulation in the medium was determined. These assays were carried out using lactate dehydrogenase conversion of lactate to pyruvate (and the coupled oxidation of NADH to NAD) in the presence of hydrazine as a trap for the product (Gloster and Harris, 1962). Following completion of the reaction, the change 
in absorbance at $340 \mathrm{~nm}$ was read spectrophotometrically (assumed molar absorption $=$ $\left.6,290 \mathrm{M}^{-1} \mathrm{~cm}^{-1}\right)$. Results were expressed as nmol lactate formed per milligram of cell protein per unit time.

Glucose consumption:

The consumption of glucose by the same cultures in which we measured lactate production was measured in samples removed at the same times as above during the incubations. Glucose was measured using hexokinase-mediated formation of glucose-6phosphate followed by glucose-6-phosphate dehydrogenase-dependent formation of NADPH. Following completion of the reaction, the change in absorbance at $340 \mathrm{~nm}$ was read spectrophotometrically (assumed molar absorption $=6,220 \mathrm{M}^{-1} \mathrm{~cm}^{-1}$ ). Results were expressed as nmol glucose consumed per milligram cell protein per unit time.

\section{Assays of the Activities of Respiratory Chain Components}

In order to measure the possible differences in the activities of the four major electron transport complexes in oxygen-tolerant and wild-type HeLa cells, assays of the activities of respiratory chain components were carried out as follows.

Cell culture:

For these experiments, the cells were cultured in polystyrene T-75 culture flasks

(surface area $75 \mathrm{~cm}^{2}$ ) under $20 \% \mathrm{O}_{2}, 5 \% \mathrm{CO}_{2}$. Otherwise, the conditions of culture were as described above. 
Preparation of cell lysates:

Lysates of fresh cells (directly counted and adjusted to $6 \times 10^{6}$ cells $/ \mathrm{ml}$ ) were prepared by suspension in $0.25 \mathrm{M}$ sucrose, $40 \mathrm{mM}$ potassium chloride, $2 \mathrm{mM}$ ethylene glycol-bis-aminoethyl ether $N, N, N^{\prime}, N^{\prime}$-tetraacetic acid (EGTA), $1 \mathrm{mg} / \mathrm{ml}$ bovine serum albumin (BSA) and $20 \mathrm{mM}$ Tris $\mathrm{HCl}(\mathrm{pH}$ 7.2), and disruption by ten $1 \mathrm{~s}$ bursts from a microtip sonic oscillator (Fisher Scientific, Pittsburgh, PA). The lysate was centrifuged at 2,000 $\mathrm{xg}$ for $10 \mathrm{~min}$. The pellet was discarded and the supernatant used for enzyme activity assays described below (Jarreta et al., 2000).

Measurement of the specific activity of the individual complexes of the respiratory chain was performed spectrophotometrically. A total of about $50 \mu \mathrm{g}$ of protein was required for determinations of the activity of each complex component. Assays were performed at $37^{\circ} \mathrm{C}$ in $1 \mathrm{ml}$ reaction volumes and the results were corrected for protein concentration measured as above.

Rotenone-sensitive NADH-decylubiquinone oxidoreductase (complex I):

This assay was carried out using the acceptor 2,3-dimethoxy-5-methyl-6-n-decyl1,4-benzoquinone $(80 \mu \mathrm{M})$ and $200 \mu \mathrm{M} \mathrm{NADH}$ as donor in $10 \mathrm{mM}$ Tris (pH 8.0) buffer containing $1 \mathrm{mg} / \mathrm{ml} \mathrm{BSA}, 0.24 \mathrm{mM} \mathrm{KCN}$ and $0.4 \mu \mathrm{M}$ antimycin A for $5 \mathrm{~min}$. The addition of $4 \mu \mathrm{M}$ rotenone allowed us to quantify the rotenone-sensitive activity. Activity was followed spectrophotometrically at $340 \mathrm{~nm}$, typically over $5 \mathrm{~min}$. To permeabilize the mitochondrial inner membrane to $\mathrm{NADH}$, the sample was first incubated in distilled 
$\mathrm{H}_{2} \mathrm{O}$ for 3 min at $37^{\circ} \mathrm{C}$. Activity was calculated from the rate of decrease of NADH absorbance $\left(\varepsilon=6.3 \mathrm{mM}^{-1} \mathrm{~cm}^{-1}\right)$ and expressed per $\mu \mathrm{g}$ protein (Jarreta et al., 2000).

Succinate decylubiquinone 2,6-dichlorophenolindophenol (DCPIP) reductase (complex II):

The assay was performed using $80 \mu \mathrm{M}$ DCPIP as electron acceptor and $10 \mathrm{mM}$ succinate as donor in a medium containing $50 \mathrm{mM} \mathrm{KH}_{2} \mathrm{PO}_{4}(\mathrm{pH}$ 7.8), $2 \mathrm{mM}$ EDTA, 1 $\mathrm{mg} / \mathrm{ml}$ BSA in the presence of $80 \mu \mathrm{M}$ 2,3-dimethoxy-5-methyl-6-n-decyl-1,4benzoquinone, $0.24 \mathrm{mM} \mathrm{KCN}, 4 \mu \mathrm{M}$ rotenone, $0.2 \mathrm{mM}$ ATP and $0.4 \mu \mathrm{M}$ antimycin A. Following a 2 min preincubation, $10 \mathrm{mM}$ malonate was added to inhibit the oxidation of succinate (Jarreta et al., 2000). The activity was calculated from the rate of decrease in DCPIP@ $600 \mathrm{~nm}\left(\varepsilon=19.1 \mathrm{mM}^{-1} \mathrm{~cm}^{-1}\right)$ (Kruidering et al., 1997).

Ubiquinol cytochrome c reductase (complex III):

This assay was carried out using $40 \mu \mathrm{M}$ ferricytochrome $c$ as the acceptor and 80 $\mu \mathrm{M}$ decylubiquinol as the donor in a medium containing $10 \mathrm{mM} \mathrm{KH}_{2} \mathrm{PO}_{4}(\mathrm{pH} 7.8), 1$ $\mathrm{mg} / \mathrm{ml} \mathrm{BSA}, 2 \mathrm{mM}$ EDTA, in the presence of $0.24 \mathrm{mM} \mathrm{KCN}, 4 \mu \mathrm{M}$ rotenone and 0.2 mM ATP. Following 2 min pre-incubation, $1 \mu \mathrm{M}$ antimycin A was added, allowing us to distinguish between the reduction of cytochrome $c$ catalyzed by complex III vs. the nonenzymatic reduction of cytochrome $c$ by the reduced quinone. The activity was calculated from the rate of cytochrome c reduction measured at $550 \mathrm{~nm}\left(\varepsilon=19.1 \mathrm{mM}^{-}\right.$ ${ }^{1} \mathrm{~cm}^{-1}$ ) (Kruidering et al., 1997). 
Cytochrome c oxidase (COX):

The assay involved the addition of $60 \mu \mathrm{M}$ ferrocytochrome $c$ in an isosmotic medium (10 mM KH $\mathrm{mO}_{4}, \mathrm{pH} 6.5,1 \mathrm{mg} / \mathrm{ml} \mathrm{BSA}, 0.3 \mathrm{M}$ sucrose) containing $2.5 \mathrm{mM} \mathrm{n-}$ duodecylmaltoside to permeabilize mitochondrial membranes (Jarreta et al., 2000). The reaction was started by addition of the reduced cytochrome $c$ and cell lysates. The activity was calculated from the rate of decrease in absorbance of ferrocytochrome $c$ at $550 \mathrm{~nm}\left(\varepsilon=19.1 \mathrm{mM}^{-1} \mathrm{~cm}^{-1}\right)$ (Kruidering et al., 1997) and results were normalized for protein. In addition, because accurate estimations of the activities of this mitochondrial electron transport terminal complex are affected by mitochondrial yield and integrity, the results were normalized using an invariant marker of mitochondrial enzyme activity, citrate synthase, as described below.

Citrate synthase:

This assay was performed as described by Williams et al. (1998) with minor modifications. It was based on the reaction of citrate synthase with oxaloacetate and acetyl-CoA to produce CoASH. Dithionitrobenzoic acid (DTNB) reacts with sulfhydryls in CoASH producing free thionitrobenzoate. $800 \mu 1$ of $50 \mathrm{mM}$ potassium phosphate buffer $\left(\mathrm{K}_{2} \mathrm{HPO}_{4}\right.$ and $\mathrm{KH}_{2} \mathrm{PO}_{4}, \mathrm{pH}$ 7.4) was warmed to $37^{\circ} \mathrm{C}$ and then $10 \mu 1$ of cell extract or crude mitochondrial extract was added along with DTNB and acetyl-CoA in final concentrations of $100 \mu \mathrm{M}$ each. The reaction was started by addition of $100 \mu \mathrm{M}$ oxaloacetate. The change in absorbance at $405 \mathrm{~nm}$ was monitored for $30 \mathrm{~min}$ (reflecting the formation of thionitrobenzoate) and results were expressed as $\mathrm{nmol} / \mathrm{min} / \mathrm{mg}$ protein. 
The citrate syntase activity was calculated from the change in absorbance using $\varepsilon=13.6$ $\mathrm{mM}^{-1} \mathrm{~cm}^{-1}$ for thionitrobenzoate (Bejma and Ji, 1999).

Protein assay:

Protein was determined using the Pierce BCA protein assay. Bicinchoninic acid (BCA), in the form of its water-soluble sodium salt, is a sensitive and highly specific chelator for cuprous copper $\left(\mathrm{Cu}^{+1}\right)$ which is formed upon incubation of proteincontaining samples with added $\mathrm{Cu}^{+2}$. The $\mathrm{BCA} / \mathrm{Cu}^{1+}$ chelate $(2: 1)$ is detected at $562 \mathrm{~nm}$. The procedure follows a standard microplate protocol in which samples were incubated for a total of $1 \mathrm{hr}$ at $37^{\circ} \mathrm{C}$.

\section{Preparation of Purified Mitochondria from Fresh Rat Liver}

Mitochondria were purified from rat liver using a combination of differential and Percoll gradient centrifugation (Croteau et al., 1997; Gasnier et al., 1993; Zhao et al., 2003). All procedures were carried out at $4^{\circ} \mathrm{C}$. Briefly, fresh liver was minced and homogenized in M-SHE buffer (0.21 M mannitol, 0.07 M sucrose, $10 \mathrm{~mm}$ Hepes pH 7.4, $1 \mathrm{~mm}$ EDTA, $1 \mathrm{~mm}$ EGTA, $0.15 \mathrm{~mm}$ spermine, $0.75 \mathrm{~mm}$ spermidine). The following protease inhibitors were added: $1 \mathrm{mM}$ dithiothreitol (DTT), $2 \mu \mathrm{g} / \mathrm{ml}$ leupeptin, $2 \mu \mathrm{M}$ benzamidine- $\mathrm{HCl}, 1 \mathrm{mM}$ phenylmethylsulfonyl fluoride (PMSF). Unbroken cells and nuclei were pelleted at $500 \mathrm{xg}$ for $10 \mathrm{~min}$. The supernatant was centrifuged at $10,000 \mathrm{xg}$ to pellet mitochondria and contaminating lysosomes which were resuspended and washed twice with M-SHE buffer. A 2-ml suspension was then layered onto $12 \mathrm{ml}$ of Percoll solution (50\% Percoll, 50\% $2 \mathrm{M}$-SHE) and centrifuged for $1 \mathrm{hr}$ at 50,000 $\mathrm{xg}$ in an SS-34 
rotor. The brown mitochondrial band was collected, either by fractionating the gradient or by direct syringe aspiration. The purified mitochondria were pooled, diluted 10 -fold with M-SHE buffer, again pelleted by centrifugation and, finally, resuspended in M-SHE buffer to a protein concentration of $1.0 \mu \mathrm{g} / \mu \mathrm{l}$. The sample was frozen at $-80^{\circ} \mathrm{C}$ until use. We were aware that lysosomal contamination could be a particular problem with such preparations. Therefore, the activity of the lysosomal marker enzyme, beta-galactosidase, was measured to monitor the extent of possible lysosomal contamination.

\section{Preparation of Mitochondria from Cultured Cells}

All buffers were made with Milli-Q deionized water and filtered $(0.2 \mu \mathrm{M})$ prior to use. Cell disruption was effected with a nitrogen bomb (Parr Instrument Co., Moline, IL) which was ice-cooled prior to use. The method for isolation of mitochondria was as previously described (Cossarizza et al., 1996; Masini et al., 1983) with some modifications. Between $10^{6}$ and $10^{7}$ cells were trypsinized and washed twice with cold PBS. The cell pellet was resuspended in $1 \mathrm{ml}$ of sterile-filtered $0.25 \mathrm{M}$ sucrose, $10 \mathrm{mM}$ Tris ( $\mathrm{pH} 7.8)$, and $1 \mathrm{mM}$ EDTA ( 1 x STE buffer) at $4^{\circ} \mathrm{C}$. All the following steps were on ice. Cells were diluted in $1 \times$ STE buffer to $8-10 \times 10^{6} / 1 \mathrm{ml}$ on ice. The $1 \mathrm{ml}$ of cell suspension was transferred to the bomb charged with $\mathrm{N}_{2}$ to 700 psi for 23 min on ice followed by fast release of the $\mathrm{N}_{2}$ from the lower outlet to a $15-\mathrm{ml}$ tube. As estimated by light microscopy, $\sim 90 \%$ of the cells were disrupted by this procedure. The suspension was transferred to a $1.5 \mathrm{ml}$ siliconized tube and unbroken cells and nuclei were pelleted at $500 \times \mathrm{g}$ for $10-15 \mathrm{~min}$. The supernatant (containing mitochondria) was put in $1.5 \mathrm{ml}$ siliconized microcentrifuge tubes. When the pellet obtained was big and $<90 \%$ cells were 
broken, we kept the pellet on ice and repeated the $\mathrm{N}_{2}$ cell disruption bomb one more time, combining the supernatants for centrifugation. Ten $\mu \mathrm{l}$ of supernatant was kept for protein assay. Finally, the supernatant was centrifuged at high speed at 14,000 xg for $20 \mathrm{~min}$ to pellet crude mitochondria. The crude mitochondria were resuspended in $1 \mathrm{x}$ STE and washed once by centrifugation at $14,000 \mathrm{xg}$ for $20 \mathrm{~min}$. Three $\mathrm{ml}$ of the pellet resuspension was mixed with a $12 \%$ Percoll solution and layered onto a previously poured, $4 \mathrm{ml} 26 \%$ Percoll, $4 \mathrm{ml}$ 40\% Percoll density gradient. The gradient was centrifuged at $35,000 \mathrm{xg}$ for $10 \mathrm{~min}$ at $4^{\circ} \mathrm{C}$. The resulting top layer containing myelin and other cellular debris was carefully removed using a Pasteur pipette and discarded. Fraction 2 (a light creamy color) (the interface between 12\% and 26\% Percoll) containing the mitochondria was removed by pipetting with a $200 \mu$ gel loading tip and diluted 1:5 in cold STE and centrifuged at 15,000 $\mathrm{xg}$ for $10 \mathrm{~min}$. The resulting pellet was then resuspended in $1 \mathrm{ml}$ of STE and centrifuged at 15,000 xg for $5 \mathrm{~min}$. The final pellet of 'pure' mitochondria was resuspended in $100 \mu \mathrm{l}$ of STE containing $10 \mathrm{mg} / \mathrm{ml}$ bovine serum albumin (BSA) (Rajapakse et al., 2001) to stabilize the mitochondria. The purified mitochondria were immediately used to measure mitochondrial marker enzyme activities (as described above) or chilled in liquid nitrogen $/-80^{\circ} \mathrm{C}$ for storage.

\section{Enzymatic Detection of the Lysosomal Marker Enzyme, $\beta$-Galactosidase ( $\beta$-GAL)}

4-methylumbelliferyl- $\beta$-D-galactopyranoside, as a substrate, was prepared at a concentration of $30 \mathrm{mM}$ in DMSO. $400 \mu 1$ of this stock solution was added to $11.2 \mathrm{ml}$ of 0.2 M Na-citrate buffer ( $\mathrm{pH} 4.5$ ). Then $125 \mu \mathrm{l}$ of this substrate solution was mixed with $0.1 \mu \mathrm{g}$ of mitochondria from rat liver or $\mathrm{HeLa}$ cells. The mixture was incubated at $37^{\circ} \mathrm{C}$ 
for $40 \mathrm{~min}$. Thereafter, $100 \mu \mathrm{l}$ of $6 \mathrm{M}$ glycine- $\mathrm{NaOH}$ ( $\mathrm{pH}$ 10.4) was added to the sample in order to stop the reaction. The assay was carried out in a 96-well cell culture plate and the fluorescence was read at 356/444 nm.

\section{JC-1 Staining as an Indicator of Mitochondrial Membrane Potential - Microscopy}

Cells were seeded in 48-well culture plates. The assay was performed when cells were $40-60 \%$ confluent. After rinsing once in HBSS, $4 \mu \mathrm{M}$ of JC-1 in HBSS was added to cells. Cells were incubated at $37^{\circ} \mathrm{C}$ for $30 \mathrm{~min}$. Following two further rinses in HBSS, cells were examined by fluorescence microscopy.

$\underline{\text { JC-1 Accumulation as an Indicator of Mitochondrial Membrane Potential - Spectroscopy }}$

Cells were seeded in 48-well culture plates. The assay was performed when cells were $80-90 \%$ confluent. Ten $\mu \mathrm{M} \mathrm{CCCP}$ was added to some wells and incubated for $1 \mathrm{hr}$. After rinsing once in HBSS, $10 \mu \mathrm{M}$ of JC-1 in HBSS was added to cells. Cells were incubated at $37^{\circ} \mathrm{C}$ for 30 min without $\mathrm{CO}_{2}$. After two further rinses in HBSS, fluorescence was read at ex535 nm, em590 nm using a spectrofluorescence plate reader. Following this, the HBSS was decanted and protein concentration within each well was measured. The results were expressed as FU per mg protein.

\section{Measurement of Heme Oxygenase Enzyme Activity}

Because of earlier reports indicating that over-expression of heme oxygenase would confer oxygen tolerance (Lee et al., 1996; Otterbein et al., 1999a), we measured the activity of this enzyme in HeLa-20 and HeLa- 80 cells. Cells were collected from T- 
75 flasks by trypsinization when they had reached $\sim 90 \%$ confluence. Following two washes in HBSS (with centrifugation at $1000 \mathrm{xg}$ for $10 \mathrm{~min}$ at $4^{\circ} \mathrm{C}$ ), cell pellets were suspended in $1 \mathrm{ml}$ lysis buffer: $\mathrm{MgCl}_{2}(2 \mathrm{mM})$ in phosphate buffer $\left(\mathrm{Na}_{\mathrm{x}} \mathrm{PO}_{\mathrm{x}}, 100 \mathrm{mM}, \mathrm{pH}\right.$ 7.4), and frozen and thawed thrice $\left(-70^{\circ} \mathrm{C}\right)$. The cell suspension was sonicated by $15 \times 1$ sec bursts in the lysis buffer on ice. The lysate pellet was obtained by centrifugation at $18,800 \mathrm{xg}$ for $10 \mathrm{~min}$ at $4^{\circ} \mathrm{C}$. The supernatant was collected and was added to a reaction mixture containing: $20 \mu \mathrm{M}$ hemin, $2 \mathrm{mM}$ glucose-6-phosphate, 0.2 units glucose-6phosphate dehydrogenase, $0.8 \mathrm{mM} \beta$-NADPH and $2 \mathrm{mg}$ rat liver cytosol (rat liver biliverdin reductase is necessary to convert biliverdin to bilirubin) (Llesuy and Tomaro, 1994). Total reaction volume was $400 \mu 1$. The mixture was incubated at $37^{\circ} \mathrm{C}$ in the dark for $1 \mathrm{hr}$. The formed bilirubin was extracted with $600 \mu \mathrm{l}$ chloroform (the reaction was performed in glass or eppendorf tubes because chloroform reacts with plastic) and the OD was measured at 464 and $530 \mathrm{~nm}$. Heme oxygenase activity was expressed as pmol of bilirubin formed/mg of cell protein/60 min. (extinction coefficient, $40 \mathrm{mM}^{-1} \mathrm{~cm}^{-1}$ for bilirubin) (Motterlini, 1996).

\section{Electrophoretic Procedures and Western Blotting}

Materials:

The following special materials were used in these electrophoretic procedures. Mouse anti-human cytochrome c oxidase subunits I, II, IV and Vb monoclonal antibodies and horseradish peroxidase-conjugated goat anti-mouse antibodies were purchased from Molecular Probes. Goat serum was from GIBCO LifeTechnologies (Grand Island, NY)., $\mathrm{H}_{2} \mathrm{O}_{2}$, antimycin $\mathrm{A}$, rotenone, $\mathrm{KCN}$, and the protease inhibitor mixture were from Sigma 
Chemical Co. (St. Louis, MO). 10-20\% gradient Tris-Glycine PAGE gels were from Invitrogen. SDS, polyoxyethylene-20-sorbitan monolaurate (Tween 20; enzyme grade) and protein standard solutions were obtained from Bio-Rad. X-Cell SureLock ${ }^{\mathrm{TM}}$ MiniCell electrophoresis apparatus was from Invitrogen (Life Techonologies, Carlsbad, CA). ECL ${ }^{\mathrm{TM}}$-Plus was purchased from Amersham Pharmacia Biotech (Little Chalfont, Bucks, U.K). Reagent alcohol, polyoxyethylene-20-sorbitan monolaurate (Tween 20), potassium chloride, ethyl acetate and methanol were from Fisher Scientific Co. (Fair Lawn, NJ). Polyclonal rabbit anti-dinitrophenyl (DNP) and horseradish peroxidase-conjugated goat anti-rabbit antibodies were purchased from Zymed (San Francisco, CA). Immobilon ${ }^{\text {TM}}-\mathrm{P}$ was purchased from Millipore (Bedford, MA). ECL ${ }^{\mathrm{TM}}$-Plus was purchased from Amersham Pharmacia Biotech (Little Chalfont, Bucks, U.K.).

1. Preparation of RIPA cell lysates for western blots:

RIPA buffer (Upstate Inc. Lake Placid, NY) contains 50 mM Tris-HCl, pH 7.4, $150 \mathrm{mM} \mathrm{NaCl}, 1 \mathrm{mM}$ PMSF, $1 \mathrm{mM}$ EDTA, $5 \mu \mathrm{g} / \mathrm{ml}$ aprotinin, $5 \mu \mathrm{g} / \mathrm{ml}$ leupeptin, $1 \%$ Triton $\mathrm{x}-100,1 \%$ sodium deoxycholate, $0.1 \%$ SDS. 2 x SDS sample buffer was from Biorad and contains $100 \mathrm{mM}$ Tris, $25 \%$ glycerol, 2\% SDS , 0.01\% bromphenol blue, $\mathrm{pH}$ 6.8, with 2-mercaptoethanol (2-ME) (10\%) freshly added.

(a) Harvest of cells from cell culture plates:

Cells were detached using a rubber policeman and concentrated by centrifugation for $10 \mathrm{~min}$ at $800 \mathrm{xg}$. Cell pellets were washed twice with ice-cold PBS. One hundred $\mu 1$ of RIPA buffer was added to $10^{6}$ cells, incubated on ice for $20 \mathrm{~min}$ and vortexed 2 to 3 
times. Cells were disrupted by passage through a 28 -gauge needle 8 times. The lysate was centrifuged for $3 \mathrm{~min}$ at $4^{\circ} \mathrm{C}$ at $9,000 \mathrm{rpm}$ in a microfuge tube, then the supernatant was transferred to a clean tube. Protein concentration in each preparation was measured and adjusted to $5 \mu \mathrm{g} / \mu 1$ with RIPA lysis buffer. An equal volume of $2 \times$ SDS sample buffer was added and the sample denatured by heating to $95^{\circ} \mathrm{C}$ for $5 \mathrm{~min}$. Samples could be stored at $-20^{\circ} \mathrm{C}$ for daily use or $-80^{\circ} \mathrm{C}$ for long term storage. Repeated freeze thaw cycles were avoided.

(b) Harvest of cells from cell culture flasks:

Cells were released by trypsin and washed twice in cold PBS. The pelleted cells were lysed in $300 \mu \mathrm{l}$ lysis buffer [ $20 \mathrm{mM}$ Tris- $\mathrm{HCl}, \mathrm{pH}$ 7.5, $150 \mathrm{mM} \mathrm{NaCl}, 5 \mathrm{mM}$ EDTA, pH 8.0, 1\% Triton X-100, 10\% glycerol, 1 mM PMSF, 5 mM DTT, and $20 \mu 1 / \mathrm{ml}$ of a proteinase inhibitor cocktail (Novagen). The cell lysate was sonicated on ice to fragment the genomic DNA and centrifuged at 8,000 rpm for 4 min to remove debris.

2. SDS-PAGE gels:

(a) SDS-PAGE for HeLa cell lysates:

Cell protein samples (50-100 $\mu \mathrm{g})$ were electrophoresed under reducing conditions using an X-Cell Surelock Mini electrophoresis cell with a 10-20\% (w/v) gradient polyacrylamide resolving gel, as described by Laemmli (Laemmli, 1970). Bio-Rad kaleidoscope prestained markers were used to track the progress of the proteins through the gel. 


\section{(b) SDS-PAGE for rat mitochondrial fraction:}

Ten $\mu \mathrm{g}$ of rat mitochondrial fractions were separated electrophoretically under reducing conditions using an X-Cell surelock Mini elctrophoresis cell with 10\% polyacrylamide resolving gel as described by Laemmli (Laemmli, 1970). As above, BioRad kaleidoscope prestained markers were used to track the progress of the proteins through the gel. After staining with Coomassie blue (below), the gel was dried using NOVEX DryEase ${ }^{\mathrm{TM}}$ Mini Gel Drying System (Invitrogen).

\section{Gel staining:}

Gels were stained with Coomassie blue and destaining was done with $40 \%$ (v/v) methanol, $10 \%$ (v/v) glacial acetic acid to remove background, usually 1-3 hr. Two identical gels were run at the same time, one of which was Coomassie stained and the other gel was processed immediately for immunoblotting.

\section{Immunoblotting:}

Protein samples, size-fractionated on 10-20\% SDS-PAGE gels, were transferred to a PVDF membrane by electroblotting using 100 Vx $1 \mathrm{hr} @ 4^{\circ} \mathrm{C}$. These membranes were blocked with 5\% non-fat milk powder in $1 \mathrm{x}$ PBS-T which contained $0.3 \%$ Tween20 and $1 \%$ non-immune goat serum to reduce background. Following an overnight incubation with constant gentle agitation, the membranes were incubated at room temperature for $1.5 \mathrm{hr}$ with mouse monoclonal antibodies against COX I (1:500 dilution, $2 \mu \mathrm{g} / \mathrm{ml}$ in $1 \times$ PBST, 0.3\% Tween-20), II (1:500 dilution, $2 \mu \mathrm{g} / \mathrm{ml}$ in $1 \times$ PBST, $0.3 \%$ Tween-20), IV (1:500 dilution, $2 \mu \mathrm{g} / \mathrm{ml}$ in $1 \times$ PBST, 0.3\% Tween-20), or Vb (1:1000 
dilution, $1 \mu \mathrm{g} / \mathrm{ml}$ in $1 \times$ PBST, $0.3 \%$ Tween-20). After washing $3 \mathrm{X}$ for 10 min each time with $1 \times$ PBST $(0.5 \%$ Tween-20), blots were then incubated with a horseradish peroxidase-conjugated goat anti-mouse secondary antibody (1:1500 dilution, $0.67 \mu \mathrm{g} / \mathrm{ml}$ in $1 \times$ PBST, $0.3 \%$ Tween-20). After washing $5 \mathrm{X}$ for 10 min with $1 \times$ PBST, immunostaining was developed using an enhanced chemiluminescence, ECL TM-Plus Western blotting detection kit, according to the manufacturer's instructions (Amersham Pharmacia Biotech).

5. Membrane staining:

In order to control the amount of protein transferred to the PVDF membranes, Ponceau S staining was carried out. After transfer, the membrance was re-wetted in $100 \%$ methanol and then rinsed in water. The membrane was incubated into 1x Ponceau S (10X Ponceau S concentrated solution from Sigma diluted with $\mathrm{H}_{2} \mathrm{O}$ ) for 15 min at room temperature. The Ponceau S was eluted with 5\% non-fat milk in PBST or TBST and the membrane was ready for blocking.

6. Immunoblotting detection of $\beta$-actin as control:

The PVDF blots were re-wetted using 100\% methanol, rinsed with water and then $2 \mathrm{X}$ with PBST for $5 \mathrm{~min}$. The membrane was incubated with $1 \mathrm{x}$ Re-blot strip Buffer (Chemicon Inc., Temecula, CA) for 15 min at room temperature with gentle agitation. Following this, the membrane was blocked with $5 \%$ non-fat milk in $1 \mathrm{x}$ PBST $(0.3 \%)$ with $1 \%$ goat serum to reduce background. After rinsing with $1 \times$ PBST, the membrane was incubated with primary anti- $\beta$-actin (1:5000 dilution in 5\% non-fat milk in $0.3 \%$ 
PBST $+1 \%$ goat serum) for $1 \mathrm{hr}$ at room temperature, washed thrice with $1 \times$ PBST (0.5\%), each time for $5 \mathrm{~min}$, and then incubated with secondary antibody:HRP conjugated-goat anti-mouse (1:8000 dilution in 5\% non-fat milk in $0.3 \%$ PBST $+1 \%$ non-immune goat serum) for $45 \mathrm{~min}$ at room temperature. Following this, the membrane was washed 5 times with $1 \times$ PBST $(0.5 \%)$ and developed using enhanced chemiluminescence ECL ${ }^{\mathrm{TM}}$-Plus Western blotting detection kit as above.

\section{$\underline{\text { Real-Time Reverse Transcript Polymerase Chain Reaction (RT-PCR) }}$}

Materials:

RNeasy Mini kit and Omniscript ${ }^{\mathrm{TM}}$ Reverse transcriptase and $\mathrm{SYBR}^{\circledR}$ Green were purchased from QIAGEN (QIAGEN Inc., Valencia, CA). RNase-free water was obtained from GIBCO. Premix Taq ${ }^{\mathrm{TM}}$ (Ex Taq ${ }^{\mathrm{TM}} \mathrm{R}-\mathrm{PCR}$ Version) was purchased from Fisher (Fisher Scientific Inc., Hampton, NH).

Ribonucleases (RNases) are very stable and active enzymes that generally do not require cofactors to function. Since RNases are difficult to inactivate and even minute amounts are sufficient to degrade RNA, great care was taken to avoid inadvertently introducing RNases into the RNA sample during or after the isolation procedure. All the following procedures were handled in an RNase-free environment.

Isolation of total RNA from HeLa cells:

HeLa cells were cultured in 6-well plates. $5 \times 10^{5}$ cells were lifted using a sterilized policeman. The cells were transferred to an RNase-free sterilized polypropylene 
eppendorf centrifuge tube and pelleted by centrifugation at 9,000 rpm for $1.5 \mathrm{~min}$ at room temperature. The culture medium was completely aspirated since incomplete removal of the cell culture medium would inhibit lysis and dilute the lysate, thereby affecting the conditions for binding of RNA to the RNeasy silica-gel membrane. Both effects might reduce RNA yield. Cell pellets could be stored at $-70^{\circ} \mathrm{C}$ for later use or used directly for RNA extraction. The number of cells was determined before freezing or direct analysis. The pelleted cells were disrupted by addition of $350 \mu 1$ (for $<5 \times 10^{6}$ cells) of lysis buffer and homogenized by passing the cell lysate 5 times through a 28 -gauge needle fitted to an RNase-free syringe. $350 \mu 1$ of ethanol was then added to the cell lysate, creating conditions that promote selective binding of RNA to the RNeasy silica-gel membrane. The sample was then applied to the RNeasy mini column. Total RNA binds to the membrane, contaminants are efficiently washed away, and high-quality RNA was eluted in $30 \mu \mathrm{l}$ of RNase-free water.

\section{Quantification of RNA:}

The concentration of RNA was determined by measuring the absorbance at 260 $\mathrm{nm}\left(\mathrm{A}_{260}\right)$ in a spectrophotometer. An absorbance of 1.0 at $260 \mathrm{~nm}$ corresponds to $40 \mu \mathrm{g}$ of RNA per ml ( $\mathrm{A}_{260}$ of $\left.1.0=40 \mu \mathrm{g} / \mathrm{ml} \mathrm{RNA}\right)$. Since this relation is valid only for measurements in water, the RNA sample was diluted in RNase-free water when measuring RNA samples. The ratio of the readings at $260 \mathrm{~nm}$ and $280 \mathrm{~nm}\left(\mathrm{~A}_{260} / \mathrm{A}_{280}\right)$ provides an estimate of the purity of RNA with respect to contaminants that absorb in the UV, such as protein. Our RNA samples fell within 1.9-2.1, typical of pure RNA. 
Reverse Transcription:

For reverse transcription, first-strand cDNA was synthesized using $1 \mu \mathrm{g}$ of RNA with Omniscript Reverse Transcriptase from QIAGEN (QIAGEN Inc., Valencia, CA). One $\mu \mathrm{g}$ of total RNA solution was mixed with $10 \mu \mathrm{M}$ random hexadeoxyribonucleotides $\{\operatorname{pd}(N) 6\}$ primers (Promega, Madison, WI), ice-cooled and subjected to first-strand DNA synthesis using 4 units of Omniscript Reverse Transcriptase and 10 units of RNase inhibitor (Promega, Madison, WI) in $20 \mu 1$ reaction for $1 \mathrm{hr}$ at $37^{\circ} \mathrm{C}$.

SYBR Green real-time reverse transcriptase (RT)-PCR assay:

The PCR primers for $\mathrm{COX} \mathrm{Vb}$ and $\beta$-actin (as a control) were designed by Jason Chesney and Sucheta Telang (University of Louisville) using a the Primer designer 2.0 software program from Invitrogen (Invitrogen Life Technologies, Carlsbad, CA) according to the published cDNA sequences (summarized in Table 2) (Grandjean et al., 2002). Premix Taq $^{\mathrm{TM}}$ (Ex Taq ${ }^{\mathrm{TM}} \mathrm{R}-\mathrm{PCR}$ Version) was used for the second strand cDNA synthesis and DNA amplification. Premix $\operatorname{Taq}^{\mathrm{TM}}\left(\mathrm{Ex}^{\mathrm{Ta}} \mathrm{Ta}^{\mathrm{TM}} \mathrm{R}-\mathrm{PCR}\right.$ Version) is a premix reagent designed specially for RT-PCR. The polymerase used in this premix reagent is TaKaRa Ex Taq for Hot Start PCR which is mixed with the neutralizing monoclonal antibody to Taq DNA polymerase. Real time monitoring of PCR was performed by addition of SYBR ${ }^{\circledR}$ Green as a detection reagent using the Smart Cycler ${ }^{\circledR}$ System. The reaction was performed with $1.5 \mu 1$ template of RT product of total COX Vb RNA, $5 \mu 1$ Premix $\operatorname{Taq}^{\mathrm{TM}}$ (Ex Taq ${ }^{\mathrm{TM}}$ R-PCR Version) $(5 \mathrm{x}), 2 \mu 1$ diluted SYBR Green PCR and 0.3 $\mu \mathrm{M}$ primers (forward and reverse) in a total volume of $25 \mu \mathrm{l}$. The amount of template was $<30 \mathrm{ng}$ since excess template may cause depletion of SYBR Green and interfere with 
the correct monitoring. PCR was performed after an initial incubation at $95^{\circ} \mathrm{C}$ for $30 \mathrm{sec}$ in order to activate the Hotstartaq DNA polymerase. Then, 22-40 cycles were run at denaturation $-95^{\circ} \mathrm{C}$ for $10 \mathrm{~s}$, annealing $-58^{\circ} \mathrm{C}$ for $20 \mathrm{~s}$, extension $-72^{\circ} \mathrm{C}$ for $30 \mathrm{~s}$ on the Smart Cycler System. Each sample was run with $\beta$-actin as a reference gene. Results were obtained by measuring the cycle threshold $\left(\mathrm{C}_{\mathrm{T}}\right)$, the first cycle in which there is significant increase in fluorescence above the background, and which correlates to the log-linear phase of PCR amplification. Generally, the runs were stopped at 8 cycles after the cycle threshold $\left(\mathrm{C}_{\mathrm{T}}\right)$ appeared. The relative quantification in mRNA levels was evaluated by the ratio between the target gene, $\mathrm{COX} \mathrm{Vb}$, and the housekeeping gene, $\beta$ actin. Data calculation was based on the 'Delta-Delta method' using the equation: R (ratio) $=2^{-\left[\Delta \mathrm{C}_{\mathrm{T}} \text { sample- } \Delta \mathrm{C}_{\mathrm{T}} \text { control }\right]}$ (Livak and Schmittgen, 2001).

\section{$\underline{\text { Small Interference RNA (siRNA) Transfection }}$}

RNA interference (RNAi) works through a conserved biological response to double-stranded RNA and involves the use of active small interfering RNA (siRNA). Conjugation of this with target mRNA activates an RNase III endonuclease complex, Dicer. The 21-23 nt siRNAs will, thereby, silence homologous gene expression by mediating, in a sequence-specific manner, degradation of the transcribed mRNA (Hannon, 2002).

siRNA primer design:

Two siRNA duplexes targeting the COX Vb gene were designed and obtained from Dharmacon (Dharmacon, Inc., Lafayette, CO). The first target sequence was 
AAAGUAGGCUGCAUCUGUGAA. The corresponding siRNA duplex \#1 (S1) was 21 nt. Sense sequence: 5'-AGUAGGCUGCAUCUGUGAAdTdT-3'; antisense sequence: 5'UUCACAGAUGCAGCCUACUdTdT-3'. The second target sequence was AACAGUAAAGACUAGCCAUUG. The corresponding siRNA duplex \#2 (S2) was also 21 nt. Sense sequence: 5'CAGUAAAGACUAGCCAUUGdTdT-3'; antisense sequence: 5'-CAAUGgCUAGUCUUUACUGdTdT-3'.

Cell cultures and siRNA transfection:

HeLa- 80 cells were cultured at $37^{\circ} \mathrm{C}$ in a humidified $5 \% \mathrm{CO}_{2} /$ air atmosphere in DMEM medium with $10 \%$ (v/v) FBS. One day before transfection, HeLa cells were seeded at sub-confluent density $\left(8 \times 10^{4}\right.$ cells per well in 6 -well plates). When the procedure was started, the cultures were fed with enriched DMEM medium (10\% FBS, supplemented with high glucose $4 \mathrm{~g} / \mathrm{L}, 100 \mu \mathrm{g} / \mathrm{ml}$ pyruvate and $50 \mu \mathrm{g} / \mathrm{ml}$ uridine). Transfection with siRNA was done with Oligofectamine (Invitrogen, Carlsbad, CA), following the manufacturer's guidelines with some modifications. Two different concentrations of siRNAs $(20 \mathrm{nM}$ or $100 \mathrm{nM})$ were employed in the experiments. siRNA was diluted with OptiMEM medium (no serum and no antibiotics) to a final volume of $200 \mu 1$ and incubated at room temperature for $20 \mathrm{~min}$. Oligofectamine also was diluted in OptiMEM to a final volume of $50 \mu \mathrm{l}$ and incubated at room temperature for $5 \mathrm{~min}$. Next, the diluted siRNA was combined with the diluted Oligofectamine (total volume $250 \mu \mathrm{l}$ ) and the mixture was incubated at room temperature for $30 \mathrm{~min}$ to allow the siRNAOligofectamine complex to form. Two $\mathrm{ml}$ of enriched DMEM was added to wells in which transfection with siRNA was to be done. Then, $250 \mu$ l of the siRNA- 
Oligofectamine complex was added to the cells with thorough mixing. Cells were further incubated for $48 \mathrm{hr}$ at $37^{\circ} \mathrm{C}$. Then the cells were processed for the evaluation of $\mathrm{COX} \mathrm{Vb}$ protein production by Western blotting analysis and evaluation of $\mathrm{COX} \mathrm{Vb}$ mRNA levels by real time RT-PCR. Mock transfections were carried out with Oligofectamine alone (without siRNA). 


\begin{tabular}{|c|c|}
\hline Target cDNA & Sequences of primers \\
\hline COX $\mathrm{Vb}$ & 5'-AATAGTAGGCTGCATCTGTG-3' \\
& 5'-GCTTGTAATGGGCTCCACAG-3' \\
\hline$\beta$-actin (human) & 5'-CAAGGCCAACCGCGAGAAGA-3' \\
& 5'-GGATAGCACAGCCTGGATAG-3' \\
\hline
\end{tabular}

Table 2. Sense and antisense primers used for quantitative RT-PCR analysis. 


\section{RESULTS}

Part I. ROS Produced by Mitochondria are Causally Related to Hyperoxic Cell Damage

We began by investigating the general and rather obvious concept that hyperoxic damage might derive from enhanced cellular production of ROS (Chance et al., 1979;

Castro and Freeman, 2001; Gerschman et al., 1954), incidentally generated from normal cellular respiratory processes. Even under normoxia, a fraction of the reducing equivalents handled by mitochondrial metabolism (variably estimated at $0.1-2 \%$ ) escape the respiratory chain as $\mathrm{O}_{2}^{-}$, most of which will be converted to $\mathrm{H}_{2} \mathrm{O}_{2}$ (Chance, 1979; Cross, 1991; Hansford, 1997). As reviewed above, a likely source of much of this electron 'leak' from the respiratory chain is ubisemiquinone (the half reduction product of ubiquinone) (Turrens et al., 1985; Freeman and Crapo, 1981; Sanders et al., 1993). Despite the weight of evidence in favor of mitochondrial ROS being involved in hyperoxic cell damage, there have been recent reports to the contrary (Budinger et al., 2002). We hypothesized that if mitochondrial metabolism were, in fact, responsible for enhanced ROS production under hyperoxic conditions, then cells with impaired mitochondrial respiration might be relatively resistant to increased $\mathrm{O}_{2}$ tensions. 
As a test of this general hypothesis, we employed HeLa cells and used three different strategies to diminish mitochondrial metabolism. First, using ethidium bromide (EB) pressure, we ablated the mitochondrial DNA, producing cloned ' $\rho$ ' HeLa cells with a very low rate of respiration. We also re-introduced normal mitochondria into this $\rho^{\circ}$ clone to control for possible unanticipated mutations in nuclear DNA caused by longterm EB exposure. Second, we exposed the wild-type HeLa cells to carbonyl cyanide mchlorophenylhydrazone (CCCP). This protonophore uncouples mitochondrial respiration, increases $\mathrm{O}_{2}$ consumption but, paradoxically, diminishes mitochondrial ROS production. Third, we treated HeLa cells with the antibiotic chloramphenicol which disrupts the synthesis of mitochondrial inner membrane proteins, thereby preventing the assembly of a complete mitochondrial electron transport complex.

Control and variously treated HeLa cells were then exposed to elevated atmospheric $\mathrm{O}_{2}\left(80 \% \mathrm{O}_{2} / 5 \% \mathrm{CO}_{2}\right)$ and the growth and survival of the cells were followed. Overall, the results of these experiments lend strong support to the general concept that interactions between respiring mitochondria and $\mathrm{O}_{2}$ are the major mechanism responsible for hyperoxic cell damage.

A. $\rho^{\circ}$ cells have a growth and survival advantage in hyperoxia

To produce a line of cells having diminished respiration, we treated cultured HeLa cells with EB for 8 months. Following this, clones were derived from candidate cells found to be negative for JC-1 staining (which estimates mitochondrial membrane potential) and these were cultured for three weeks to ensure that $\rho^{\circ}$ status was durable. 
One negative clone was selected and found to have no PCR-amplifiable mtDNA (25 cycles) (results not shown). These cells also had very low cytochrome oxidase activity and almost undetectable $\mathrm{O}_{2}$ consumption (Table 3). The growth and survival of these $\rho^{\mathrm{o}}$ cells was compared to that of the wild-type cells under $20 \%$ and $80 \% \mathrm{O}_{2}$. As shown in Figure 5, both wild-type and $\rho^{\circ}$ cells exhibited normal replication when cultured under normoxic conditions. However, under $80 \% \mathrm{O}_{2}$, the $\rho^{\circ}$ cells had a distinct survival advantage, with a growth rate approximately $70 \%$ that observed under normoxic conditions. In contrast, the wild-type cells progressively died after $\sim 5$ days under hyperoxia (Figure 5). 
Table 3. Cytochrome c oxidase activity and $\mathrm{O}_{2}$ consumption in wild-type and respirationdeficient HeLa cells.

\begin{tabular}{|l|c|c|}
\hline Cell line/treatment & $\begin{array}{l}\text { Cytochrome } c \text { oxidase } \\
\text { activity }(\mathrm{nmol} / \mathrm{min} / \mathrm{mg} \\
\text { protein })\end{array}$ & $\begin{array}{l}\mathrm{O}_{2} \text { consumption } \\
\left(\mathrm{nmol} / \mathrm{min} / 10^{7} \text { cells }\right)\end{array}$ \\
\hline Wild-type & $7.36 \pm 0.85$ & $16.56 \pm 1.60$ \\
\hline$\rho^{\text {o }}$ & $1.35 \pm 0.34 *$ & $0.14 \pm 0.01 *$ \\
\hline cybrids & $6.89 \pm 0.77$ & $10.06 \pm 1.02$ \\
\hline Chloramphenicol-treated & $0.20 \pm 0.08 *$ & $0 \pm 0 *$ \\
\hline
\end{tabular}

Results are expressed as means $\pm 1 \mathrm{SD}(\mathrm{n}=4$ separate cell preparations $)$.

Statistical evaluation was performed using Student's ' $t$ ' test, two-tailed. * $\mathrm{P}<0.01 \mathrm{vs}$ wild-type cells. 

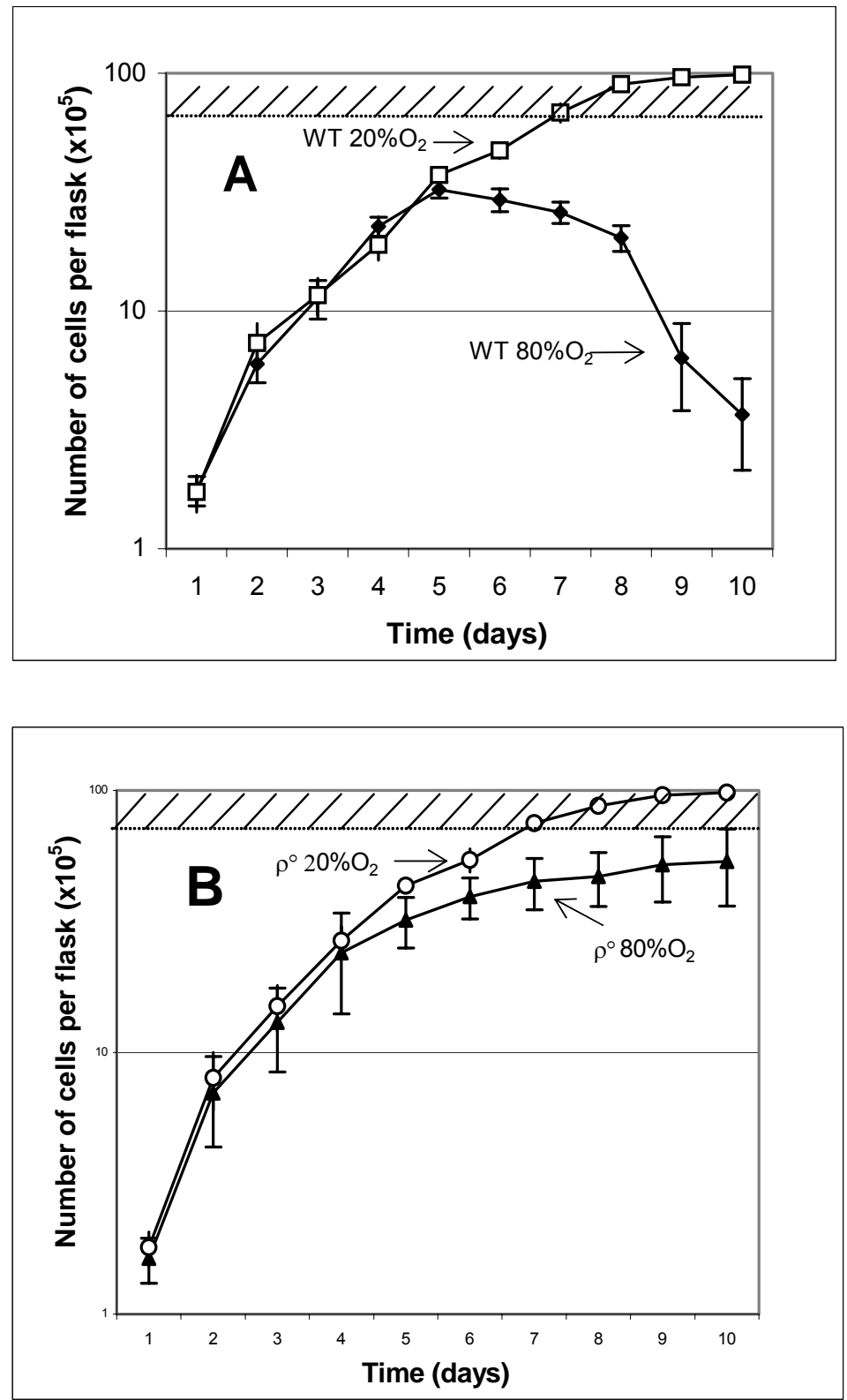

Figure 5. Growth characteristics of wild-type (A) and $\rho^{\circ} \mathrm{HeLa}$ cells (B) in normoxic $\left(20 \% \mathrm{O}_{2}\right)$ and hyperoxic $\left(80 \% \mathrm{O}_{2}\right)$ conditions. Medium was replenished every 4 days and the atmosphere of the cells grown under $80 \% \mathrm{O}_{2}$ was replaced every $48 \mathrm{hr}$. Cell growth was monitored by repeated microscopic examination of marked sectors of the culture 
dishes. Note the $\log$ scale. Under $80 \% \mathrm{O}_{2}$, following an early period of cell replication, wild-type HeLa cells stopped growing and progressively died after 5 days; however, $\rho^{\circ}$ cells continued to grow at a rate approximately $70 \%$ that observed under $20 \% \mathrm{O}_{2}$. The cell numbers at confluence are indicated by the shaded area at top. (- $\square-=$ wild-type and $-\mathrm{O}-=\rho^{\mathrm{o}}$ under $20 \% \mathrm{O}_{2} ;---=$ wild-type and $-\mathbf{\Lambda}-=\rho^{\circ}$ under $\left.80 \% \mathrm{O}_{2}\right)$. In each case, results are means $\pm 1 \mathrm{SD}$ of three independent cultures. 
B. $\rho^{\circ}$ cybrids exhibit wild-type sensitivity to hyperoxia

While the resistance of the $\rho^{0}$ HeLa cells to hyperoxia was quite likely a result of diminished mitochondrial respiration and ROS production, EB is mutagenic for both mitochondrial and nuclear DNA. To control for possible effects due to simultaneous nuclear mutations, in a sub-set of $\rho^{\circ}$ cells normal mitochondria were re-introduced via fusion with normal human platelets. As shown in Figure 6, the previously $\rho^{\circ} \mathrm{HeLa}$ cells once again containing functional mitochondria showed wild-type susceptibility to hyperoxia, having diminished early growth and later cell death under these conditions. Note that the re-introduction of normal mitochondria also restored $\mathrm{O}_{2}$ consumption to near normal rates (Table 3). As might be expected, ROS production in the cybrids was similar to that in wild-type HeLa cells and much higher than $\rho^{\circ}$ cells under both $20 \%$ and $80 \% \mathrm{O}_{2}$ detected using the fluorescent probe dihydroethidium (Figure 7). 


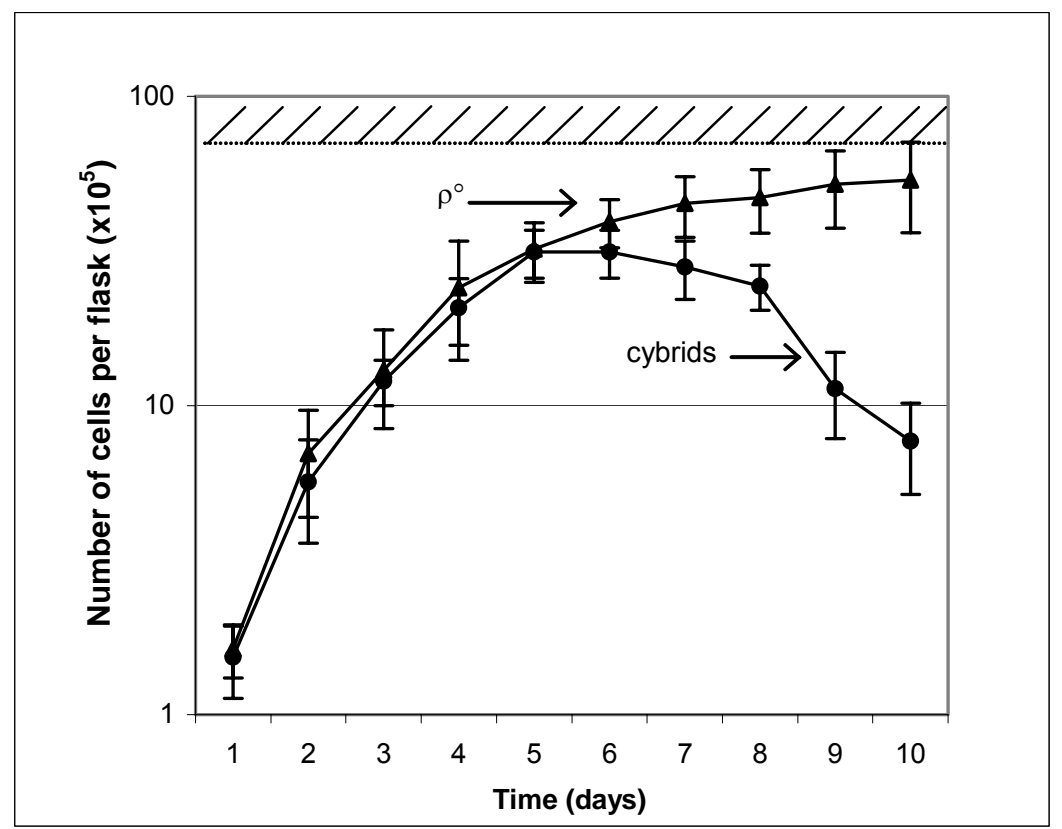

Figure 6. Growth characteristics of $\rho^{\circ} \mathrm{HeLa}$ cells $(-\mathbf{\Delta}-)$ and cybrids $\left(-\mathbf{O}_{-}\right)$in hyperoxic $\left(80 \% \mathrm{O}_{2}\right)$ conditions. Following an early period of cell replication, cybrids stopped growing and progressively died after about 5 days as did wild-type HeLa cells (Figure $5 \mathrm{~A})$. Results represent the average $\pm 1 \mathrm{SD}$ of three independent exposures. 

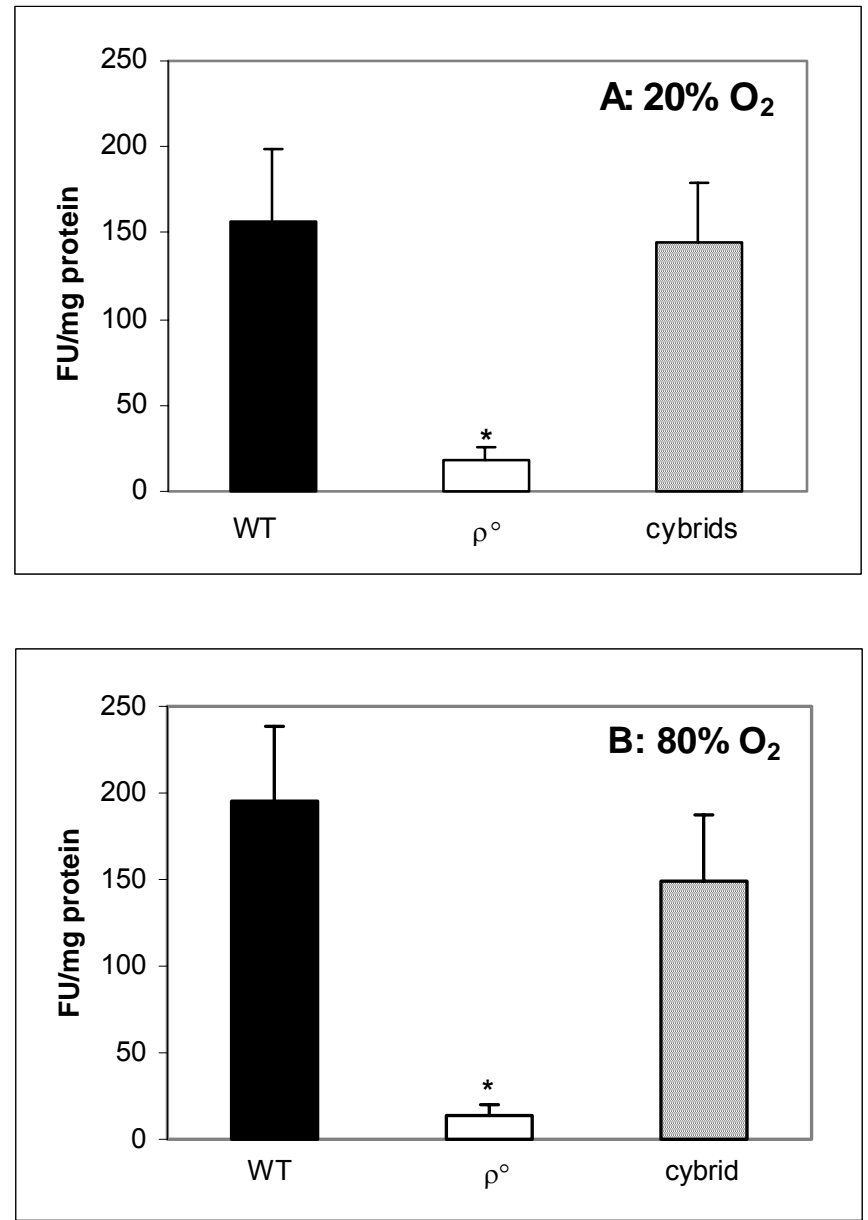

Figure 7. Mitochondrial ROS generation in wild-type, $\rho^{\circ}$ and cybrid HeLa cells. ROS production was evaluated under both $20 \% \mathrm{O}_{2}(\mathrm{~A})$ and $80 \% \mathrm{O}_{2}(\mathrm{~B})$ during a $4 \mathrm{hr}$ incubation with the fluorescent probe dihydroethidium. ROS generation (expressed as fluorescence units [FU]) was reduced by $90 \%$ and $95 \%$ in $\rho^{\circ} \mathrm{HeLa}$ cells under $20 \% \mathrm{O}_{2}$ (A) and $80 \% \mathrm{O}_{2}(\mathrm{~B})$, respectively, and was restored to near-normal in the cybrid cells (* $\mathrm{P}<0.01, \mathrm{n}=6)$. 
C. $\rho^{\circ}$ cells are not resistant to oxidant killing

One alternative explanation to the findings presented above might be that something about $\rho^{\circ}$ status - aside from effects on cellular respiration and associated ROS generation - might confer relative resistance to oxidant challenge. As a partial test for this possibility, we measured cell killing by increasing amounts of both $\mathrm{H}_{2} \mathrm{O}_{2}$ (Figure 8A) and t-butyl hydroperoxide (Figure 8B). The results indicate that, if anything, the $\mathrm{O}_{2^{-}}$ tolerant $\rho^{\circ}$ cells are somewhat more susceptible to oxidant killing. Interestingly, and for presently unknown reasons, restoration of normal mitochondria into these cells appears to improve resistance to oxidant killing. Overall, these results indicate that the tolerance of $\rho^{0}$ cells to hyperoxia does not derive from enhanced antioxidant defense. 

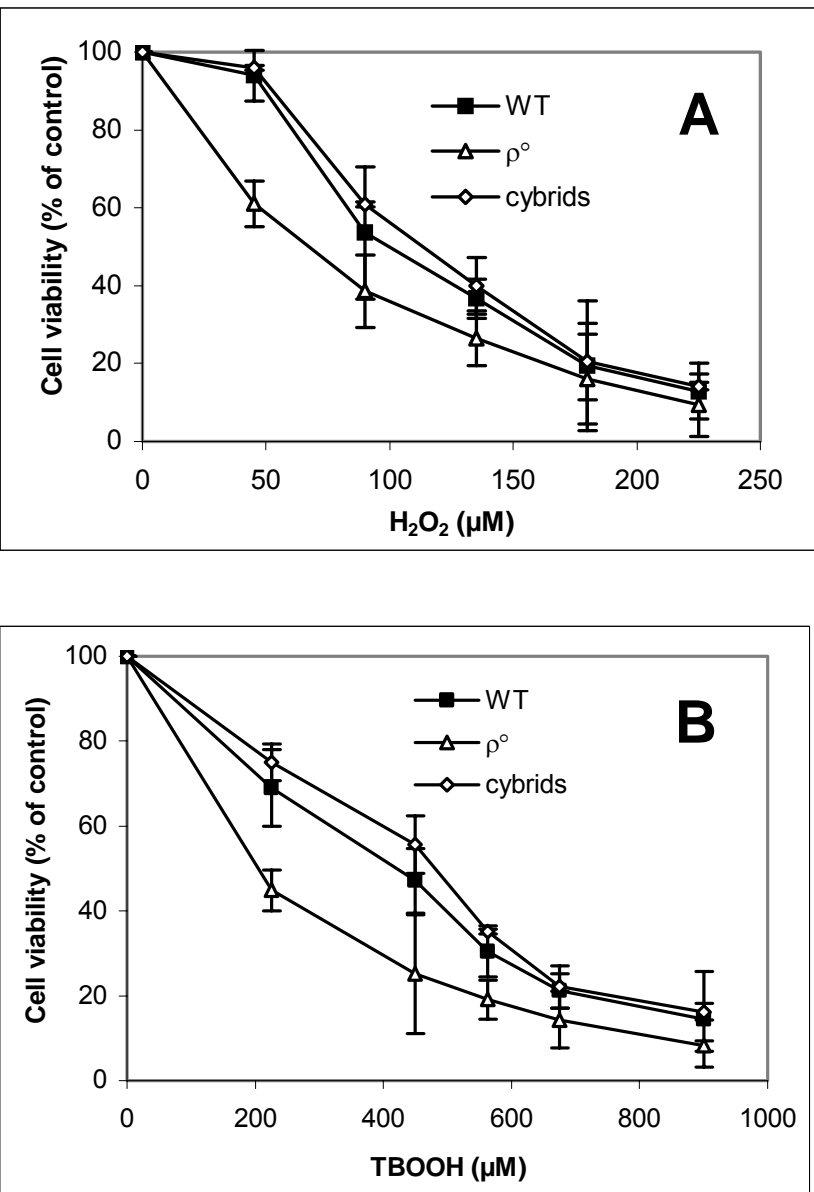

Figure 8. Susceptibility of wild-type, $\rho^{\circ}$ and cybrid HeLa cells to oxidant-mediated cell death. Wild-type HeLa cells, $\rho^{\circ}$ and cybrids cells were seeded at $4 \times 10^{4}$ cells per well in 48 -well plates and grown for 3 days at which time the cells ( $\sim 90 \%$ confluent) were exposed to $\mathrm{H}_{2} \mathrm{O}_{2}$ (A) or t-butyl hydroperoxide (B) in $\mathrm{HBSS}$ at $37^{\circ} \mathrm{C}$ for $2 \mathrm{hr}$. Upon return to complete culture medium, cell viability was estimated $10 \mathrm{hr}$ later using reduction of alamarBlue (ex530 nm, em590 nm). (-ח-= wild-type; $-\Delta-=\rho^{\circ}$ and $-0-=$ cybrids). 
D. Differences in intracellular ROS generation in wild-type vs. $\rho^{\circ}$ cells

If $\rho^{o}$ cells avoid the cytotoxic and cytocidal effects of hyperoxia by virtue of diminished mitochondrial production of ROS, then this latter also should be reflected in other measures of intracellular ROS production. Two additional parameters generally support this idea. First, we measured aconitase activity under normoxic and hyperoxic conditions. Given the susceptibility of aconitase to inactivation by ROS (Gardner et al., 1994), changes in the activity of this enzyme can be used as an indirect measure of intracellular ROS production. As shown in Figure 9, exposure of the wild-type HeLa cells to hyperoxia for $24 \mathrm{hr}$ caused a $\sim 70 \%$ decrease in total aconitase activity whereas the (already low) aconitase activity in $\rho^{\circ} \mathrm{HeLa}$ cells was relatively unaffected. Note that the activity of a reference enzyme, citrate synthase, was unchanged following similar exposure of either wild-type or $\rho^{\circ}$ cells to hyperoxia (data not shown). Second, because oxidation is most prominent in mitochondria (Das et al., 2001), we also measured mitochondrial protein carbonyl content as an indication of the extent of protein oxidation. As shown in Figure 10, protein carbonyls increased significantly in wild-type HeLa cells after $48 \mathrm{hr}$ culture in $80 \% \mathrm{O}_{2}$. In contrast, $\rho^{\circ} \mathrm{HeLa}$ cells showed no significant change in protein carbonyls. 


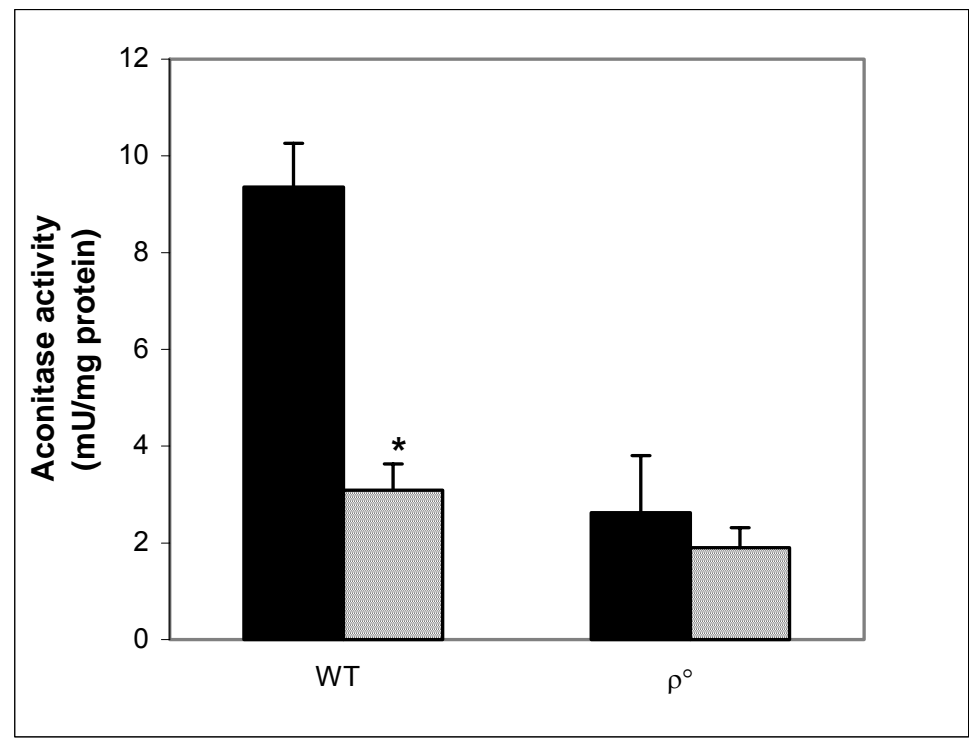

Figure 9. Wild-type, but not $\rho^{\circ}$, HeLa cells show hyperoxia-dependent inhibition of aconitase activity. Following $24 \mathrm{hr}$ culture under $20 \%$ (black bars) or $80 \%$ (gray bars) $\mathrm{O}_{2}$, aconitase activity was measured. Note the marked ( $70 \%)$ loss of aconitase activity in wild-type cells and lack of inhibition in $\rho^{\circ}$ cells. 


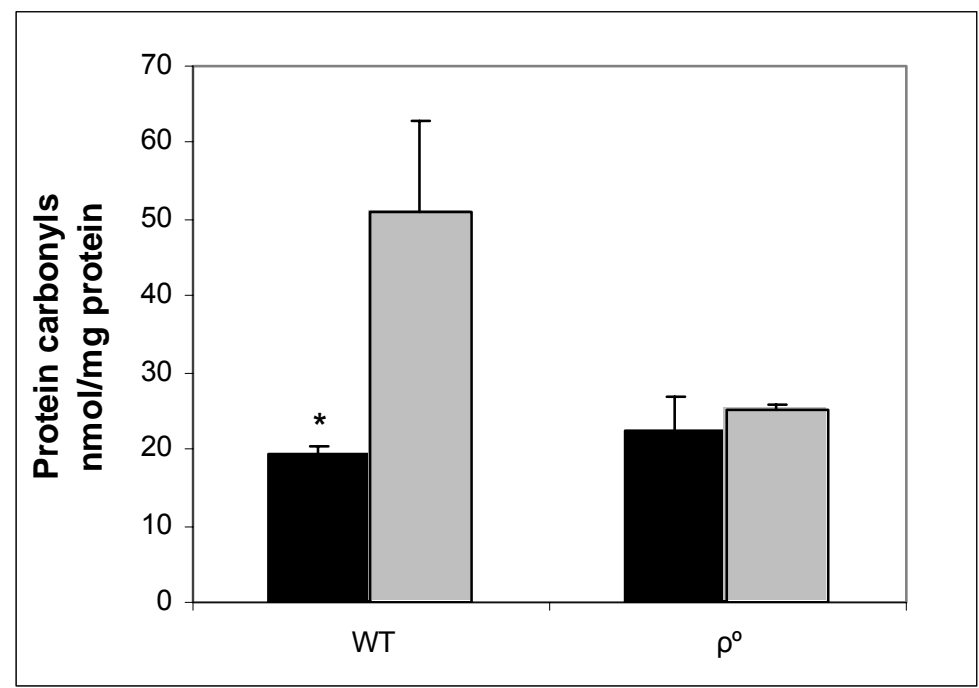

Figure 10. Wild-type, but not $\rho^{\circ}$, HeLa cells show hyperoxia-dependent increased mitochondrial protein carbonyl formation. Following $48 \mathrm{hr}$ exposure to either 20\% (solid bars) or $80 \%$ (cross-hatched bars) $\mathrm{O}_{2}$, mitochondrial protein carbonyl content was measured. Whereas wild-type cells showed a significant increase in protein carbonyls, there was no change in $\rho^{\circ}$ cells. Results represent means $\pm 1 \mathrm{SD}$ of four independent cultures $(* \mathrm{P}<0.01)$. 
E. Pharmacologic suppression of mitochondrial ROS production also permits the survival and growth of wild-type HeLa cells under hyperoxia

If $\rho^{\circ}$ cells are, indeed, protected against the cytostatic and cytotoxic effects of hyperoxia by virtue of diminished mitochondrial ROS production, then other maneuvers which similarly suppress ROS generation also should favor cell survival in hyperoxia. Indeed, two additional lines of evidence support this conclusion. First, wild-type HeLa cells were exposed to hyperoxia in the presence of the protonophoric uncoupler, CCCP. Like other uncouplers, this protonophore increases cell respiration (Kessler et al., 1976). Paradoxically, as shown in Figure 11A, CCCP causes a $\sim 60 \%$ decrease in ROS production under both normoxic and hyperoxic conditions. (This is likely because CCCP accelerates the passage of electrons down the transport chain and thereby depletes electron-rich intermediates such as ubisemiquinone.) This diminished intracellular ROS generation is associated with enhanced cell survival under hyperoxia, although some toxicity of the agent itself is reflected in the fact that these cultures did not reach confluence (Figure 11B). 

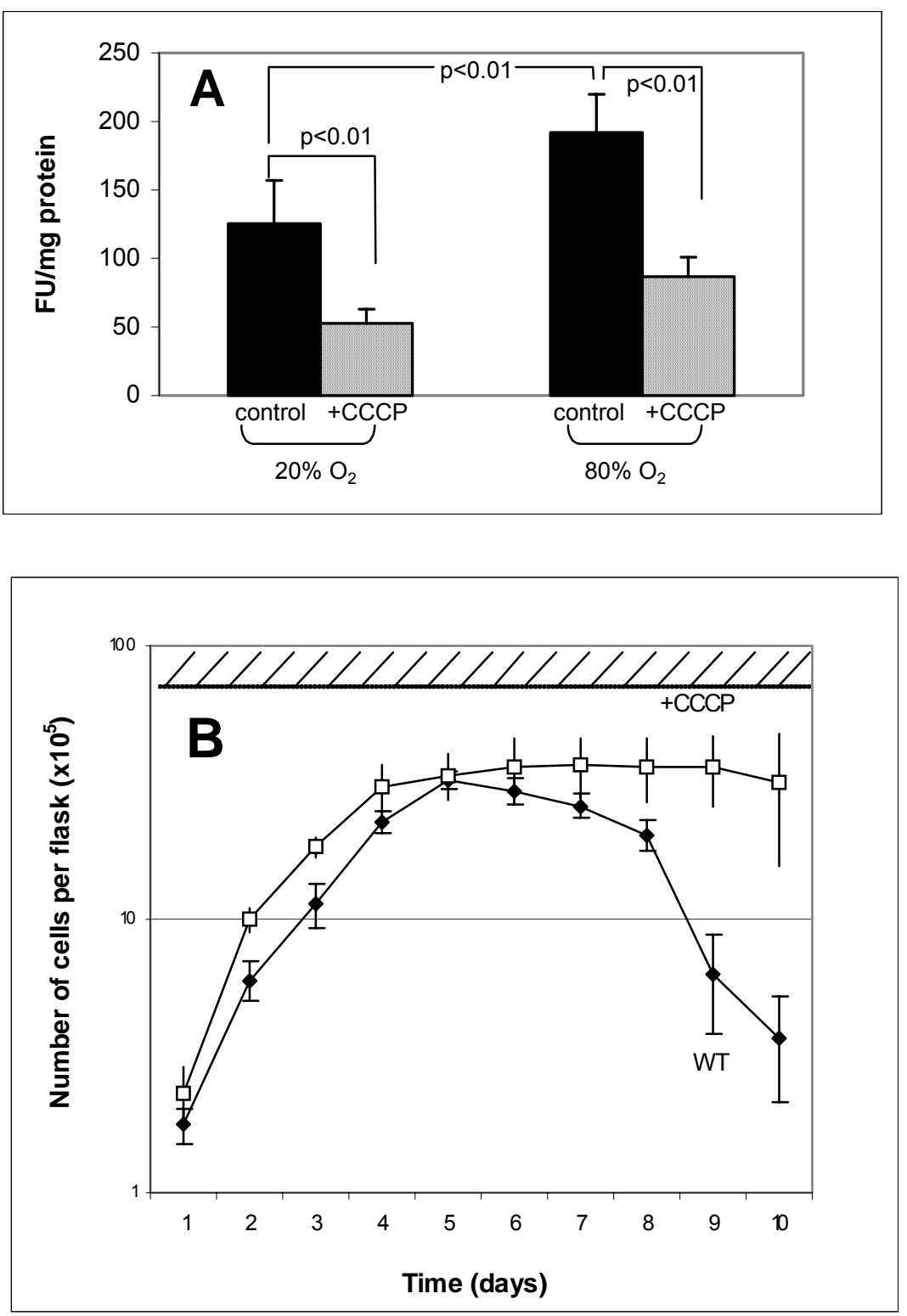

Figure 11. The protonophoric uncoupler, CCCP, decreases ROS production and enhances the survival of HeLa cells under hyperoxia. (A) ROS production was evaluated in wild-type $\mathrm{HeLa}$ cells under $20 \% \mathrm{O}_{2}$ and $80 \% \mathrm{O}_{2}$ during $4 \mathrm{hr}$ incubations with dihydroethidium in the presence and absence of CCCP. ROS production in treated cells 
was reduced $60 \%$ and $56 \%$ under normoxia and hyperoxia, respectively $(\mathrm{P}<0.01, \mathrm{n}=6)$.

(B) Wild-type HeLa cells grown in the continuous presence of $1 \mu \mathrm{M} \mathrm{CCCP}$ were relatively resistant to the cytostatic and cytocidal effects of hyperoxia. Results represent means $\pm 1 \mathrm{SD}$ of three independent cultures. 
As an additional means of achieving decreased mitochondrial ROS generation, other cultures of wild-type HeLa cells were grown in the presence of chloramphenicol. As would be expected-and in contrast to CCCP-treated cells (vide supra)-these chloramphenicol-treated HeLa cells exhibited greatly decreased $\mathrm{O}_{2}$ consumption (Table 3) and decreased ROS production under both $20 \%$ and $80 \% \mathrm{O}_{2}$ (Figure 12A). Subsequent exposure of these cells to hyperoxia (in the continued presence of chloramphenicol) revealed a substantial improvement of both growth and survival under $80 \% \mathrm{O}_{2}$ (Figure 12B). 

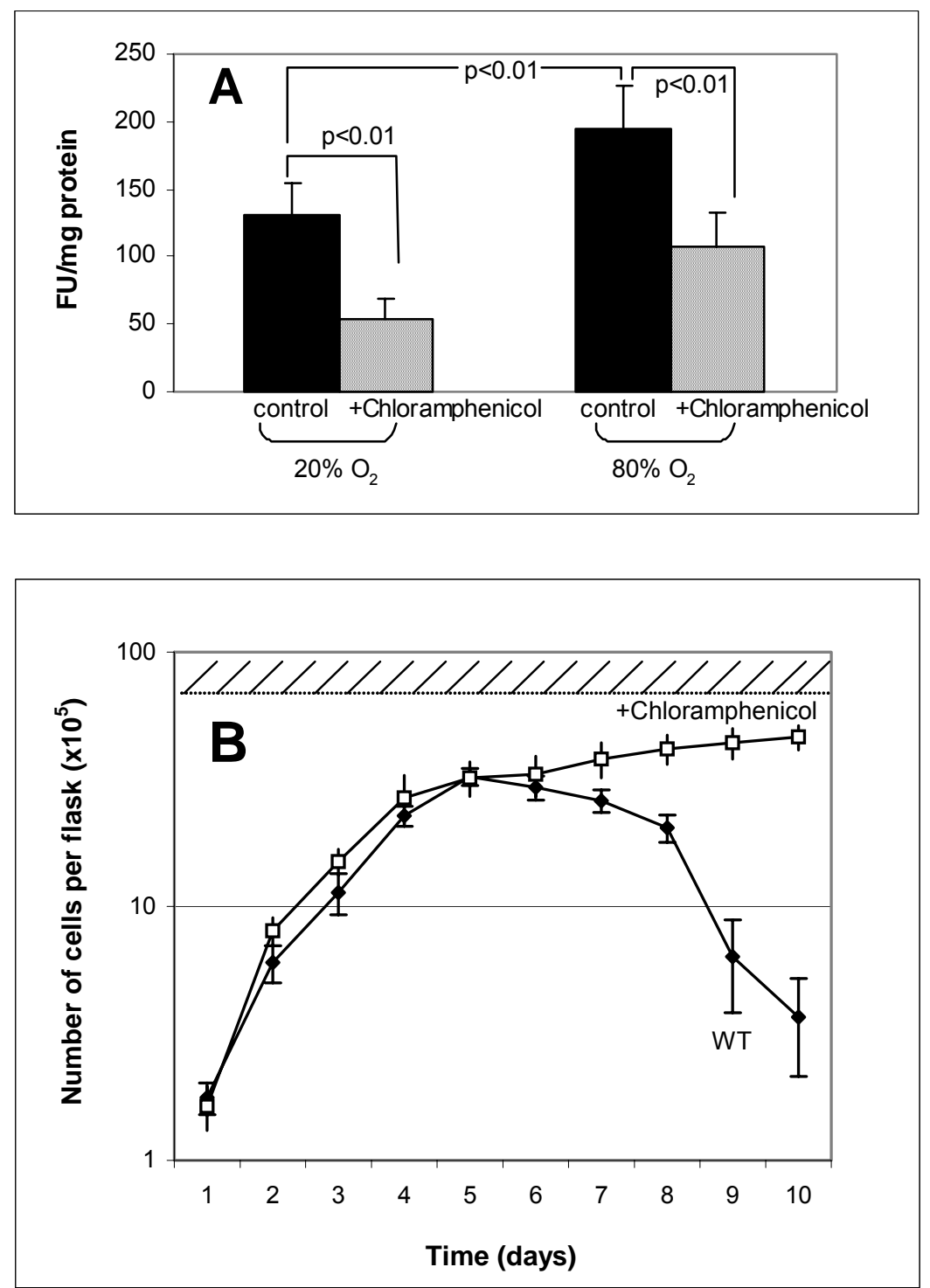

Figure 12. (A) Inhibition of mitochondrial protein synthesis with chloramphenicol decreases ROS production and increases survival of HeLa cells under hyperoxia. Wildtype HeLa cells were pretreated with $50 \mu \mathrm{g} / \mathrm{ml}$ chloramphenicol for 5 days to inhibit 
mitochondrial protein synthesis. ROS production was evaluated under $20 \% \mathrm{O}_{2}$ and $80 \%$ $\mathrm{O}_{2}$ during $4 \mathrm{hr}$ incubations with dihydroethidium. ROS production in treated cells was reduced 59\% and 45\% under normoxia and hyperoxia, respectively $(\mathrm{P}<0.01, \mathrm{n}=4)$. (B) Wild-type HeLa cells grown under $80 \% \mathrm{O}_{2}$ in the continual presence of chloramphenicol were relatively resistant to the cytostatic and cytocidal effects of hyperoxia. Results represent means $\pm 1 \mathrm{SD}$ of three independent cultures. 


\section{F. Summary of Part I.}

The above results provide substantial support for the idea that the adverse effects of hyperoxia largely derive from enhanced mitochondrial formation of ROS (Chance et al., 1979; Castro and Freeman, 2001; Gerschman et al., 1954). The amplified cellular ROS production under hyperoxia most likely arises from increased reduction of $\mathrm{O}_{2}$ to $\mathrm{O}_{2}{ }^{-}$ in metabolically-dependent reactions. These ROS may then interact with transition metals, which are present even in normal cells, to generate even more damaging species such as hydroxyl and metal-centered radicals. The increased ROS generation during exposure to hyperoxia can potentially overwhelm antioxidant defense mechanisms, even in the presence of exogenously administered antioxidants (Ho et al., 1998a).

To determine whether ROS of mitochondrial origin might be involved in cell injury and death under hyperoxia, we created $\rho^{\circ} \mathrm{HeLa}$ cells and exposed them to hyperoxia. Such $\rho^{\circ}$ cells, lacking most mitochondrial DNA, still contain intact mitochondria but lack critical subunits of the electron transport chain and do not respire. In contrast to wild-type HeLa cells, we find that $\rho^{0}$ cells are relatively resistant to the cytostatic and cytocidal effects of hyperoxia. This tolerance to high $\mathrm{O}_{2}$ concentrations coincides with diminished intracellular production of ROS during exposure to hyperoxia as estimated by (i) dihydroethidium oxidation, (ii) suppression of aconitase activity and (iii) accumulation of protein carbonyls. Both susceptibility to hyperoxic damage and intracellular ROS generation are restored in cybrids in which normal human mitochondria have been re-introduced into the $\rho^{\circ}$ cells. 
From these results, we conclude that the very organelles which permit such efficient metabolism under normoxic conditions are a clear and present danger under hyperoxia. The relentless mitochondrial production of ROS, easily detected under normoxic conditions, is increased under elevated partial pressures of $\mathrm{O}_{2}$. The likely net effect of this amplified ROS production - at least under in vitro culture conditions - is cessation of cell growth followed by cell death. Our results indicate that strategies which act to limit respiration and/or suppress intracellular ROS production will significantly diminish the toxicity of hyperoxia. 


\section{Part II: Investigations of a Unique Line of Oxygen-Tolerant HeLa Cells}

The results reported in Part I indicted ROS of mitochondrial origin in hyperoxiamediated cytostasis and cell death. In the following investigations we employed an unusual line of HeLa cells ('HeLa-80') selected for tolerance to step-wise increases in partial pressures of $\mathrm{O}_{2}$. Our hope was that elucidation of the mechanisms underlying this unusual oxygen tolerance might lead to a more comprehensive understanding of oxygen toxicity and, perhaps, suggests ways in which oxygen tolerance might be conferred to normal cells and tissues.

In attempting to understand the oxygen tolerance of the HeLa-80 strain, we focused our attention on ROS production. As described below, we found that the HeLa80 cells produced less ROS under both normoxic and hyperoxic conditions. While searching for a possible reason for this, we also observed that addition of CCCP (described above) blocked ROS production in both wild-type HeLa-20 cells and HeLa-80 cells. As also indicated above, this may be because the dissipation of the proton gradient across the inner mitochondrial membrane accelerates electron transport and, thereby, depletes electron-rich intermediates (perhaps most importantly ubisemiquinone at complex III). This suggested to us that something similar might have somehow occurred in the oxygen-tolerant HeLa-80 cells.

A. HeLa-80 cells grow and survive in hyperoxia

We began by affirming the previously reported oxygen tolerance of the HeLa-80 cells (cell lines were very generously provided by our collaborator, Dr. Hans Joenje 
(Institute of Human Genetics, Free University, Amsterdam, The Netherlands). Cell growth under $80 \% \mathrm{O}_{2}$ was monitored by microscopic examination of particular sectors of the culture plates. As shown in Figure 13A (and previously reported by Dr. Joenje (Joenje et al., 1985a), when cultured under $80 \%$ oxygen and $5 \% \mathrm{CO}_{2}$ at $37^{\circ} \mathrm{C}$, the wildtype ('Hela-20') cells ceased growing after 5-6 days and then underwent extensive cell death. In contrast, the Hela- 80 cells continued to grow throughout the period of exposure (Figure 13B). As shown in Figure 13, both Hela-20 and HeLa-80 cells exhibited normal replication when cultured under normoxic conditions. 

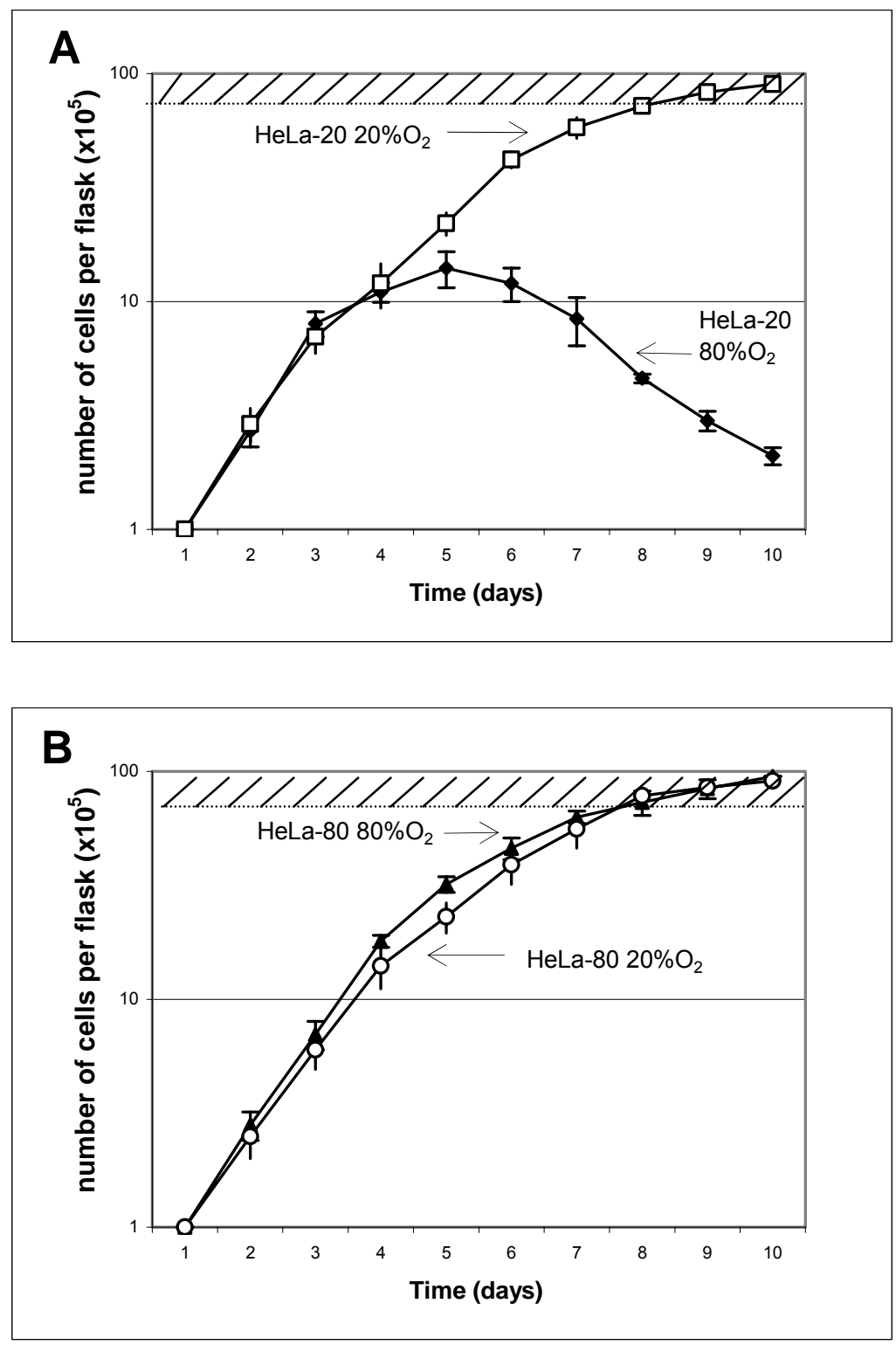

Figure 13. Growth characteristics of wild-type HeLa-20 (A) and oxygen-tolerant HeLa80 cells $(\mathrm{B})$ in normoxic $\left(20 \% \mathrm{O}_{2}\right)$ and hyperoxic $\left(80 \% \mathrm{O}_{2}\right)$ conditions. Medium was replenished every 4 days and the atmosphere of the cells grown under $80 \% \mathrm{O}_{2}$ was replaced every $48 \mathrm{hr}$. Cell growth was monitored by repeated microscopic examination of 
marked sectors of the culture plates. Note the log scale. Under $80 \% \mathrm{O}_{2}$, following an early period of cell replication, wild-type HeLa-20 cells stopped growing and progressively died after 5 days; however, oxygen tolerant HeLa-80 cells continued grow at a rate approximately the same as that observed under $20 \% \mathrm{O}_{2}$. The cell numbers at confluence are indicated by the shaded area at top. (“ $\square ”=$ HeLa-20 and "०”= HeLa-80 under $20 \% \mathrm{O}_{2} ; " \triangleleft "=\mathrm{HeLa}-20$ and " $\boldsymbol{\Delta} "=\mathrm{HeLa}-80$ under $80 \% \mathrm{O}_{2}$ ). In each case, results are means $\pm 1 \mathrm{SD}$ of three independent cultures. 
Preliminary analyses did not reveal any obvious differences in mitochondrial number or membrane potential (Figure 14). Figure 15 (bottom) presents the results of staining of these cells with JC-1 (a fluorescent dye which, by its mitochondrial concentration, specifically reflects mitochondrial membrane potential. In cells loaded with this dye, the ratio between red fluorescence (JC-1 aggregates concentrated within mitochondria) and green fluorescence (cytoplasmic JC-1 monomers) reflects mitochondrial membrane potential. Thus, JC-1 simultaneously probes mitochondrial activity, localization and abundance. 


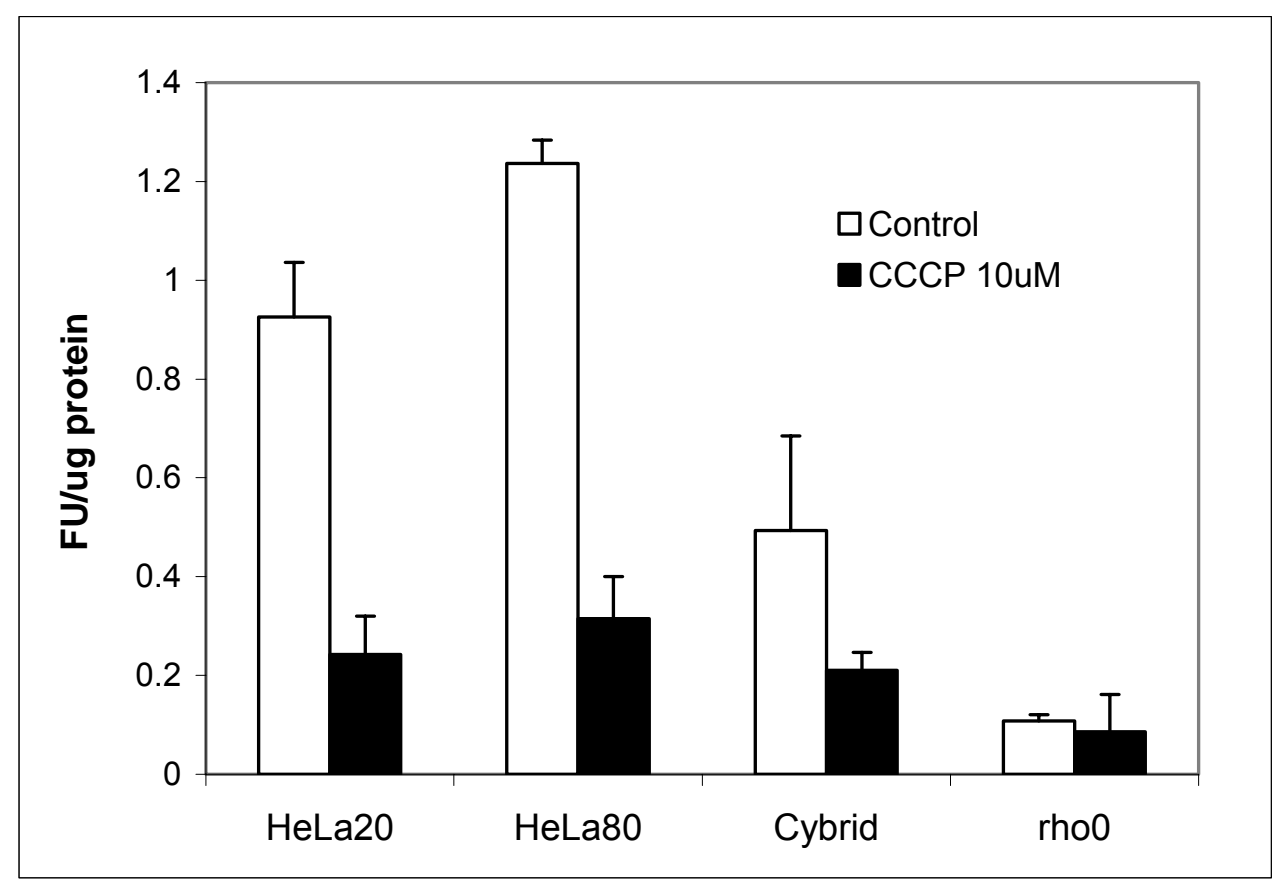

Figure 14. Changes in mitochondrial membrane potential (reflected by JC-1 staining) in the absence and presence of $10 \mu \mathrm{M} \mathrm{CCCP}$. Note the profound (and expected) decrease in membrane potential following exposure to this uncoupling agent. $n=3$ in all cases. 

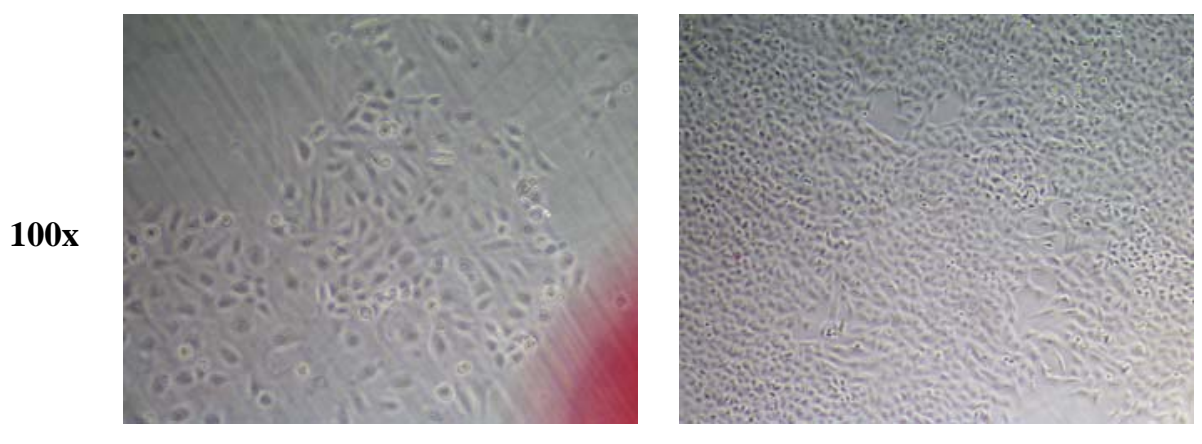

Phase
contrast
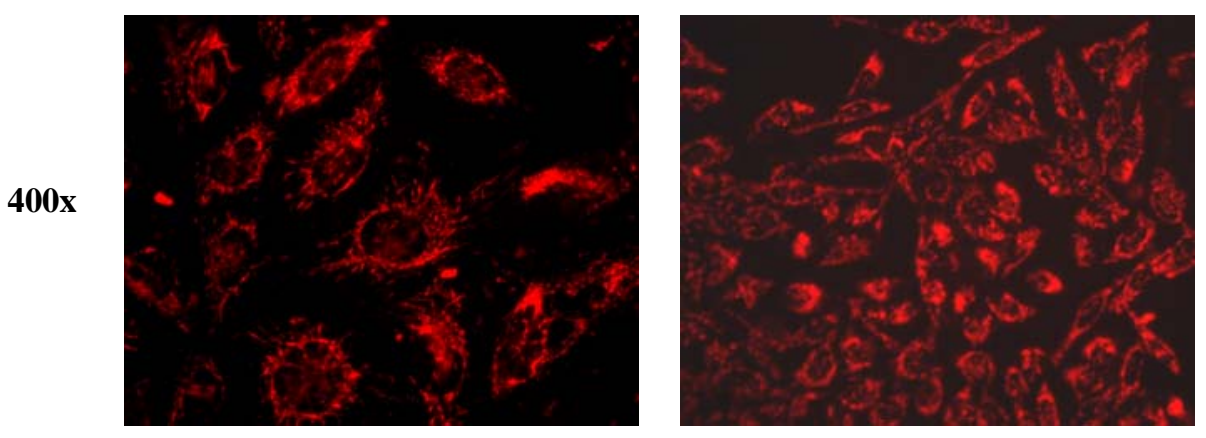

JC-1

fluorescent

microscopy

Figure 15. HeLa-20 and HeLa- 80 cells were grown under $80 \%$ oxygen for 10 days.

These pictures were taken on day 10 by normal light microscopy (top two panels) and after JC-1 staining (which reveals mitochondria with normal membrane potential). Note: After 10 days of growth under $80 \%$ oxygen, HeLa-20 cells are sparse with enlarged and less abundant mitochondria. 
B. HeLa-20 and HeLa-80 cells do not differ in susceptibility to oxidant killing

One obvious explanation for the oxygen tolerance of the HeLa- 80 cells might be a generalized resistance to the oxidants produced under hyperoxic conditions. However, we reaffirmed Dr. Joenje's earlier findings (Gille et al., 1988; Joenje et al., 1985b) that there are no significant differences in antioxidant enzymes, such as superoxide dismutases, catalase, reduced glutathione, glutathione reductase and glutathione peroxidase, between these two strains of HeLa cells. In view of earlier reports that elevated heme oxygenase-1 might protect against hyperoxia-induced lung damage (Lee et al., 1996; Otterbein et al., 1999a), we also measured total heme oxygenase activity. Once again, no significant differences were found (Figure 16). We also measured the Bcl-2 levels in these two cell lines because some reports suggested that over-expression of Bcl-2 might be associated with oxygen tolerance (Budinger et al., 2002). Here as well, no significant differences were observed (Figure 17). As a more direct test of the overall oxidant defenses of these two cell lines, we investigated cell killing by increasing amounts of both $\mathrm{H}_{2} \mathrm{O}_{2}$ and tbutylhydroperoxide. As shown in Figure 18, these two cell lines show nearly identical killing curves and $\mathrm{LD}_{50}$ s for both oxidants. For $\mathrm{H}_{2} \mathrm{O}_{2}, \mathrm{LD}_{50}$ is $140 \pm 21 \mu \mathrm{M}$ and $125 \pm 28$ $\mu \mathrm{M}, \mathrm{n}=4$ (Figure 18A); for t-butylhydroperoxide, $\mathrm{LD}_{50}$ is $470 \pm 35 \mu \mathrm{M}$ and $410 \pm 62$ $\mu \mathrm{M}, \mathrm{n}=4$ for HeLa-20 and HeLa-80 cells respectively (Figure 18B). 


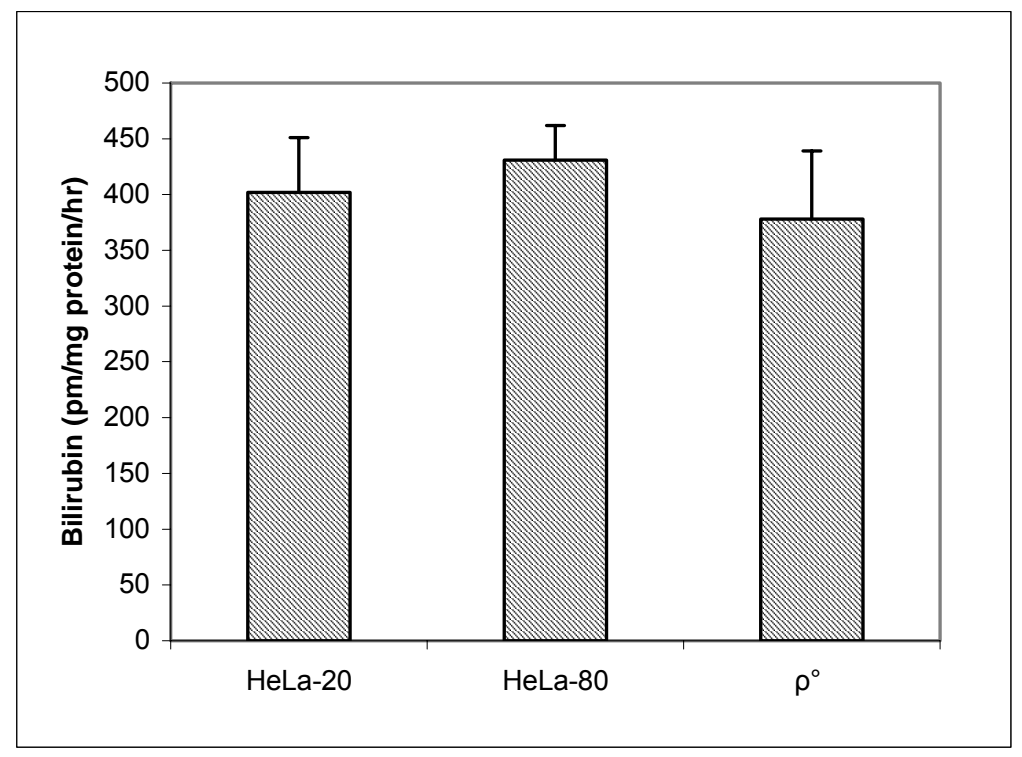

Figure 16. Total heme oxygenase activities measured in HeLa-20, HeLa-80 and $\rho^{0}$ HeLa-20 cell lines. No significant difference was found $(n=3)$. 


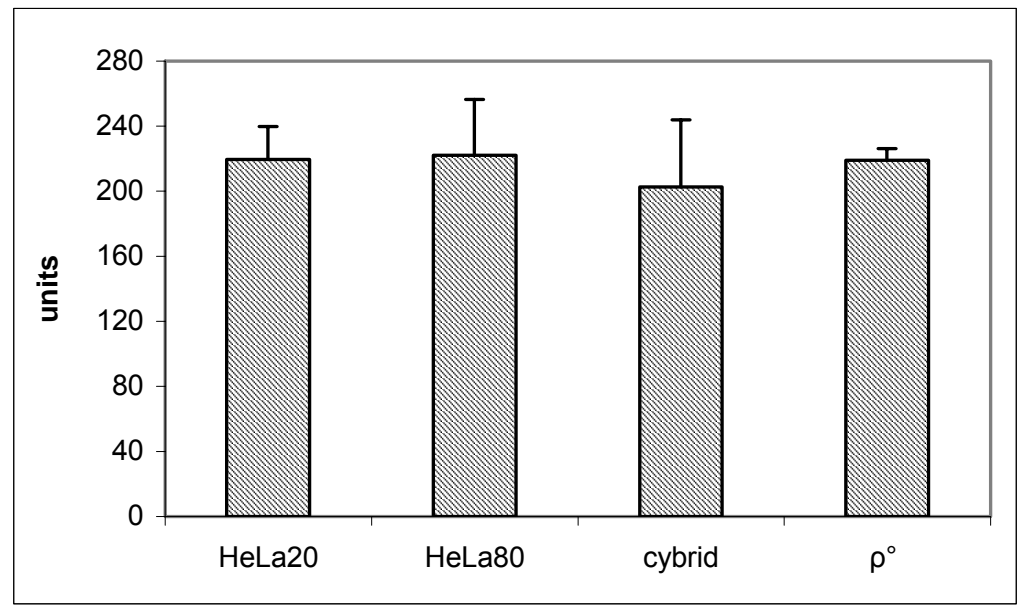

Figure 17. Bcl-2 levels were measured in HeLa-20, HeLa-80, $\rho^{\circ} \mathrm{HeLa}-20$ and the corresponding cybrids. The assay was carried out at absorbance $450 \mathrm{~nm}$. The Bcl2 units were calculated by Bcl-2 ELISA standard curve. No significant difference in Bcl-2 levels was found $(\mathrm{n}=4)$. 

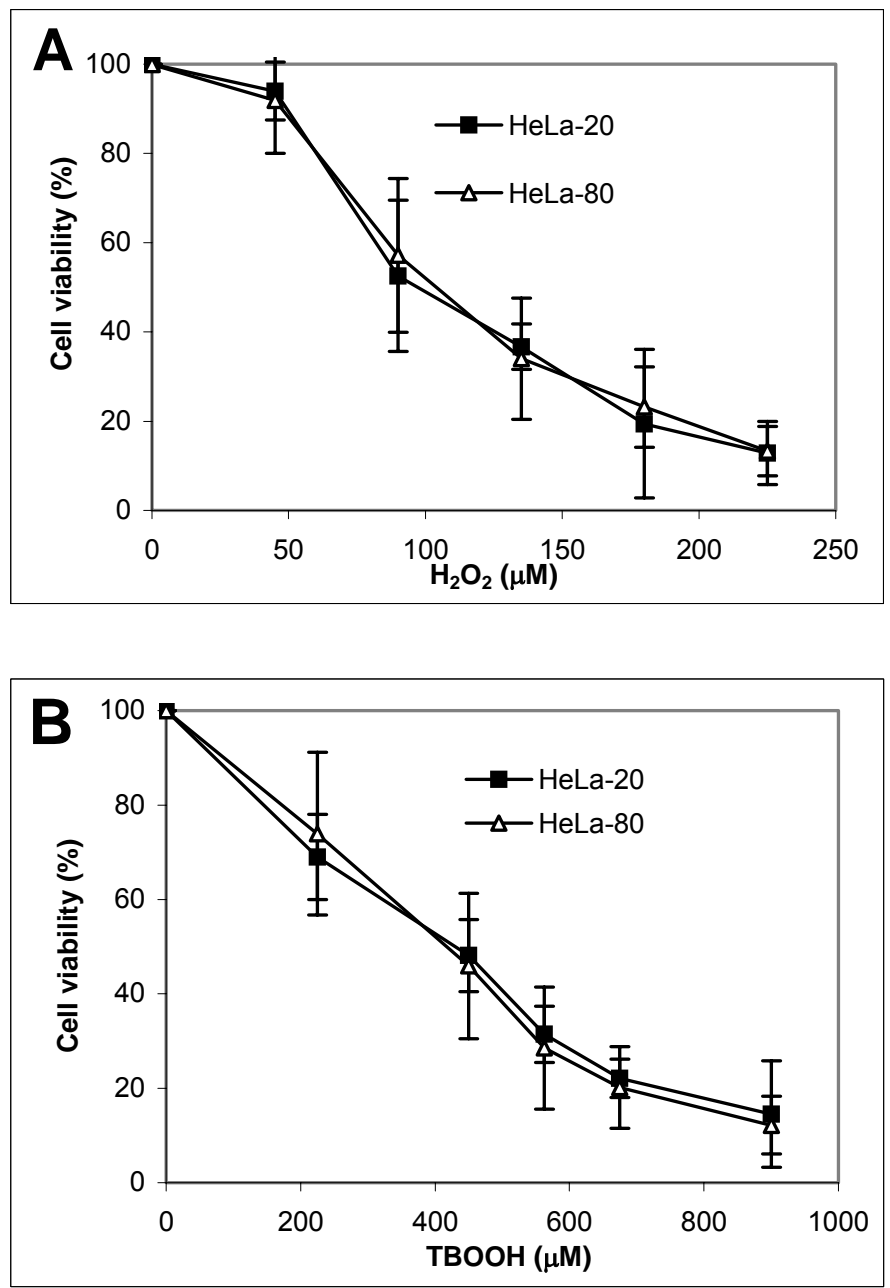

Figure 18. Susceptibility of wild-type HeLa-20 and oxygen-tolerant HeLa-80 cells to oxidant-mediated cell death. HeLa-20 and HeLa-80 cells were seeded in 48 -well plates at an initial density of $2 \times 10^{4}$ cells per well and grown 3 days at which time the cells $(\sim 90 \%$ confluent) were exposed to $\mathrm{H}_{2} \mathrm{O}_{2}$ (A) or t-butyl hydroperoxide (B) in $\mathrm{HBSS}$ at $37^{\circ} \mathrm{C}$ without $\mathrm{CO}_{2}$ for $2 \mathrm{hr}$. Upon return to complete culture medium, cell viability was estimated $10 \mathrm{hr}$ later using reduction of alamarBlue (ex530 nm, em590 nm) (“口”= HeLa$20 ; " \Delta "=$ HeLa-80). 
C. Oxygen tolerant HeLa-80 cells exhibit decreased ROS production under both normoxia and hyperoxia

The above results directed our attention to possible differences in the production of ROS by HeLa- 20 vs. HeLa- 80 cells. This was first estimated using the fluorescent probe dihydrodichlorofluorescein diacetate (DCF-DA). This cell permeable nonfluorescent probe enters cells by passive diffusion whereupon the two acetate groups are esterolytically cleaved. Within the cell, the probe can be oxidized in a reaction which requires $\mathrm{H}_{2} \mathrm{O}_{2}$ and a peroxidase or pseudoperoxidase such as cytochrome $c$ or redoxactive Fe. Upon oxidation, the probe is converted to highly fluorescent 2 ',7'dichlorofluorescin. The results (Figure 19) indicate that the steady state production of ROS by Hela- 80 cells is substantially less than that of HeLa- 20 cells, supplying at least partial support for our general hypothesis that the tolerance of HeLa- 80 cells might arise from lessened ROS generation. 


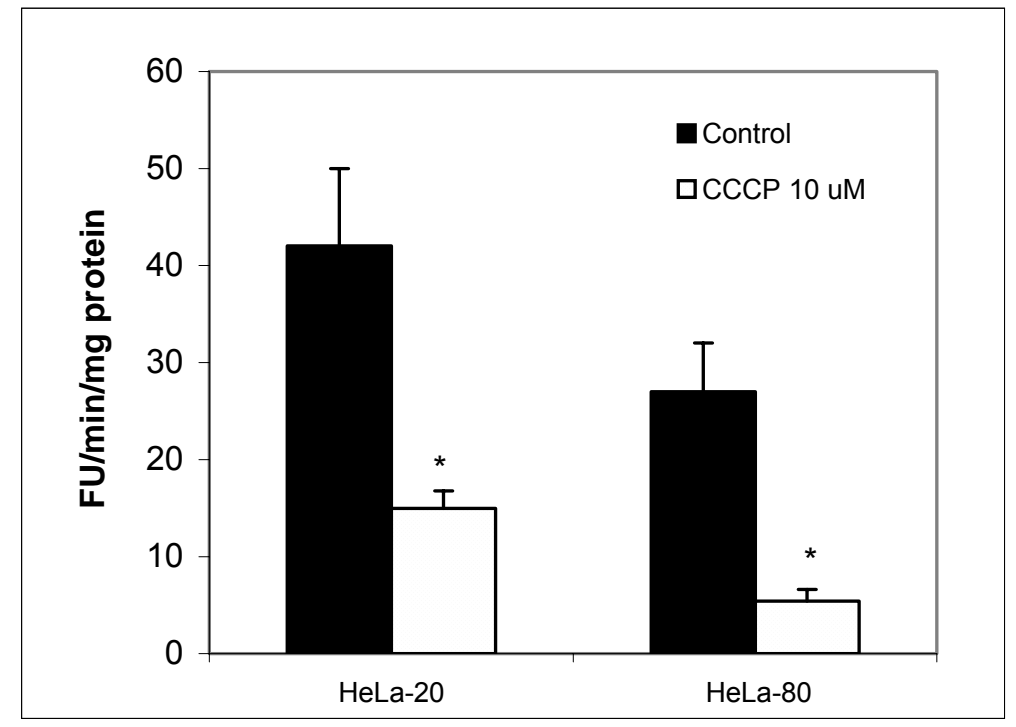

Figure 19. Mitochondrial ROS generation in wild-type HeLa-20 and oxygen-tolerant HeLa- 80 cells. ROS production was evaluated under $20 \% \mathrm{O}_{2}$ detected by oxidation of the fluorescent probe, dihydrodichlorofluorescein diacetate (DCF-DA) in the presence and absence of the protonophoric uncoupler carbonyl cyanide m-chlorophenylhydrazone (CCCP). Even under normoxia, ROS production by HeLa-80 cells is markedly lower than that by HeLa-20 cells ( $1 \mathrm{hr}$ exposure to $20 \mu \mathrm{M}$ DCF-DA in HBSS, $\mathrm{p}<0.01, \mathrm{n}=6$ ). In both cell types, the addition of CCCP $(10 \mu \mathrm{M})$ inhibits most ROS generation, strongly supporting a mitochondrial origin of this reactive oxygen $(\mathrm{p}<0.01, \mathrm{n}=6)$. 
To ensure that this difference in ROS generation was truly present, we employed an alternative method for ROS determination. In this case, the production of ROS by HeLa- 20 and HeLa- 80 cells was estimated by the oxidation of dihydroethidium which, upon peroxidatic oxidation by $\mathrm{H}_{2} \mathrm{O}_{2}$, is converted to ethidium. The ethidium then rapidly intercalates into DNA, thereby trapping the product of the reaction. We should note that in estimating the relative generation of ROS by these different cell lines, there were some technical problems. Introducing the fluorescent probe while the cells are in an $80 \% \mathrm{O}_{2}$ environment is impossible. Therefore, the cells must first be equilibrated with this atmosphere, the probe quickly added and the cells returned to hyperoxia. As a result, the initial $\mathrm{pO}_{2}$ will fluctuate. This was controlled by carrying out such incubations for 1, 2, 4, and $6 \mathrm{hr}$ and expressing the ROS production per unit time. Using the dihydroethidium procedure, we were able to study ROS production over longer periods of time which allowed for equilibration of the cultured cells with the hyperoxic atmosphere. In this case, even greater differences in intracellular ROS generation were observed (Figure 20). As also shown in Figures 19 and 20, in both cell types, the addition of CCCP $(10 \mu \mathrm{M})$ inhibited most ROS production under both $20 \%$ and $80 \% \mathrm{O}_{2}$, strongly supporting a mitochondrial origin of this reactive oxygen. We should note that the results obtained with both probes were corrected for measured cell protein in each well. 

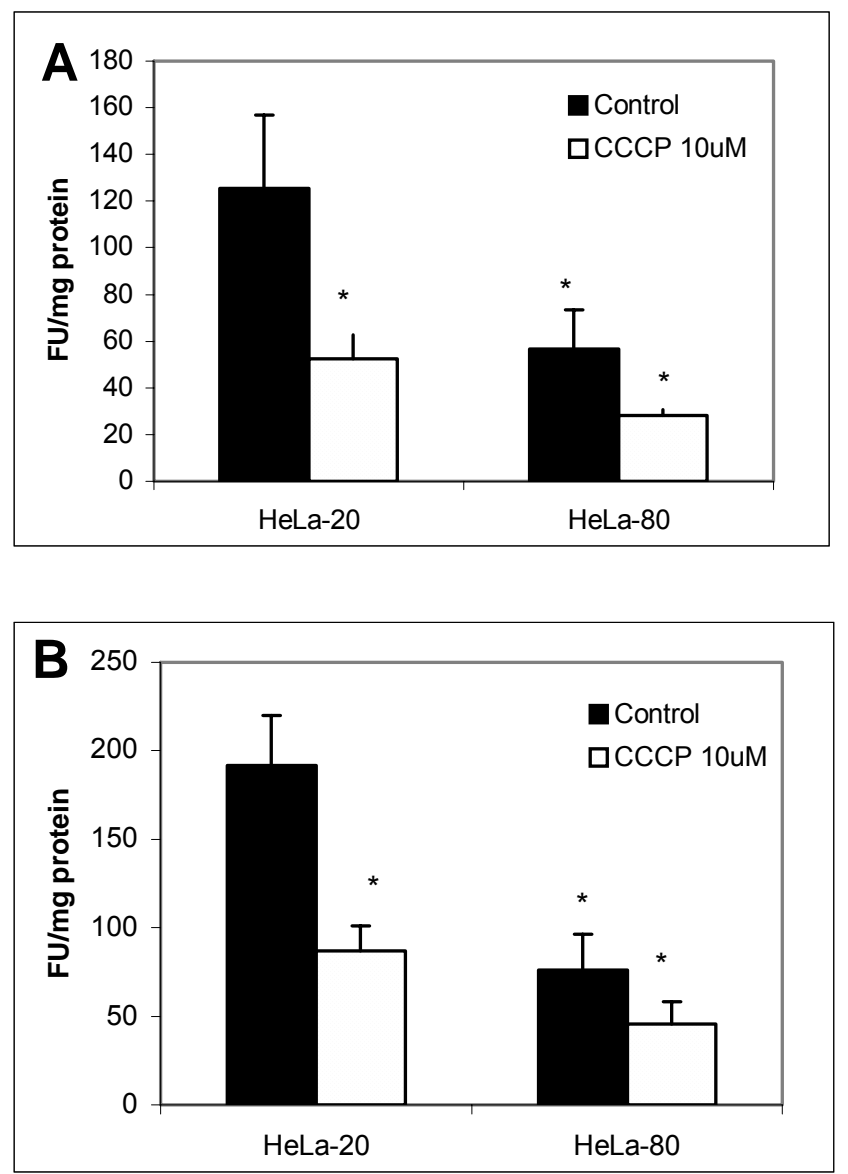

Figure 20. Mitochondrial ROS generation in wild-type HeLa-20 and oxygen-tolerant HeLa-80 cells. ROS production was evaluated under both $20 \% \mathrm{O}_{2}(\mathrm{~A})$ and $80 \% \mathrm{O}_{2}$ (B). (A): ROS production under $20 \% \mathrm{O}_{2}$ was detected by the oxidation of the fluorescent probe dihydroethidium in the absence and presence of CCCP. These results are very similar to those obtained with DCF-DA (Figure 19), showing significantly lower ROS production by HeLa- 80 vs. HeLa-20 cells (a $4 \mathrm{hr}$ exposure to $100 \mu \mathrm{M}$ dihydroethidium in complete culture medium, $\mathrm{p}<0.01, \mathrm{n}=4$ ). Once again, addition of the uncoupler CCCP $(10 \mu \mathrm{M})$ eliminated most of the ROS generation $(\mathrm{p}<0.05, \mathrm{n}=4)$. (B): ROS production 
under $80 \% \mathrm{O}_{2}$ was tested by the oxidation of dihydroethidium in the absence and presence of CCCP. Under hyperoxia, ROS production increased 30-40\% vs. normoxia in the wild-type HeLa-20 cells and was significantly higher in HeLa-20 vs. HeLa-80 cells (a $4 \mathrm{hr}$ exposure to $100 \mu \mathrm{M}$ dihydroethidium in complete culture medium under $80 \% \mathrm{O}_{2}$, $\mathrm{p}<0.01, \mathrm{n}=4$. In both cell types, the addition of CCCP $(10 \mu \mathrm{M})$ inhibited most ROS generation $(\mathrm{p}<0.05, \mathrm{n}=4)$, strongly supporting a mitochondrial origin of this reactive oxygen. 
D. Additional evidence that oxygen tolerant HeLa- 80 cells generate less ROS under both normoxia and hyperoxia

If HeLa- 80 cells avoid the cytotoxic and cytocidal effects of hyperoxia by virtue of diminished mitochondrial production of ROS, then this latter also should be reflected in other measures of intracellular ROS production. Two additional parameters generally support this idea. First, we measured total aconitase activity under normoxic and hyperoxic conditions. Given the susceptibility of aconitase to inactivation by ROS (Gardner et al., 1994), changes in the activity of this enzyme can be used as an indirect measure of intracellular ROS production. As shown in Figure 21, exposure of the wildtype HeLa-20 cells to hyperoxia for $24 \mathrm{hr}$ caused a $\sim 70 \%$ decrease in total aconitase activity whereas the aconitase activity in oxygen-tolerant HeLa-80 cells was much less affected. Note that the activity of a reference enzyme, citrate synthase, was unchanged following similar exposure of either HeLa-20 or HeLa-80 cells to hyperoxia (data not shown). Second, we also measured the mitochondrial protein carbonyl content of the cells as an indication of the extent of protein oxidation. As shown in Figure 22, mitochondrial protein carbonyls increased significantly in HeLa-20 cells after $24 \mathrm{hr}$ culture in $80 \% \mathrm{O}_{2}$. In contrast, HeLa-80 cells showed no significant change in protein carbonyls. 


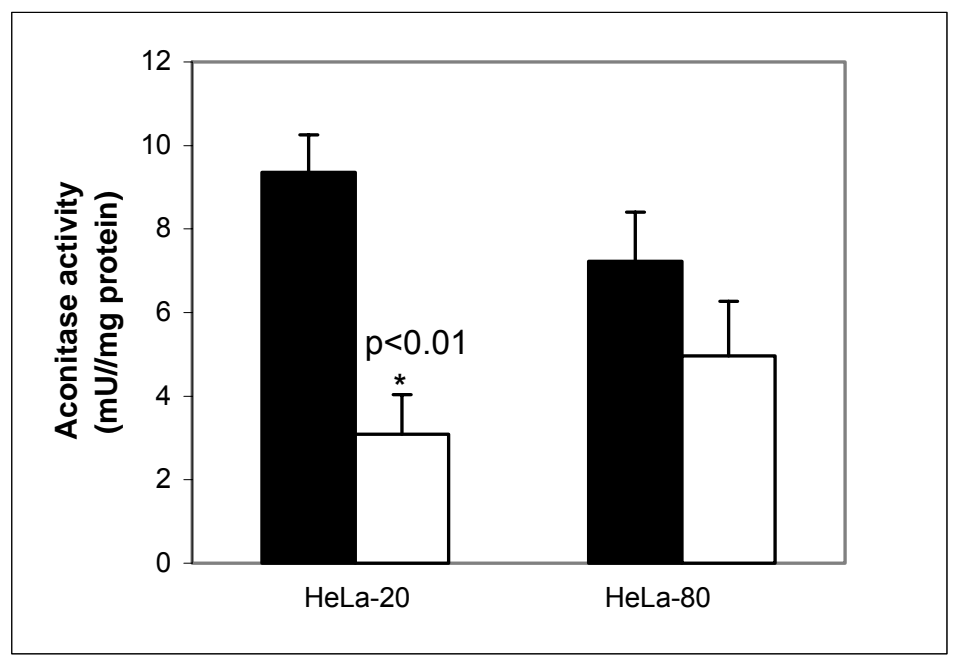

Figure 21. Wild-type HeLa-20, but not oxygen-tolerant HeLa-80 cells, show hyperoxiadependent inhibition of aconitase activity. Following $24 \mathrm{hr}$ culture under $20 \%$ (filled bars) or $80 \%$ (blank bars) $\mathrm{O}_{2}$, aconitase activity was measured. Note the marked ( $\left.70 \%\right)$ loss of aconitase activity in HeLa-20 cells and lack of inhibition in HeLa-80 cells. 


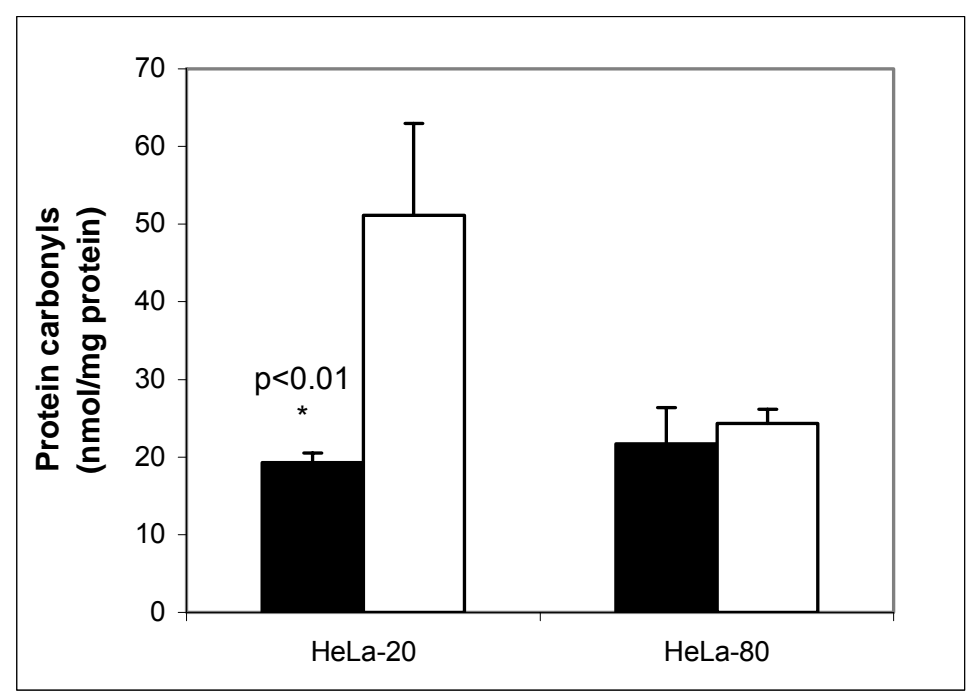

Figure 22. Wild-type HeLa-20, but not oxygen-tolerant HeLa-80 cells, show hyperoxiadependent increased mitochondrial protein carbonyl formation. Following $48 \mathrm{hr}$ exposure to either $20 \%$ (filled bars) or $80 \%$ (blank bars) $\mathrm{O}_{2}$, mitochondrial protein carbonyl content was measured. Whereas HeLa-20 cells showed a significant increase in protein carbonyls, there was no change in HeLa-80 cells. Results represent means \pm 1 SD of four independent cultures. 
E. Mitochondrial respiration inhibitors modulate ROS production by both HeLa-20 and HeLa-80 cells

Although the above results (Figures 19 and 20) indicate that the majority of ROS being detected in both cell strains is almost certainly of mitochondrial origin, we conducted additional tests with three other inhibitors of mitochondrial respiration to further define the respiratory chain complex(es) which might be involved. For this, we used rotenone (a complex I inhibitor), thenoyltrifluoroacetone (TTFA) (a complex II inhibitor) and antimycin-A (a complex III inhibitor). Given that inhibition of complexes I and II will not completely prevent ROS production, we expected that the first two inhibitors would have lesser effect than did CCCP on ROS production. This appears to be the case; ROS production was reduced by a combination of these agents by $50 \%$ and $40 \%$ in HeLa-20 and HeLa-80 cells, respectively (Figure 23). 


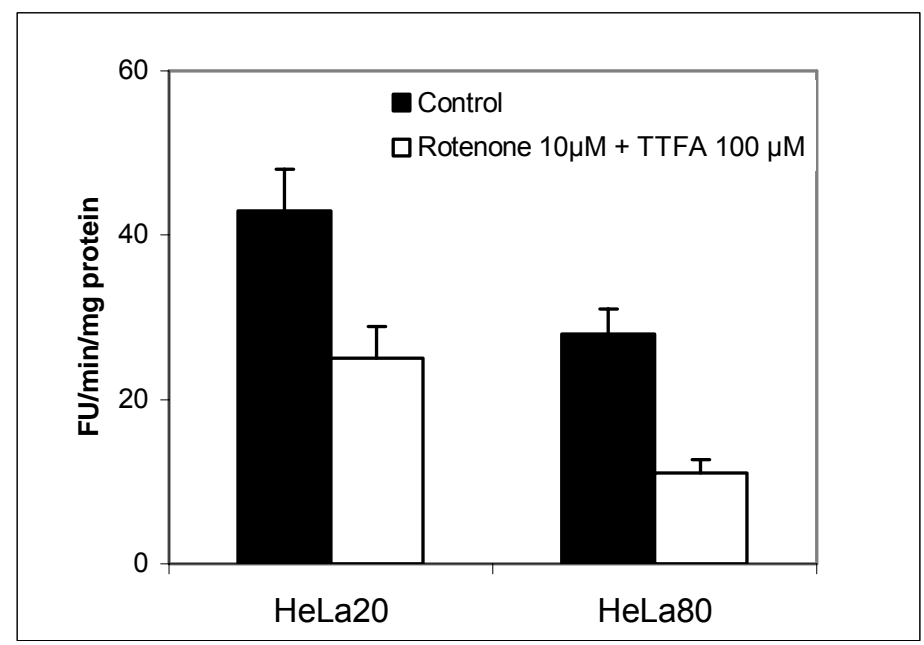

Figure 23. Inhibitors of complexes I and II decrease ROS production in both HeLa-20 and HeLa-80 cells as detected by DCF-DA oxidation under normoxia. ROS production was evaluated in the presence of rotenone (complex I inhibitor) and TTFA (complex II inhibitor) $(\mathrm{p}<0.01, \mathrm{n}=5)$. 
Interestingly, antimycin-A, a complex III inhibitor, greatly increased ROS production in both cell lines (Figure 24). This phenomenon has been observed previously (Zhang et al., 2001) and likely stems from an accumulation of the ubisemiquinone radical in the Q cycle of complex III. This also lends further support to the general view that complex III is the main site of ROS production under normal metabolic conditions (Finkel and Holbrook, 2000; Goijman and Stoppani, 1985). This involves the reduction of $\mathrm{O}_{2}$ to $\mathrm{O}_{2}^{-}$by ubisemiquinone. In the absence of respiratory chain inhibition at complex III, the small steady state concentrations of ubisemiquinone are normally oxidized to ubiquinone by means of sequential reactions with cytochromes in the Q cycle, thereby preventing the accumulation of this potentially dangerous redox species. Overall, these results above further confirm that the generation of ROS is, in both cell types, mitochondrial in origin under both normoxia and hyperoxia. 


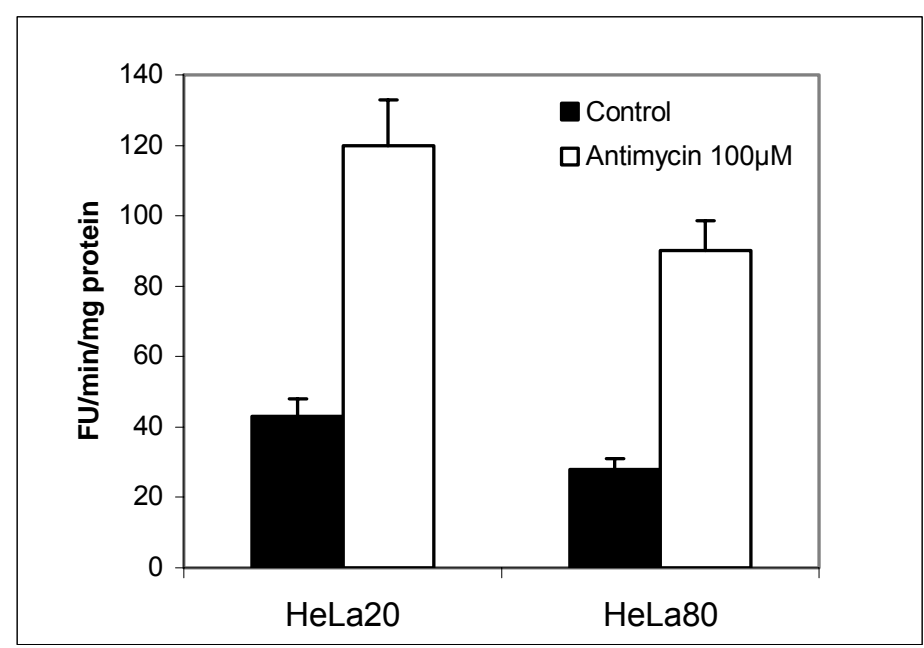

Figure 24. The mitochondrial inhibitor, antimycin A, increases ROS production in both HeLa-20 and HeLa-80 cells as detected by DCF-DA oxidation under normoxia. ROS production in the presence of antimycin A (complex III inhibitor) was markedly increased by the addition of antimycin $\mathrm{A}(\mathrm{p}<0.05, \mathrm{n}=4)$. 


\section{F. Summary of Part II}

Based on these results, we conclude that oxygen tolerant HeLa- 80 cells do produce less ROS under both $20 \% \mathrm{O}_{2}$ and $80 \% \mathrm{O}_{2}$. The results of limited tests with inhibitors of various complexes within the mitochondrial electron transport chain support the view that these ROS mainly come from mitochondria. These observations raised the central question of the nature of the difference(s) in mitochondrial function responsible for the lessened ROS generation by HeLa-80 cells, a question addressed below in Part III. 


\section{Part III: Why Do the Mitochondria in HeLa-80 Cells Generate Less ROS?}

The diminished ROS production by HeLa- 80 cells could potentially reflect either an overall suppression of mitochondrial metabolism or an enhanced efficiency of mitochondrial metabolism. In the former case (and assuming an equivalent demand for energy in both cell types), the less efficient mitochondrial metabolism would have to be compensated for by enhanced glucose consumption and production of lactic acid (reflecting increased need for glucose consumption and reduced oxidative carbohydrate metabolism by the mitochondria). However, in the event that mitochondrial metabolism were to be more tightly coupled (and, therefore, more efficient) both these parameters might be diminished.

A. HeLa-80 cells are more metabolically efficient

In an attempt to dissect the above possibilities, we compared wild-type HeLa-20 and oxygen-tolerant HeLa-80 cell lines in terms of overall energy metabolism and oxygen consumption. As argued above, if HeLa-80 cells showed increased glucose consumption and lactate production it would imply lessened energy production through aerobic metabolism. On the other hand, decreased glucose consumption and lactate production would imply more efficient mitochondrial production of energy in HeLa- 80 cells (which our results support). As shown in Figures 25 and 26, it appears that both glucose consumption and lactate production are lower in the HeLa-80 cells under both normoxia and hyperoxia, supporting the idea that mitochondrial electron transport might be more tightly coupled. 

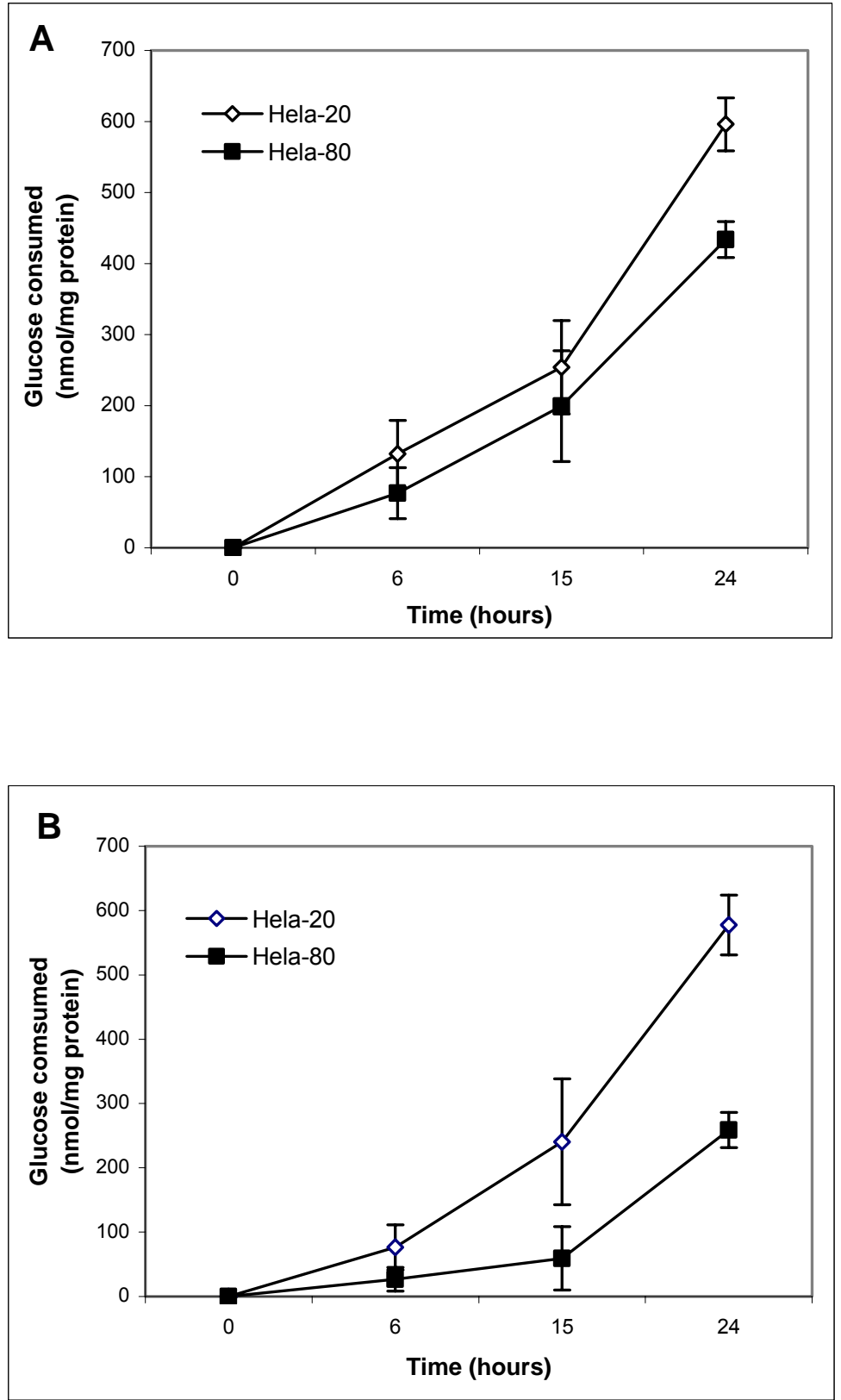

Figure 25. Glucose consumption by HeLa cells were measured over a 24-hr period under both normoxic $\left(20 \% \mathrm{O}_{2}\right)(\mathrm{A})$ and hyperoxic $\left(80 \% \mathrm{O}_{2}\right)(\mathrm{B})$. Glucose consumption was decreased in oxygen-tolerant HeLa-80 cells under both conditions. $(\mathrm{p}<0.05, \mathrm{n}=3)$ 

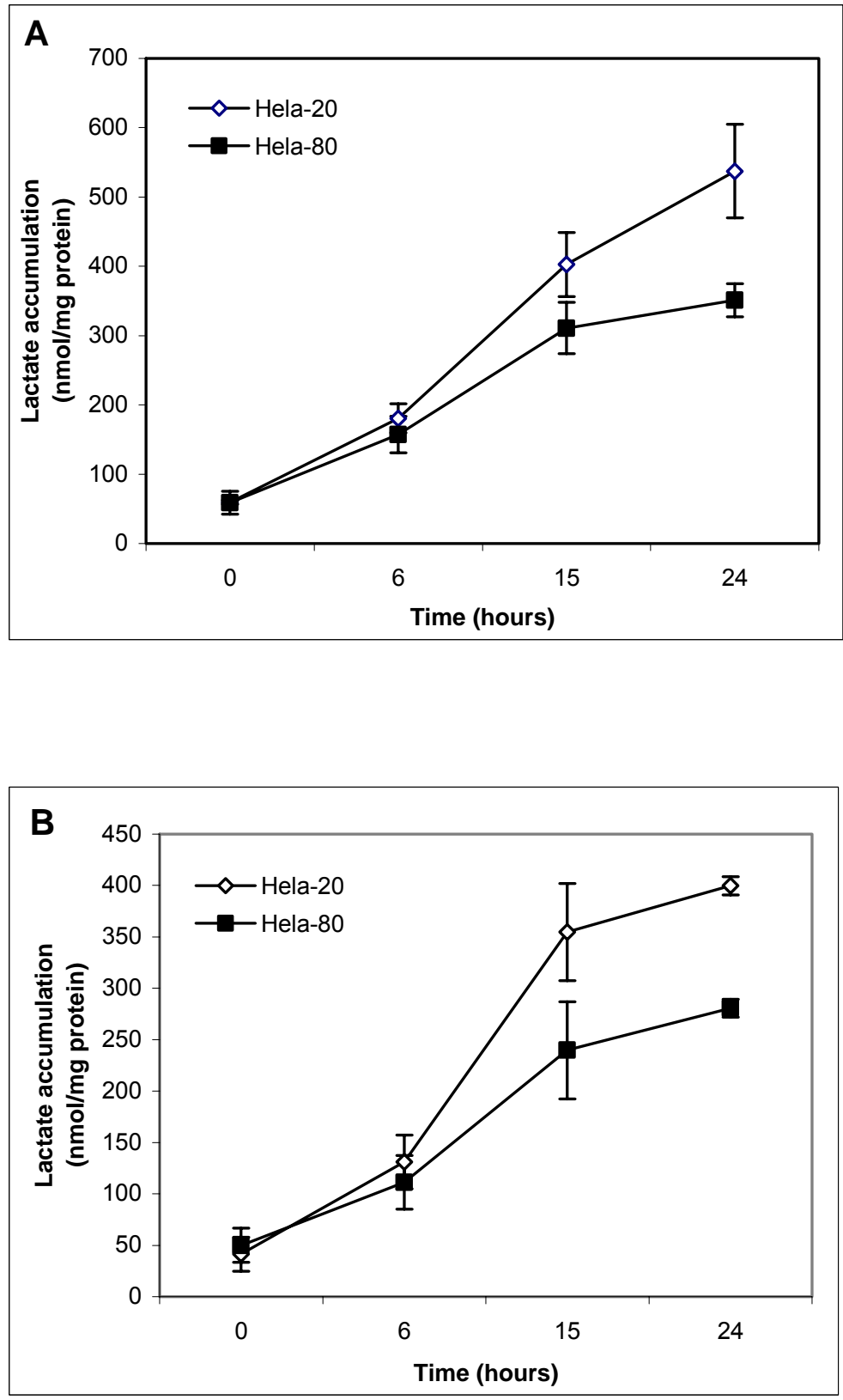

Figure 26. Lactate production by HeLa cells were measured over a 24-hr period under both normoxic $\left(20 \% \mathrm{O}_{2}\right)(\mathrm{A})$ and hyperoxic $\left(80 \% \mathrm{O}_{2}\right)(\mathrm{B})$. Lactate production was decreased in oxygen-tolerant HeLa-80 cells under both conditions at 15 and $24 \mathrm{hr}$ time points $(\mathrm{p}<0.05, \mathrm{n}=3)$. 
Measurements of glucose consumption required that we not use the usual glucosesupplemented media but rather physiologic glucose $(5 \mathrm{mM})$. Therefore, it is possible that this low glucose may have unanticipated effects on the normal rate of glucose metabolism. We should also note that this is by no means a complete metabolic survey; although in HeLa cells exogenous glucose is the main carbon source for glycolysis, glutamine and glutamate are important carbon fuels for oxidative metabolism (Donnelly and Scheffler, 1976). With regard to the basic energy supply in these cells we have conducted preliminary analyses of adenine nucleotide related intermediates (hypoxanthine, xanthine, inosine, inosine monophosphate, AMP, ADP and ATP) and find no substantial differences between HeLa-20 and HeLa-80 (although $\rho^{\circ} \mathrm{HeLa}-20$ cells do have a $\sim 50 \%$ reduction in ATP as might be expected) (Table 4). 
Table 4. Adenine nucleotide related intermediates in HeLa cells.

\begin{tabular}{|c|c|c|c|c|c|c|c|c|c|c|c|}
\hline \multirow[b]{2}{*}{$\begin{array}{l}\text { Cell } \\
\text { line }\end{array}$} & \multirow[b]{2}{*}{$\begin{array}{l}\text { Culture } \\
\text { condition } \\
(2 \text { days })\end{array}$} & \multicolumn{8}{|c|}{ Metabolites (nmol/1×10 $0^{6}$ cells) } & \multicolumn{2}{|c|}{ ratio } \\
\hline & & Hypoxanthine & Xanthine & Inosine & $\begin{array}{l}\text { Inosine } \\
\text { monophosphate } \\
\text { (IMP) }\end{array}$ & Adenosine & AMP & ADP & ATP & IMP/ATP & $\begin{array}{l}\mathrm{ADP} / \mathrm{A} \\
\mathrm{TP}\end{array}$ \\
\hline \multirow{2}{*}{$\begin{array}{l}\text { HeLa- } \\
20\end{array}$} & $20 \% \mathrm{O}_{2}$ & 0.51 & $\mathrm{~N} / \mathrm{A}$ & $\mathrm{N} / \mathrm{A}$ & 1.24 & 0.22 & 0.16 & 1.59 & 4.70 & 0.26 & 0.34 \\
\hline & $80 \% \mathrm{O}_{2}$ & 0.50 & 0.05 & $\mathrm{~N} / \mathrm{A}$ & 0.86 & 0.17 & 0.24 & 1.79 & 4.33 & 0.21 & 0.41 \\
\hline \multirow{2}{*}{$\begin{array}{l}\text { HeLa- } \\
80\end{array}$} & $20 \% \mathrm{O}_{2}$ & 0.48 & 0.33 & $\mathrm{~N} / \mathrm{A}$ & 1.81 & 0.18 & 0.15 & 1.45 & 5.12 & 0.35 & 0.28 \\
\hline & $80 \% \mathrm{O}_{2}$ & 0.55 & 0.09 & 0.24 & 2.24 & 0.23 & 0.19 & 1.68 & 6.41 & 0.34 & 0.26 \\
\hline \multirow{2}{*}{$\begin{array}{l}\rho^{\circ} \\
\text { HeLa- } \\
20\end{array}$} & $20 \% \mathrm{O}_{2}$ & 0.23 & 0.28 & 0.31 & 1.20 & $\mathrm{~N} / \mathrm{A}$ & 0.35 & 1.14 & 2.45 & 0.49 & 0.47 \\
\hline & $80 \% \mathrm{O}_{2}$ & 0.31 & 0.30 & 0.26 & 1.21 & $\mathrm{~N} / \mathrm{A}$ & 0.38 & 1.16 & 2.17 & 0.55 & 0.53 \\
\hline
\end{tabular}

HeLa cells were cultured under $20 \%$ oxygen or $80 \%$ oxygen for 2 days. The metabolites were expressed as nmol per million cells and were calculated against standards. Absent (N/A) data mean the amount was too small to be calculated. There are no significant differences between HeLa-20 and HeLa-80 cells, although $\rho^{\circ} \mathrm{HeLa}-20$ cells have a $\sim 50 \%$ reduction in ATP. 
B. Cytochrome c oxidase (COX) activity is elevated in HeLa-80 cells

In aggregate, the above results suggested an enhanced efficiency of electron transport in HeLa- 80 cells. In view of the great reduction in ROS production caused by CCCP (Figure 19), we hypothesized that anything which would accelerate the movement of electrons down the electron transport chain would, by depleting the electron rich intermediates such as ubisemiquinone, decrease incidental one electron reduction of $\mathrm{O}_{2}$. Indeed, as shown in Figure 27, it appears that the activity of the terminal complex, COX, is substantially higher in HeLa- 80 vs. HeLa-20 cells. Enhanced activity of this complex might well cause the aforementioned depletion of electron-rich intermediates.

We might note that in the performance of these assays, there were several technical problems. First, preparation of cell lysates was not easy to control well and the enzyme activities can be affected by the cell preparation steps. There are several methods to release mitochondria from cells, such as homogenization, sonication and nitrogen cavitation. We have elected to use carefully timed sonication at a set energy for cell lysate preparation because it appeared the process was more reproduceable. Because variations in preparation of cell lysates or sonicates is a crucial variable, we used three different ways of expressing complex activities: cell protein concentrations, citrate synthase activities and cell numbers (Figure 27A, B \& C). 

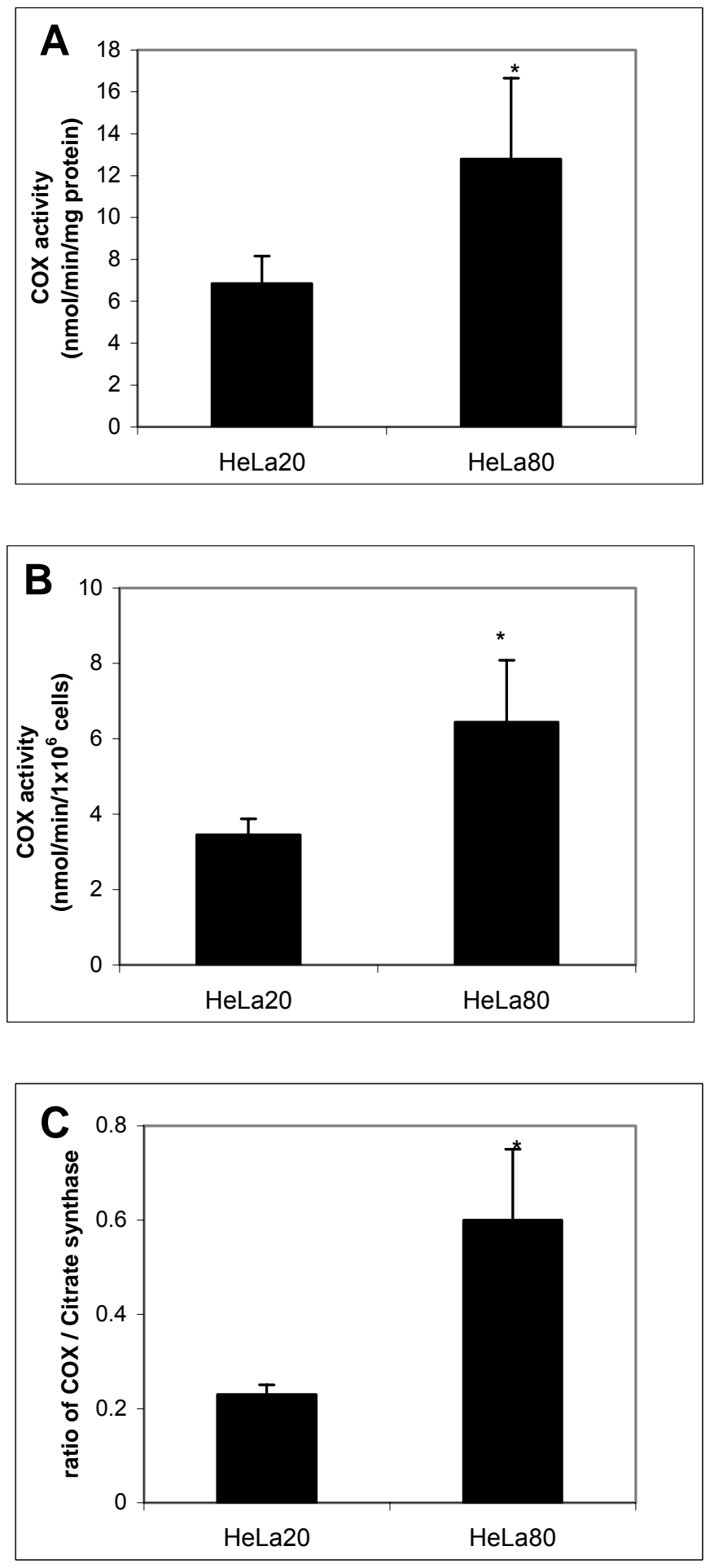
Figure 27. Cytochrome c oxidase activity in HeLa-20 and HeLa-80 cells expressed as activity per mg cell protein (A); COX activity per million cells (B); and as a ratio of COX activity vs. mitohondrial matrix enzyme, citrate synthase activity (C). Regardless of the way in which COX activity is calculated, it appears that HeLa-80 cells have $\sim 2$-fold higher activity than HeLa-20 cells $(\mathrm{p}<0.01, \mathrm{n}=6)$. 
C. There are no corresponding differences in the activities of complexes I-III in HeLa-20

vs. HeLa-80 cells

Measurements of the specific activities of the other complexes of the respiratory

chain revealed, as shown in Figure 28, no differences in complex I (NADH reductase), complex II (succinate reductase) (Figure 29) or complex III (cytochrome $c$ reductase) activities between the two cell lines (Figure 30). The above results which suggest that only COX activity is substantially increased in HeLa- 80 cells whereas the activities of other components of the electron transport chain appear unaffected. This focussed our further attention on COX. 


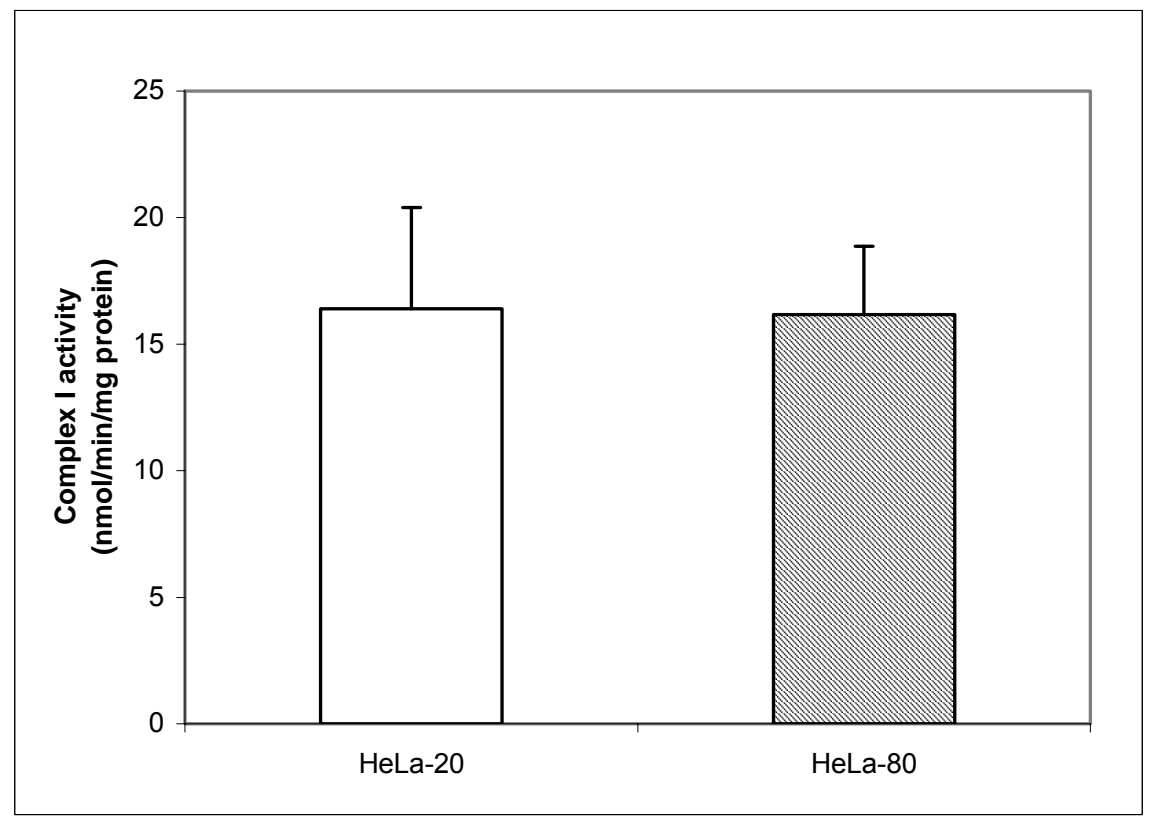

Figure 28. Complex I (NADH reductase) activity in HeLa-20 and HeLa-80 cells expressed as activity per mg cell protein. Similar complex I activities were found in these two cell lines. 


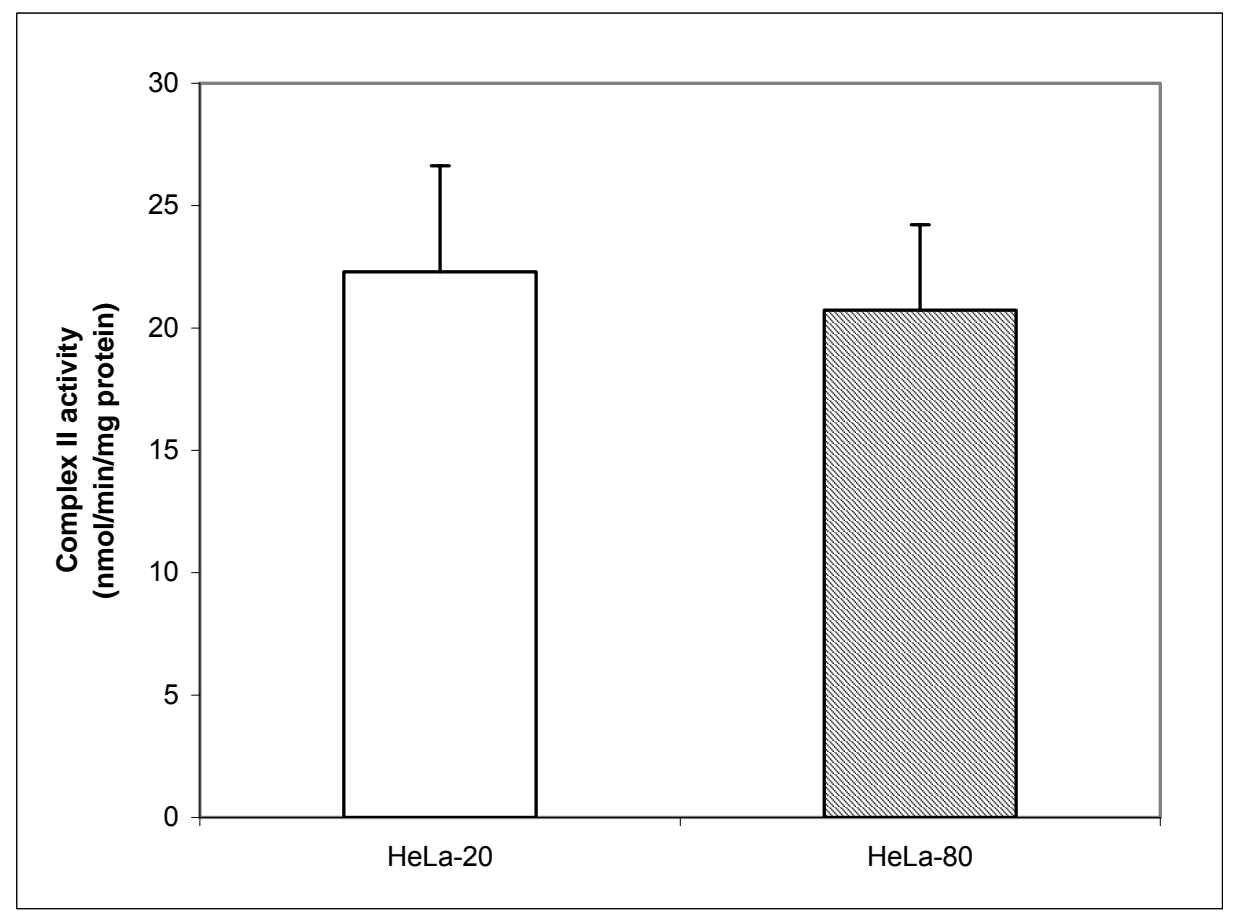

Figure 29. Complex II (succinate reductase) activity in HeLa-20 and HeLa-80 cells expressed as activity per mg cell protein. Equivalent complex II activities were found in these two cell lines. 


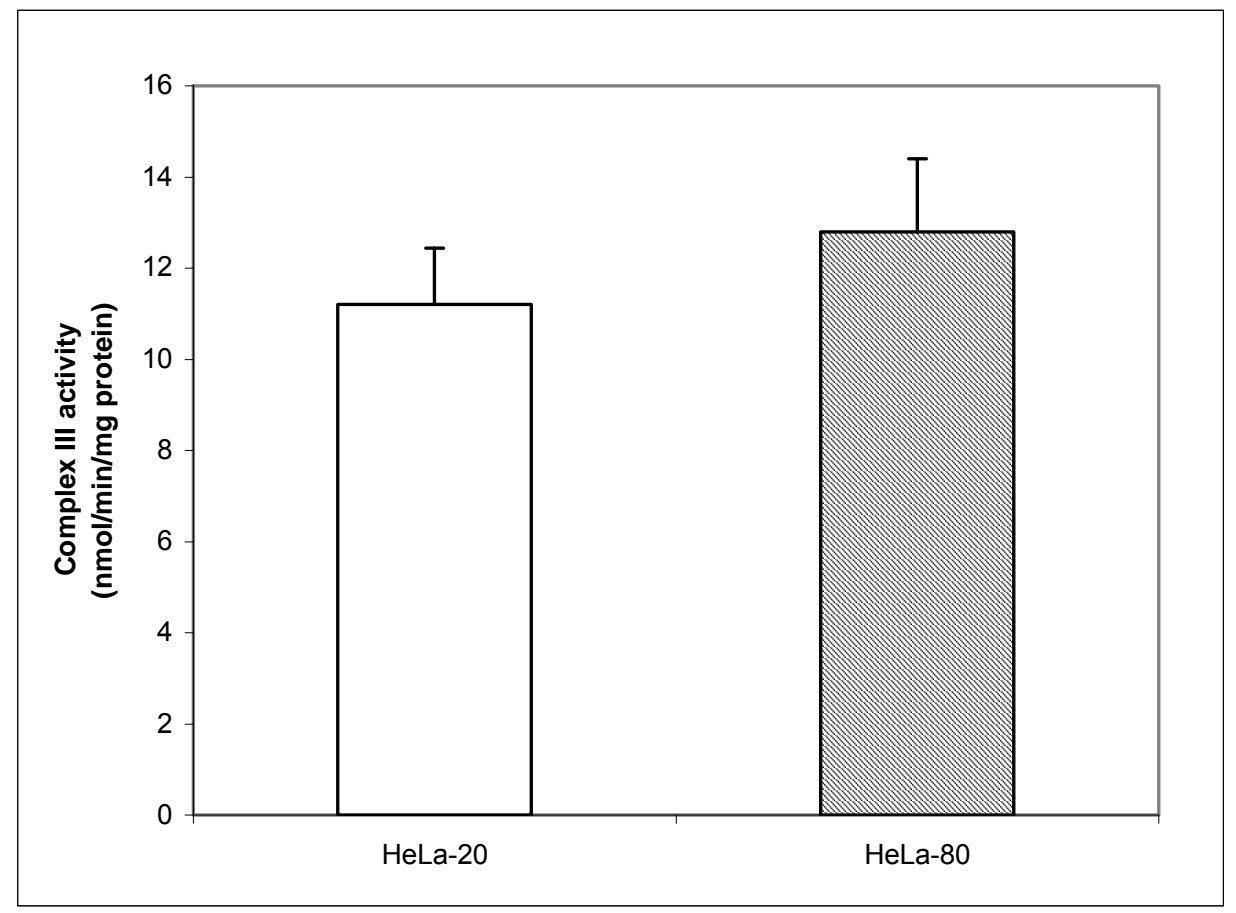

Figure 30. Complex III (cytochrome $c$ reductase) activity in HeLa-20 and HeLa-80 cells expressed as activity per mg cell protein. Equivalent complex III activities were found in these two cell lines. 
D. Preferential inhibition of cytochrome c oxidase activity in HeLa-80 cells abrogates their oxygen tolerance

If HeLa- 80 cells are protected against the cytostatic and cytotoxic effects of hyperoxia by increased COX activity and diminished ROS production, then blocking COX should restore susceptibility to hyperoxia. Because COX contains a unique type of heme (heme $a$ ), we investigated the effect of selective heme $a$ deficiency on the tolerance of HeLa- 80 cells to hyperoxia. We selectively reduced the synthesis of heme $a$ using the ferrochelatase inhibitor, n-methyl protoporphyrin (NMP) (Atamna et al., 2001; Gamble et al., 2000).

Cells were treated with $5 \mu \mathrm{M}$ NMP for one week at which point COX activity was measured. As shown in Figure 31, significantly decreased COX activity was found. Importantly, we observed only slight decreases in catalase (heme $b$ ) and cytochrome $c$ reductase (heme $c$ ) activities ( $\sim 15 \%$ and $\sim 10 \%$ reduction, respectively, in both cell lines). Decreased COX subunit II expression was found by western blotting in both HeLa-20 and HeLa-80 cells (Figure 32). This result was not surprising inasmuch as failure to insert heme into the enzyme complex would be expected to lead to instability. It is also possible that deficiency of heme a per se might, by negative feedback, limit the synthesis of COX components. 


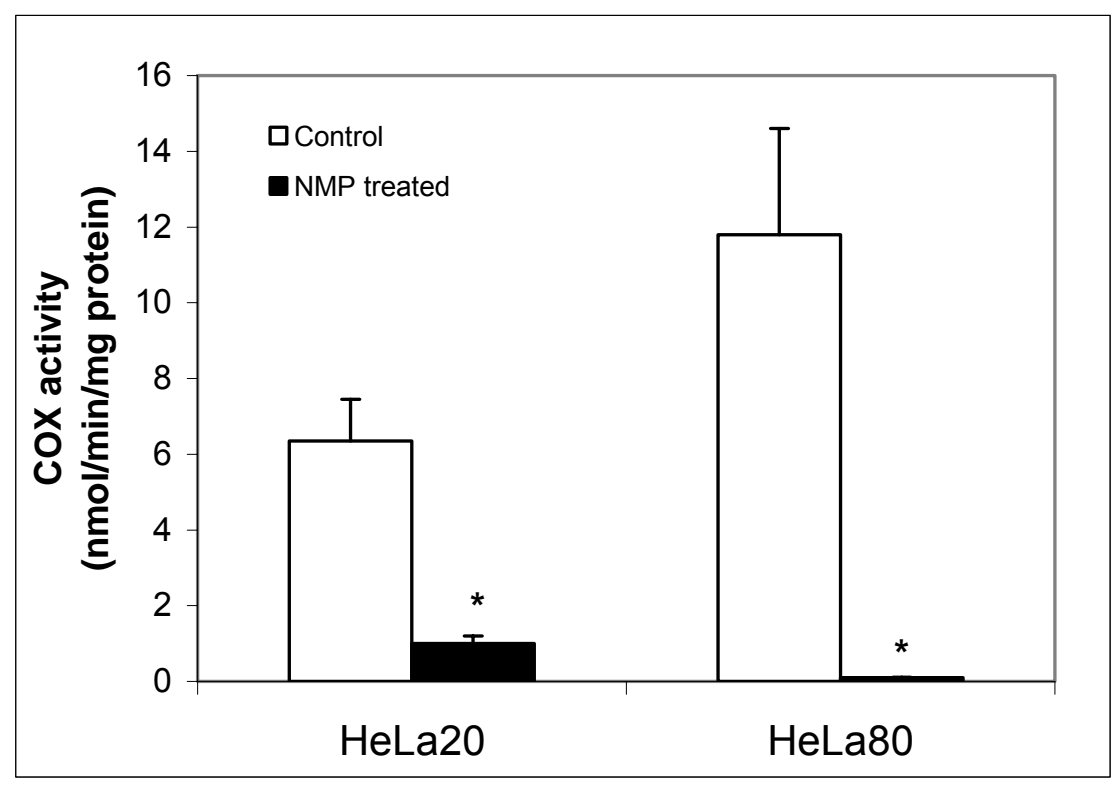

Figure 31. N-methyl protoporphyrin (NMP) preferentially blocks COX activity. Cells were cultured in the presence of $5 \mu \mathrm{M}$ of NMP for 4 days, then COX activities were measured in all these cells. Greatly decreased COX activities, almost to baseline, were found in both HeLa-20 and HeLa-80 cells treated with NMP $(p<0.01, n=4)$. Similar results were obtained when data were normalized by the ratio of COX/Citrate synthase (data not shown). 


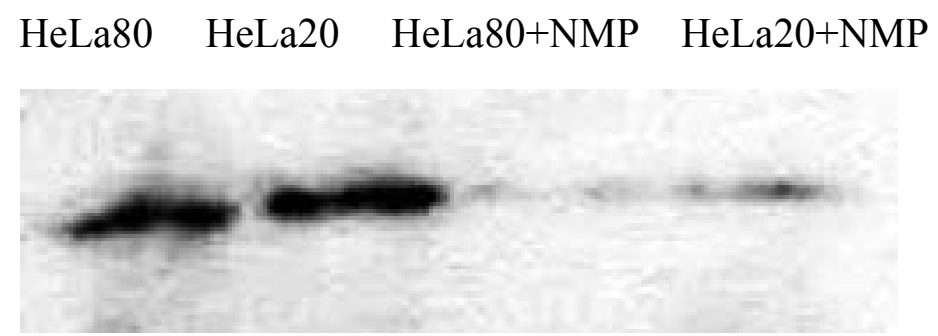

Figure 32. N-methyl protoporphyrin (NMP) preferentially decreases COX subunit II. Cells were cultured in the presence of $5 \mu \mathrm{M}$ of NMP for 4 days, then COX subunit II protein expression was assessed by Western blotting. 
The NMP-induced deficiency in COX activity was, as expected, associated with ROS formation in HeLa-80 cells cultured in the presence of NMP in hyperoxia (Figure 33). Most importantly, HeLa-80 cells cultured continually with $5 \mu \mathrm{M}$ NMP lost resistance to hyperoxia, stopped growing and progressively died after 6 days exposure to $80 \% \mathrm{O}_{2}$ (Figure 34), resembling in this respect the behavior of the wild type HeLa-20 cells. These results further support the general concept that the oxygen tolerance of HeLa-80 cells derives from tighter coupling of the electron transport chain due to higher COX activity, which depletes electron-rich intermediates within the electron transport chain, thereby diminishing the leak of ROS. 


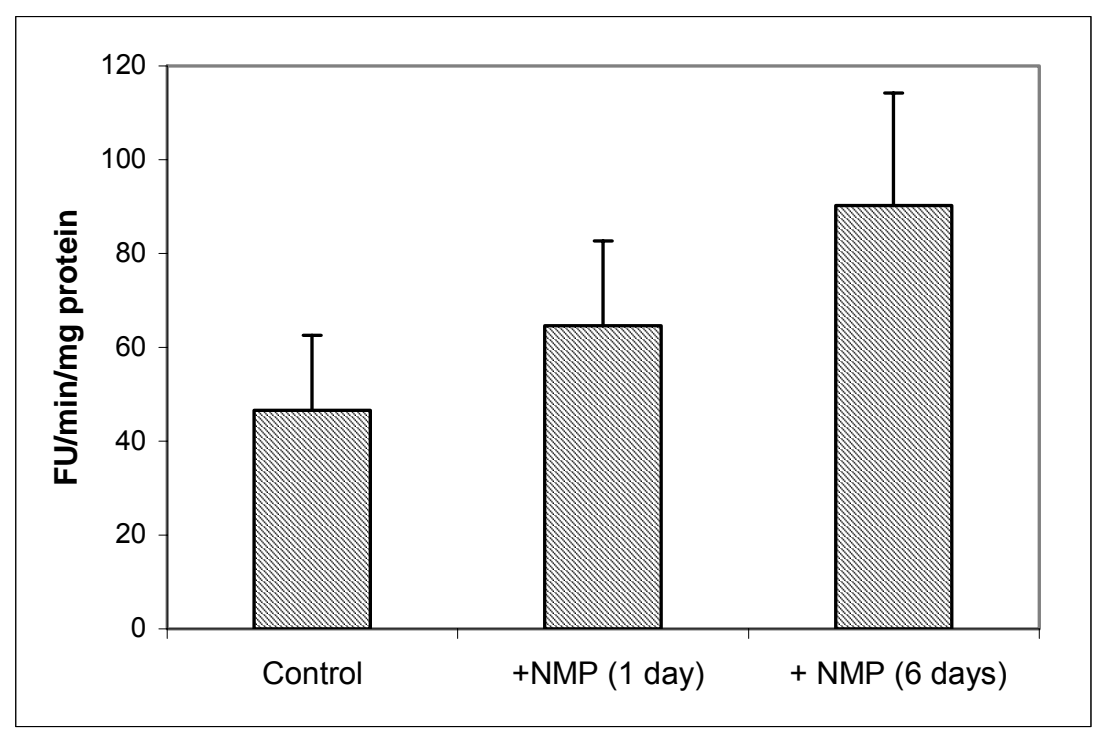

Figure 33. ROS production by HeLa- 80 cells grown in the continuous presence of $5 \mu \mathrm{M}$ N-methyl protoporphyrin (NMP) for different periods. Increased ROS formation was found in HeLa-80 cells cultured in the presence of NMP at both 1 day and 6 days. $(\mathrm{p}<0.05, \mathrm{n}=4)$ 


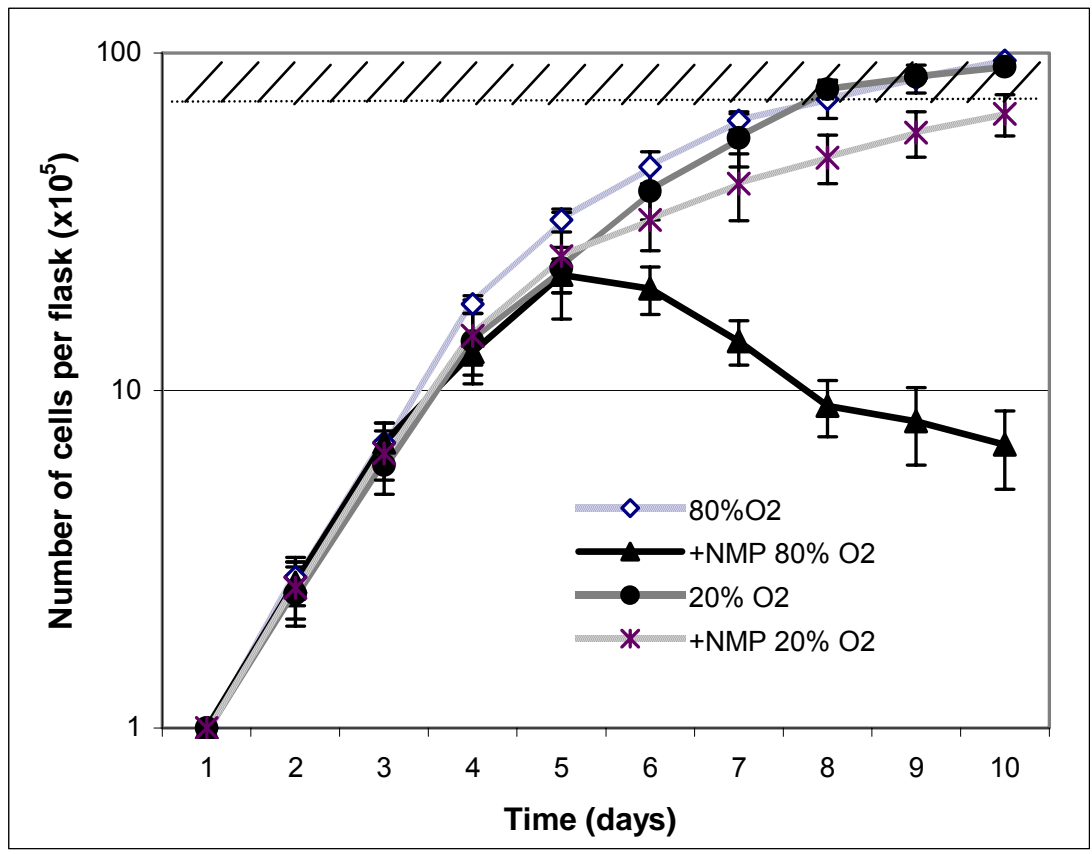

Figure 34. COX suppression abrogates the oxygen tolerance of HeLa-80 cells. HeLa-80 cells were grown in the continuous presence of $5 \mu \mathrm{M}$ N-methyl protoporphyrin (NMP) for 10 days. Results represent means $\pm 1 \mathrm{SD}$ of three independent cultures. 
E. HeLa-80 cells show a highly significant increase in 'respiratory potential'

If the increased COX activity in HeLa-80 cells has any physiologic significance, one might expect that this 'reserve' of COX activity might be apparent in the maximal $\mathrm{O}_{2}$ consumption by these cells. As shown in Figure 35, steady-state $\mathrm{O}_{2}$ consumption was similar between these two cell lines. However, the rate was disproportionately increased in HeLa-80 cells exposed to CCCP compared to the increase observed in HeLa-20 cells (Figure 35). This result is in agreement with the recent suggestions (Villani et al., 1998; Villani and Attardi, 2000) that COX may actually be the rate limiting step in overall electron transport. To our knowledge, this is the first direct demonstration of this phenomenon. Our results also call into serious question earlier arguments that COX activity is present in vast excess and, therefore, not limiting of respiration (Letellier et al., 1993). These earlier investigations involved the use of isolated mitochondria the respiratory activities of which which may not be representative of the intracellular situation (Kadenbach and Arnold, 1999). 


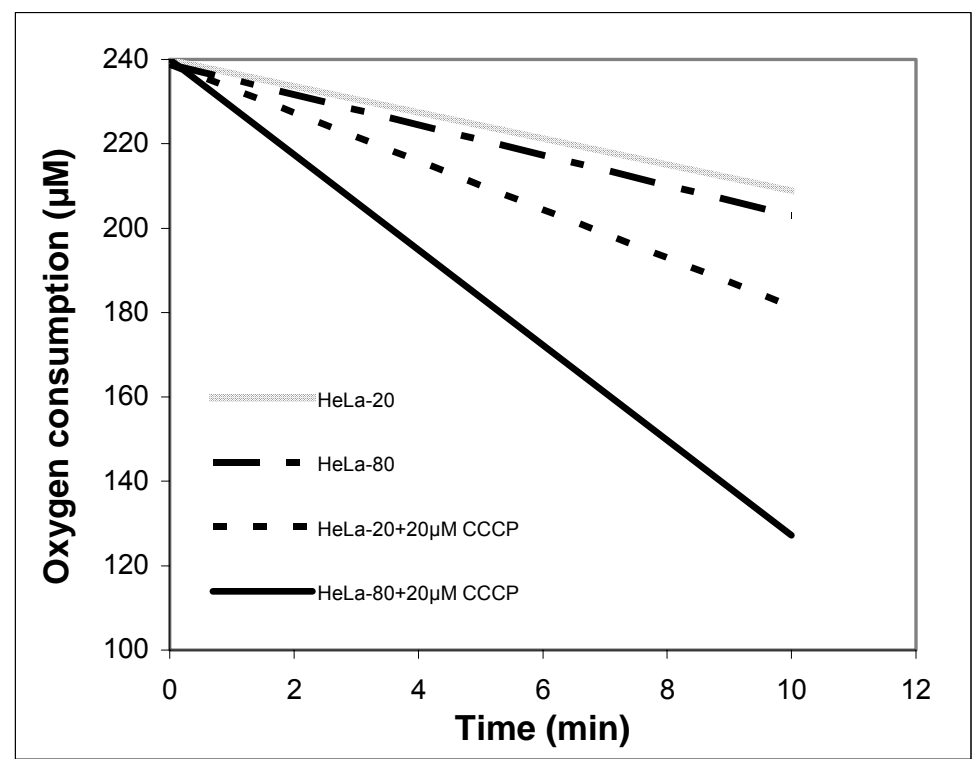

Figure 35. Oxygen consumption by HeLa-20 and HeLa- 80 cells in the absence and presence of $20 \mu \mathrm{M} \mathrm{CCCP}$. Note that addition of the uncoupler increases oxygen consumption in both lines but that the increase in very much greater in the HeLa-80 cells suggesting that these cells have enhanced 'respiratory potential'. Measurements were made on cell suspensions ( $3-5 \times 10^{6}$ cells in $3 \mathrm{ml}$ of complete culture medium) using a Yellow Springs Gilson Oxygraph. $\mathrm{n}=4$ in all cases. 


\section{F. Summary of part III}

In an effort to explain the unusal oxygen tolerance and decreased ROS production of HeLa-80 cells, we hypothesized that an increase of COX activity might, like CCCP exposure, improve electron shuttling and accelerate proton pumping. Therefore, we measured COX activity in HeLa-20 and HeLa-80 cells. We found that COX activity was $\sim 2$-fold higher in the oxygen-tolerant HeLa-80 cells. Other aspects of mitochondrial and general cell metabolism, including $\mathrm{O}_{2}$ consumption, appeared similar (although HeLa-80 cells showed somewhat less glucose consumption and lactate production). Preferential blockade of COX activity by the ferrochelatase inhibitor, NMP, selectively diminished synthesis of heme $a$, decreased COX activity, increased ROS production and restored wild type oxygen sensitivity of HeLa-80 cells. In aggregate, this is strong evidence in favor of a critical role of hypertrophied COX activity in the unique ability of HeLa- 80 cells to survive in a hyperoxic environment.

These findings, all favoring a central role for COX activity in tolerance to hyperoxia, prompted further investigations of the molecular basis of this increased activity as reported below in Part IV. 


\section{$\underline{\text { Part IV. Molecular Basis for the Increased COX Activity in HeLa-80 Cells }}$}

Given the large number of subunits in complex IV (13; 3 encoded by the mitochondrial genome and 10 by the nuclear genome), the observed $\sim 2$-fold increase in COX activity was somewhat puzzling. That is, given that all these subunits must be independently synthesized, it was something of a mystery that all might be elevated simultaneously in HeLa-80 cells. Therefore, in an attempt to decipher the reasons for this, we measured the expression of protein and mRNA for selected components of COX.

A. Subunit $\mathrm{Vb}$ of COX is over-expressed in HeLa-80 cells

COX consists of 13 subunits variously encoded by mitochondrial and nuclear DNA as described above. The three larger subunits (I-III) are involved in the catalytic activity of COX and the smaller subunits are important in its regulation (Capaldi, 1990). For example, $\mathrm{COX} \mathrm{Vb}$, one of the smaller subunits of the cytochrome $c$ oxidase complex, has been reported to be important in the regulation of overall COX activity (Sandona et al., 1995; Allen et al., 1995; Waterland et al., 1991). COX Va and Vb are differentially regulated by oxygen and heme (Allen et al., 1995). There are significant species and tissue differences in the relative expression of the nuclear-encoded subunits and these are also differentially regulated by environmental and developmental signals, which allows for metabolic adjustments to different energy demands (Capaldi, 1990; Vijayasarathy et al., 1998). In the following experiments, we examined four components of COX, two encoded by the mitochondrial genome (COX subunits I and II) and two encoded by the nuclear genome (COX subunits IV and $\mathrm{Vb}$ ). We were careful to include $\mathrm{Vb}$ in these 
analyses because, as discussed above, this has been invoked as an important regulator of overall COX activity.

The most important result of these experiments is shown in Figure 36. $\mathrm{COX} \mathrm{Vb}$ expression is increased $>2$-fold in HeLa- 80 cells whereas we found no significant differences between the two cell lines in the levels of expression of other COX subunits (I, II, IV). In Western blot analyses, the amounts of protein in each sample must be identical; otherwise it is impossible to distinguish significant differences in the intensity of various immunoreactive bands. Therefore, we controlled for this in three separate ways: protein quantification, Ponceau S staining and $\beta$-actin control. In the final analyses, we choose to express COX levels as a ratio between $\mathrm{COX}$ and $\beta$-actin. 

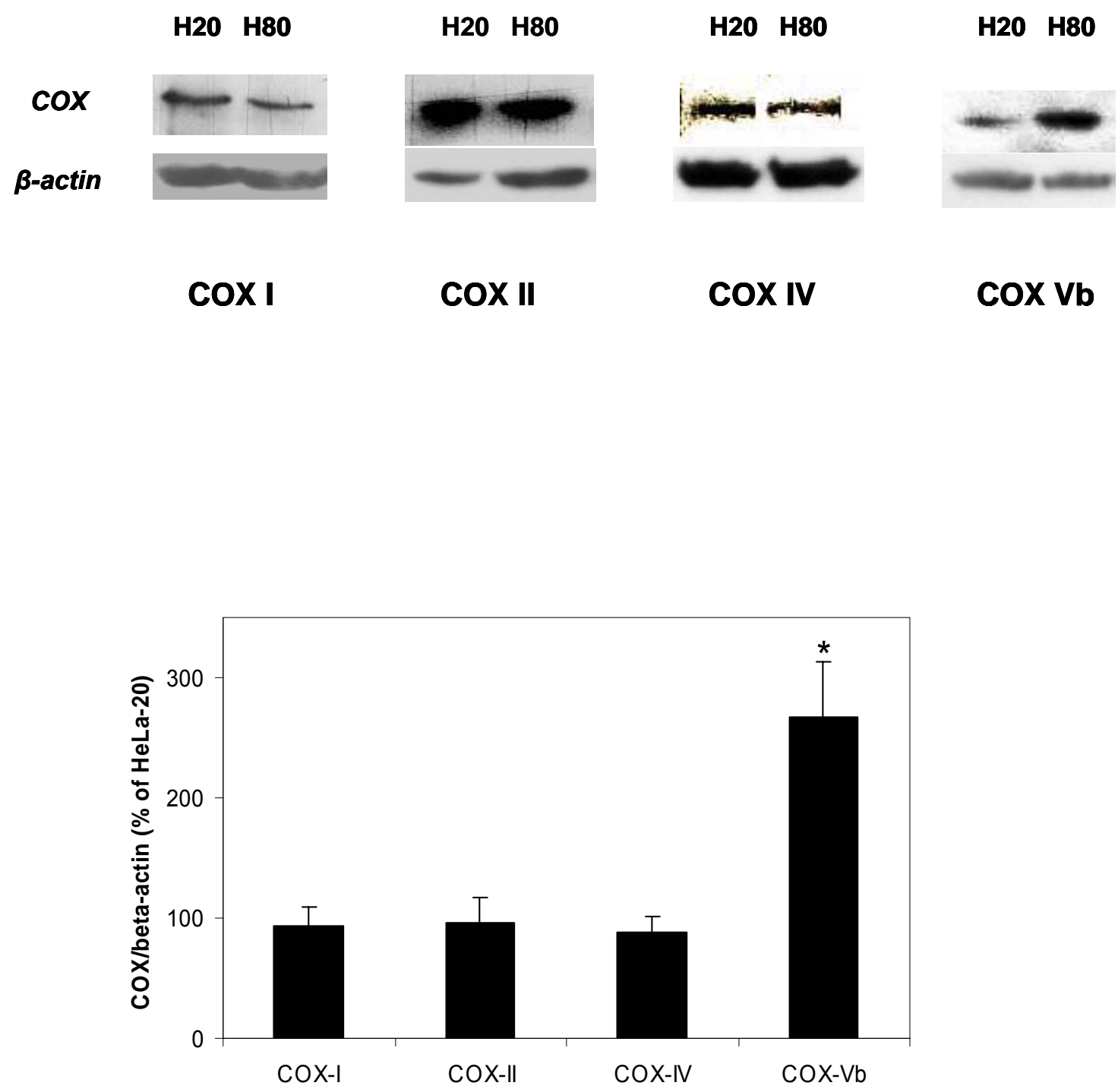

Figure 36. Western blot analysis of COX subunit expression in HeLa-20 and HeLa-80 cells. Protein samples were separated by SDS-PAGE, transferred to PVDF membranes and immunoblotted with goat anti-mouse IgG antibody. The blot was probed with $\beta$-actin as a loading control. $\mathrm{COX} \mathrm{Vb}$ expression was increased $>2$-fold in HeLa- 80 cells though other COX subunits (I, II \& IV) were close to HeLa-20 cells. 
Despite these results, we should mention that alternative mechanisms of control of COX activity exist which might not involve quantitative changes in $\mathrm{COX}$ subunit expression. These include phosphorylation/dephosphorylation (probably of subunit IV) (Steenaart and Shore, 1997) and allosteric inhibition by ATP (Kadenbach and Arnold, 1999). Modifications which affect the former would certainly be missed by this analysis. The latter possibility is made unlikely (but not ruled out) by our observations that adenine nucleotide status in these two strains of cells is very similar.

B. COX Vb mRNA levels are similar in HeLa-20 and HeLa-80 cells

To further investigate the reasons for the distinct up-regulation of subunit $\mathrm{Vb}$, we carried out real time RT-PCR to estimate the amounts of mRNA for this subunit. In extracts from both HeLa-20 and HeLa-80 cells, the $C_{\mathrm{T}}$ values, which represent the threshold cycle, were nearly identical when referred to the total quantity of input mRNA. There was also no significant difference in $\mathrm{COX} \mathrm{Vb}$ mRNA when expressed as a ratio to $\beta$-actin mRNA (Figure 37). 

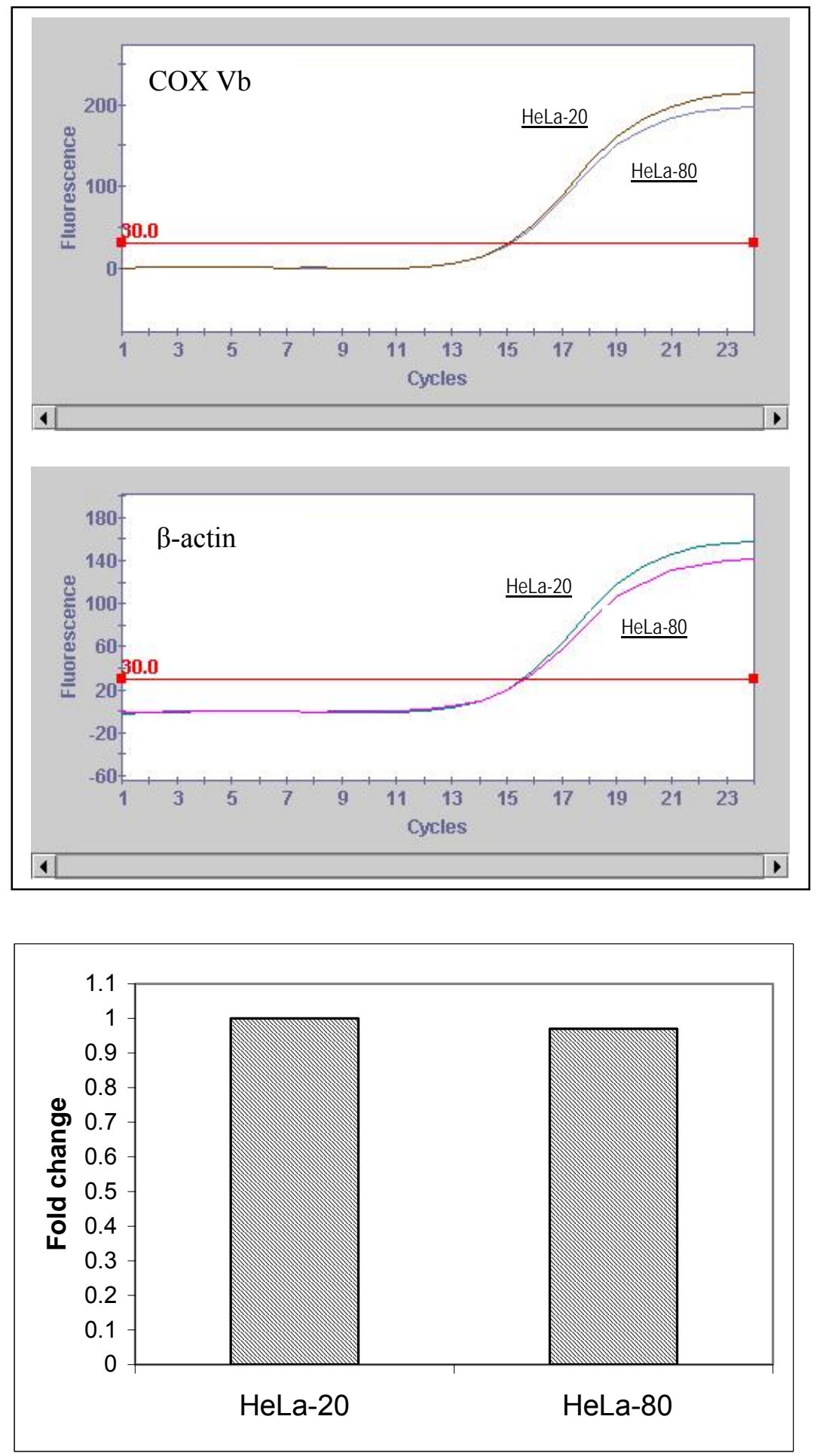

Figure 37. Similar mRNA levels of COX Vb in HeLa-20 and HeLa-80 cells detected by real time RT-PCR. 
C. Suppression of COX Vb expression via Small - interference RNA (SiRNA) in HeLa80 cells

The above results lead to the tentative conclusion that the exaggerated COX activity of $\mathrm{HeLa}-80$ cells derives from increased expression of $\mathrm{COX} \mathrm{Vb}$, probably through a post-transcriptional mechanism. To more directly test whether $\mathrm{Vb}$ expression levels critically affect overall COX activity, we employed siRNA transfection (an antisense strategy) to selectively decrease the expression of $\mathrm{COX} \mathrm{Vb}$ in HeLa-80 cells.

We designed and tested two different pairs of siRNA primers because some siRNAs may have multiple effects, may not work against the intended mRNA or may exhibit nonspecific primer annealing. After $48 \mathrm{hr}$ incubation at $37^{\circ} \mathrm{C}$, cells were processed for the evaluation of $\mathrm{COX} \mathrm{Vb}$ protein production by Western blotting analysis and real-time RT-PCR. As shown in Figure 38A, Western blots revealed significantly decreased $\mathrm{COX} \mathrm{Vb}$ in siRNA treated HeLa- 80 cells and the extent of inhibition of expression was dependent on the dose of siRNA added. For these Western blotting analyses, $\beta$-actin was used as control and the results were calculated as the ratio of COX $\mathrm{Vb} / \beta$-actin (Figure 38B). Consistently, mRNA levels of COX $\mathrm{Vb}$ referred to $\beta$-actin were decreased as well, as shown by real time RT-PCR (Figure 39). 

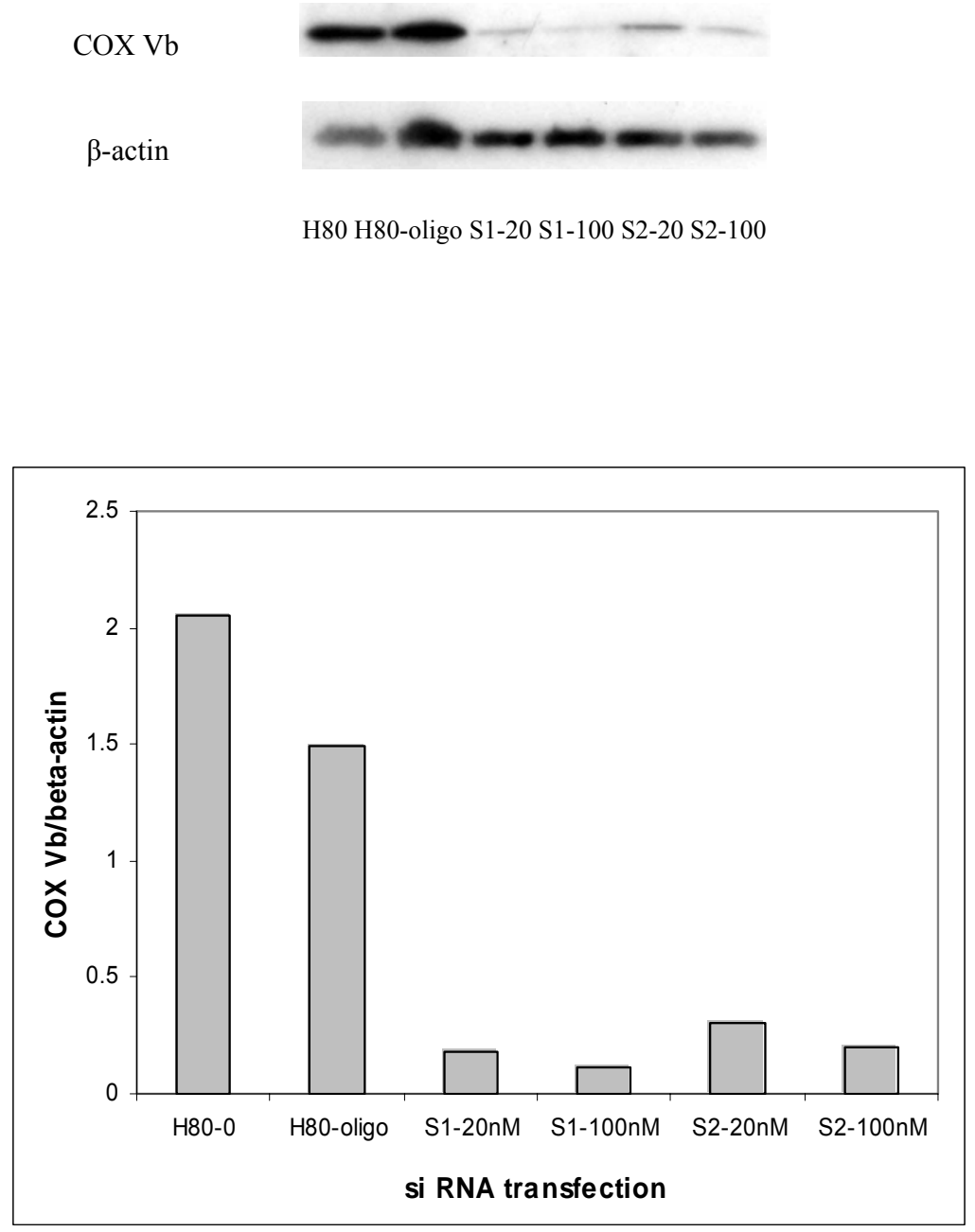

Figure 38. Significantly decreased $\mathrm{COX} \mathrm{Vb}$ proteins were found in siRNA transfected HeLa- 80 cells by Western blot. The results shown were obtained using two separate siRNAs (S1 and S2). Data were normalized for $\beta$-actin (as a control). 

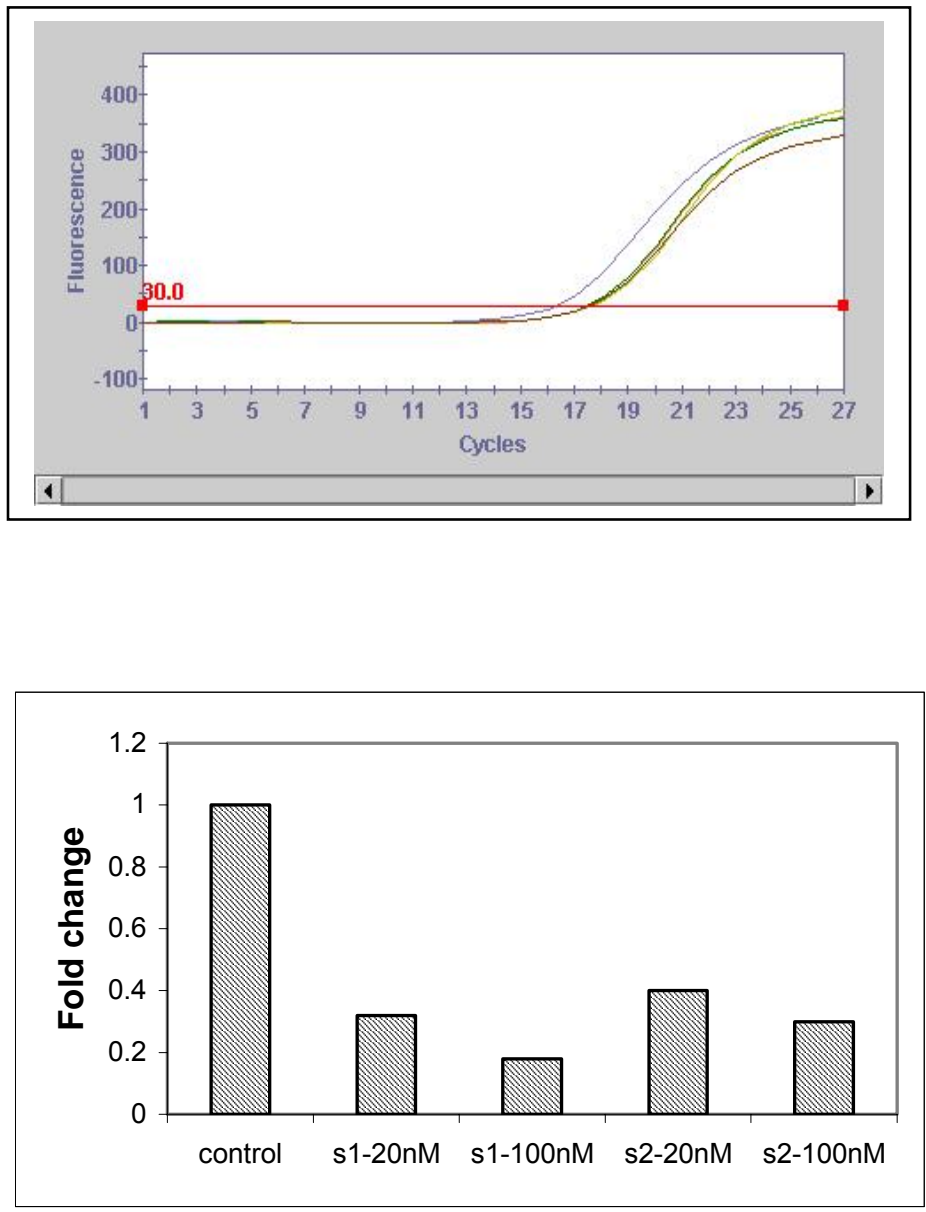

Figure 39. Significantly decreased mRNA level for $\mathrm{COX} \mathrm{Vb}$ was found in siRNA transfected HeLa- 80 cells as detected by real time RT-PCR. Data were normalized for $\beta$ actin (as a control). 
The above investigations employing siRNA are ongoing, with the ultimate goal of directly testing whether overall COX activity and, specifically, COX Vb expression, is critical for the ability of HeLa-80 cells to survive hyperoxic challenge.

\section{Summary of Part IV}

Although we still do not have a certain explanation for the elevated COX activity in HeLa-80 cells, the above results suggest that the over-expression of $\mathrm{COX}$ subunit $\mathrm{Vb}$ might be the cause of increased COX activity and therefore of oxygen tolerance.

However, absolute proof is not yet available. The enhanced synthesis of $\mathrm{Vb}$ appears to arise from a post-transcriptional mechanism inasmuch as no significant differences were found in $\mathrm{Vb}$ mRNA levels using real time RT-PCR. Assuming that increased $\mathrm{COX} \mathrm{Vb}$ synthesis might be critical for the elevated COX activity and oxygen tolerance in HeLa80 cells, we are now engaged in studies using siRNA to selectively down-regulate the expression of this sub-unit. 


\section{$\underline{\text { Part V: Oxygen Tolerant Rats and HeLa-80 Cells: A Common Mechanism? }}$}

\section{A. Background}

A strain of oxygen tolerant rats, which survive indefinitely in $100 \% \mathrm{O}_{2}$, was developed by our collaborator, Dr. John Repine, at the University of Colorado. This strain was derived from a single Sprague Dawley male rat which survived for an amazing $144 \mathrm{hr}$ in $100 \% \mathrm{O}_{2}$ (almost $100 \%$ of wild type Sprague-Dawley rats are dead after $72 \mathrm{hr}$ under these conditions). This unusual rat was bred to normal Sprague Dawley female rats, with the progeny being selected at 2 months of age for ability to survive $100 \% \mathrm{O}_{2}$ for $96 \mathrm{hr}$. Development of this oxygen tolerant strain required 25 generations of breeding. Subsequent tests have revealed that exercise tolerance is $60 \%$ better than that of the wild type rats and the oxygen tolerant rats have increased longevity (with the males living ca. $25 \%$ longer than wild type).

As was the case in the HeLa-80 cells, there were no differences in antioxidants (such as reduced glutathione (GSH) levels and the enzyme activities of manganese and copper/zinc superoxide dismutases, catalase, glucose-6-phosphate dehydrogenase, glutathione reductase and glutathione peroxidase between oxygen tolerant and control rats either under normoxia or following exposure to hyperoxia for $54 \mathrm{hr}$. However, hepatic mitochondria from the oxygen tolerant rats were found to generate significantly less ROS. Overall, these characteristics seemed to resemble those of the oxygen tolerant HeLa cells, prompting us to investigate the oxygen tolerance of fibroblasts derived from these unusual rats as well as their mitochondrial COX activity. 
B. Pulmonary fibroblasts from oxygen tolerant rats are more sensitive to peroxidemediated killing

As we had done with the oxygen tolerant HeLa cells, we tested the sensitivity of lung fibroblasts from the oxygen tolerant rats to killing by $\mathrm{H}_{2} \mathrm{O}_{2}$ and t-butyl hydroperoxide. Whereas the HeLa-20 and HeLa-80 cells exhibited no significant difference in killing by these oxidants, the fibroblasts from the oxygen tolerant rats were significantly more susceptible to such killing (Figure 40). In the course of these experiments, we inadvertently found that the oxygen tolerant rat fibroblasts reduce Alamar Blue at a rate $<2$-fold less than the wild type, suggesting some derangement in cellular redox poise. As of yet, we have no satisfactory explanation for these two characteristics. 

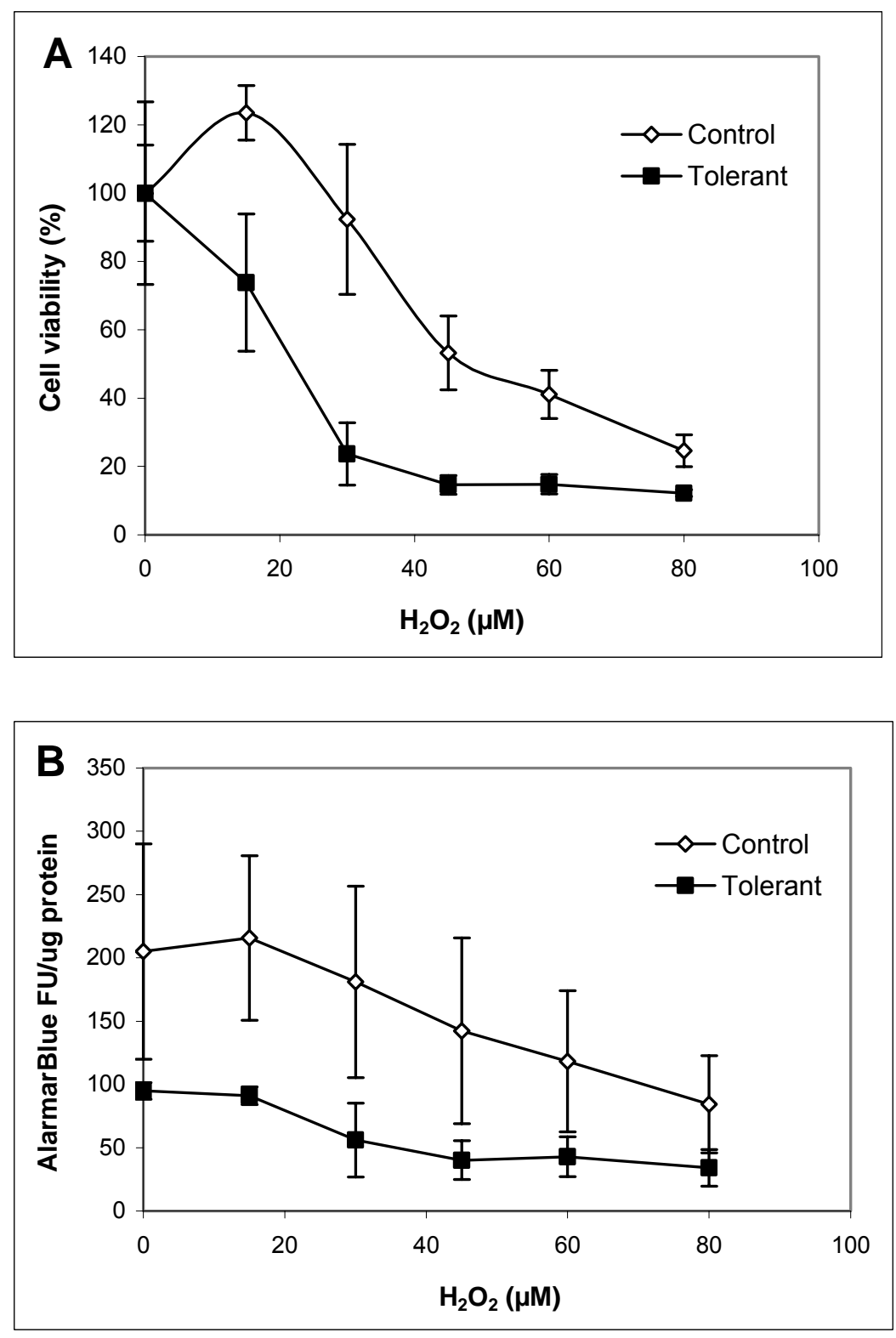

Figure 40. Primary pulmonary fibroblasts cultured from oxygen tolerant rats are more sensitive to peroxide-mediated killing (A). Cell viability was estimated using reduction of Alamar blue. Note that fibroblasts derived from the oxygen tolerant rats have a significantly lower rate of dye reduction per $\mu \mathrm{g}$ protein compared to control cells from control rats $(B)(p<0.05, n=4)$. 
C. In the oxygen tolerant rats, mitochondrial COX activity is amplified

These puzzling results notwithstanding, we proceeded to measure COX activity in the mitochondria of these rats to determine whether there might be differences in activity similar to those observed in the oxygen-tolerant HeLa cells. Very recent results suggest that the oxygen tolerant rats have an increase in COX activity of $>2$-fold, quite similar to the situation in the oxygen tolerant HeLa cells (Figure 41). This very exciting result suggests that there may be few and perhaps only one way to satisfactorily adjust to hyperoxia; i.e., limit the leak of electrons from the electron transport chain to oxygen. Furthermore, there may be only one way of accomplishing the latter - increased COX activity. 


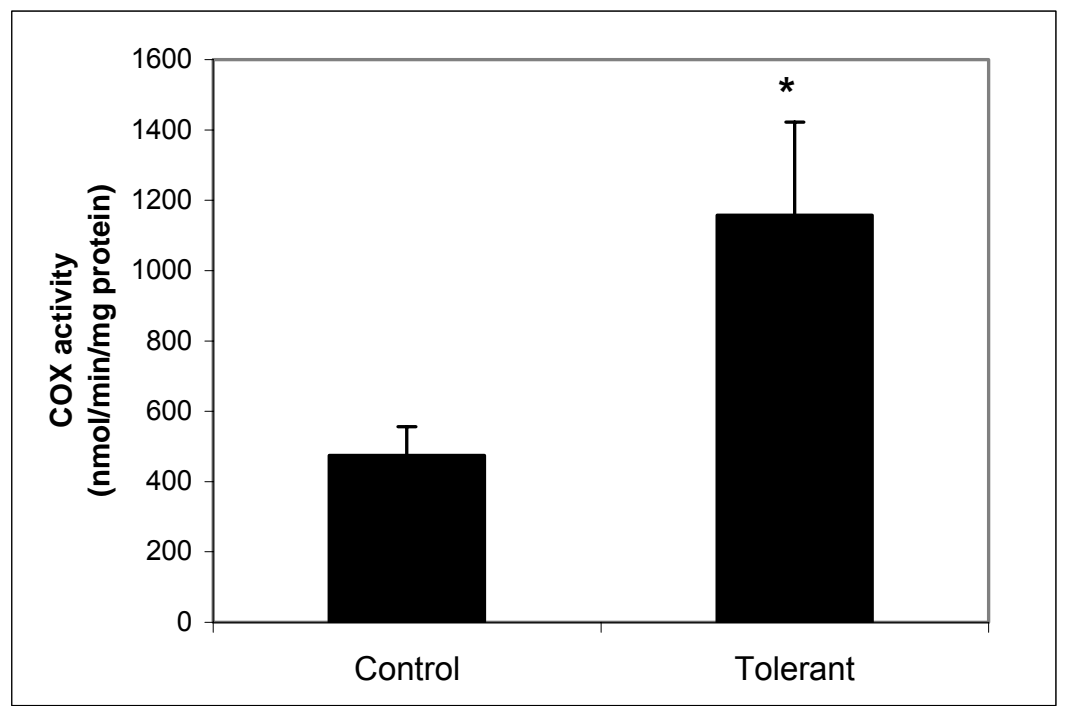

Figure 41. Hepatic mitochondrial COX activity in control and oxygen tolerant rats expressed per mg protein. Oxygen tolerant rats have $\sim 2$-fold higher COX activity than control rats $(\mathrm{p}<0.05, \mathrm{n}=2$ control and 2 tolerant; triplicate assays of each in both cases). 


\section{DISCUSSION}

In the hope of achieving a more fundamental understanding of the nature of oxygen toxicity, we have investigated the characteristics of a unique strain of HeLa cells selected for ability to survive and grow in $80 \%$ oxygen. There are two possible explanations for their oxygen tolerance: enhanced oxidant defenses or decreased ROS generation in a hyperoxic environment.

Surprisingly, these cells do not appear to have increased anti-oxidant defenses (such as superoxide dismutases, catalase, reduced glutathione, glutathione reductase and glutathione peroxidase). Most directly, they are not more resistant to killing by exogenous oxidants such as hydrogen peroxide and t-butyl hydroperoxide.

This directed our attention to possible differences in ROS production and in mitochondrial electron transport. We find a substantial difference in ROS generation under both normoxic and hyperoxic conditions. This appears to be related to a major change in mitochondrial electron transport. Whereas the oxygen tolerant cells have normal activities of complexes I-III, they show a distinct upregulation of the activity of complex IV, COX. 
The consequences of this increased activity of COX include enhanced metabolic efficiency (i.e., somewhat decreased glucose consumption and lactate production) while the rate of oxygen consumption remains at near wild-type levels. However, the most important effect of upregulated COX activity would appear to be depletion of electronrich intermediates with the transport chain by 'mass action'. The resultant decrease in tonic levels of ubisemiquinone (especially at complex III) leads to decreased incidental reduction of oxygen to superoxide, thereby explaining the very significant decrease in ROS production (Figure 42). 

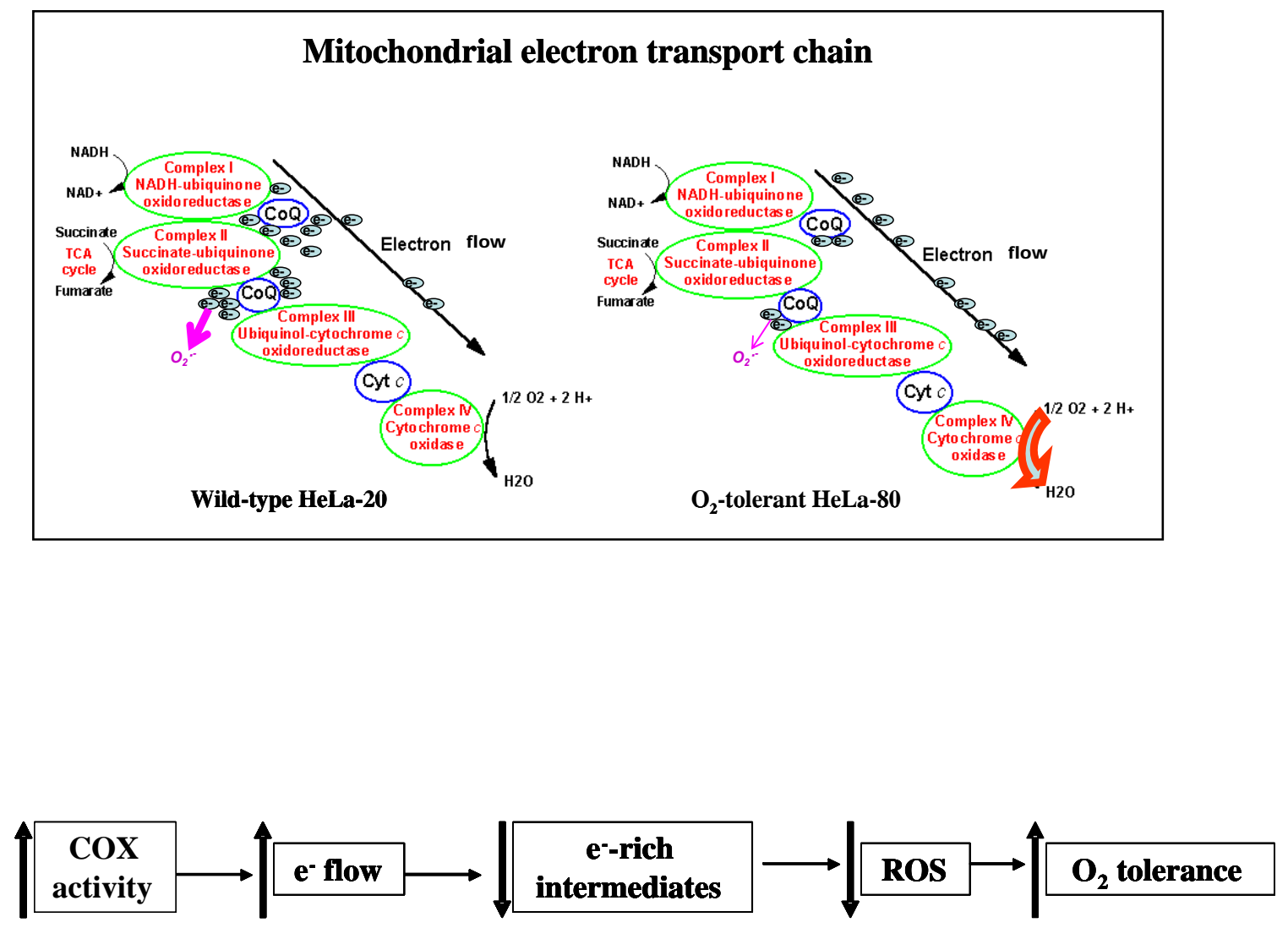

Figure 42. Schematic representation of our tentative conclusions.

Oxygen tolerance derives from tighter coupling of the electron transport chain in HeLa-80 cells due to higher COX activity, which depletes electron-rich intermediates within the chain, thereby diminishing the leak of ROS. 
The implication of the present findings is that perhaps the most effective way of dealing with the challenge of hyperoxia may be to decrease ROS production, rather than enhance anti-oxidant mechanisms. This tentative conclusion is further supported by preliminary observations in HeLa 99 cells (a strain separately selected for resistance to even higher levels of oxygen) and in a remarkable strain of oxygen tolerant SpragueDawley rats derived by our collaborator, Dr. John Repine, in Denver, Colorado. In preliminary experiments, the HeLa 99 cells have similarly magnified activity of COX and, once again, apparently normal anti-oxidant defenses. In the case of the oxygen tolerant rats, early results indicate a similar increase in COX activity whereas, once again, antioxidant defenses appear to be completely normal.

The overall implication of our observations is that effective adaptation of eukaryotes - from yeast to humans - may require upregulation of COX activity. We believe these results supply valuable additional information regarding the toxic effects of hyperoxia. We further believe that this information may be of use in devising strategies to manipulate mitochondrial electron transport and, thereby, limit the toxicity of oxygen.

Below, we have tried to relate our observations to results derived from earlier investigations.

The Cytostatic and Cytocidal Effects of Hyperoxia are Associated with Enhanced Intracellular ROS Production 
As mentioned at the outset, the adverse effects of hyperoxia almost certainly derive from increased formation of ROS (Castro and Freeman, 2001; Chance et al., 1979; Gerschman et al., 1954). Chemically, it is unlikely that increments in the partial pressure of $\mathrm{O}_{2}$ will substantially change the potential for direct, chemical oxidation of biological molecules. Therefore, amplified cellular ROS production under hyperoxia most likely arises from increased reduction of $\mathrm{O}_{2}$ to $\mathrm{O}_{2}^{-}$in metabolically-dependent reactions. However, the precise mechanism(s) involved in this process have not been fully elucidated. It is reasonable to suspect that excessive cellular ROS production at high $\mathrm{O}_{2}$ tensions represents a by-product of mitochondrial electron transport, perhaps generated through the intermediacy of ubisemiquinone (Sanders et al., 1993). These ROS may then interact with transition metals to generate even more damaging species such as hydroxyl and metal-centered radicals. The increased ROS generation during exposure to hyperoxia can potentially overwhelm antioxidant defense mechanisms, even in the presence of exogenously administered antioxidants (Ho et al., 1998). In support of the latter supposition, we have found that the survival of wild-type HeLa-20 cells is improved when the cells are cultured in the presence of added exogenous catalase $(100 \mu \mathrm{g} / \mathrm{ml})$ (results not shown). Assuming that the enzyme is not internalized by fluid phase endocytosis, this implies that a portion of hyperoxia-mediated cell damage may arise through the production of readily diffusable oxidants such as hydrogen peroxide which may reach toxic concentrations.

The Origins of Hyperoxia-Mediated ROS Generation 
A number of earlier investigations have indicted increased mitochondrial ROS production in hyperoxic cell damage. For example, in studies with yeast, it was found that manganese superoxide dismutase (MnSOD, the form of SOD targeted to the mitochondria) deficient organisms were readily killed by $100 \% \mathrm{O}_{2}$ whereas wild type yeast was not affected by hyperoxia. However, if the MnSOD-deficient yeast were also $\rho^{\circ}$, these organisms had a clear survival advantage under hyperoxic conditions (Guidot et al., 1993). These results imply that ROS generated under hyperoxic conditions probably have a mitochondrial origin and, further, that the mitochondria may be a target for this toxicity. In studies with mammals, increased ROS generation was found in sheep pulmonary microvascular endothelial cells exposed to $100 \%$ oxygen (Sanders et al., 1993) and numerous reports show evidence of greatly increased oxidation of pulmonary components (protein carbonyl formation and oxidation of polyunsaturated fatty acids) in animals and humans exposed to hyperoxia (Freeman and Crapo, 1981; Freeman and Tanswell, 1985; Vozzelli et al., 2003).

\section{The Importance of Antioxidant Status in Oxygen Toxicity}

Pertinent to the results obtained with MnSOD-deficient yeast described above, homozygous MnSOD deficient mice have also been reported to be much more sensitive to oxygen toxicity (Asikainen et al., 2002). This and other observations on animals deficient in MnSOD are important inasmuch as they imply that this mitochondrial form of SOD is particularly important in anti-oxidant defense. A further implication is that damage to mitochondria under hyperoxic conditions may be an important factor in the damaging effects of high oxygen pressures. In this regard, it is worth noting that 
endotoxin pre-treatment increases mitochondrial MnSOD activity and, simultaneously, improves the survival of rats exposed to hyperoxia (Guidot, 1996). MnSOD overexpression has also been shown to protect pulmonary epithelial cells from hyperoxic damage while overexpression of catalase was without effect (Ilizarov et al., 2001). This is in apparent conflict with our findings of a significant protection by exogenous catalase when wild-type HeLa-20 cells were grown under $80 \%$ oxygen. However, in our system, the amounts of catalase may have been far greater than those produced by the transgenic rats.

Although not directly pertinent to damage caused by hyperoxia and related ROS production, heme oxygenase-1 (HO-1) overexpression has been reported to provide protection against oxidative stress (Lee et al., 1996). The mechanism(s) through which this might confer resistance to hyperoxia were not clear. In a possibly related observation, Otterbein et al. (1999) (Otterbein et al., 1999a) found that carbon monoxide (CO), a major by-product of heme degradation by HO-1, provided protection against hyperoxic lung damage in rats. These authors proposed that judicious $\mathrm{CO}$ administration might be therapeutically useful for the patients who need high oxygen therapy (Otterbein et al., 1999b). We propose that these two observations might actually have the same root mechanism: both overexpression of HO-1 (through possible depletion of cellular heme and consequent depression of mitochondrial respiration) and $\mathrm{CO}$ exposure (which will also suppress mitochondrial function) might lead to diminished mitochondrial ROS production under hyperoxic conditions. Overexpression of hexokinase II (HK II) was found to protect lung epithelial-like A549 cells against oxygen toxicity (Ahmad et al., 
2002). This overexpression had the net effect of protecting mitochondria from oxidative assault (HKII is targeted for mitochondria) and these findings at least indirectly support our view that mitochondria may be the major target of oxygen toxicity (Ahmad et al., 2002).

Although these observations and a number of others suggest that antioxidants may lessen hyperoxic cell damage, the mechanism(s) involved in such protection are not clear and the extent of protection has typically been suboptimal. Thus, whereas modest protection against hyperoxia was reported to be afforded by MnSOD overexpression in rats by Ho et al. (1998), other investigators found little or no effect of similar overexpression in mice (Jackson et al., 1999).

\section{$\underline{\text { Oxygen Tolerant HeLa Cells Have Normal Antioxidant Defenses }}$}

Surprisingly, antioxidant defenses (superoxide dismutases, catalase, reduced glutathione, glutathione reductase and glutathione peroxidase) do not differ between oxygen-tolerant HeLe- 80 and wild-type HeLa-20 cells. Perhaps most directly, these two strains of HeLa cells are equally susceptible to the lethal effects of hydrogen peroxide and t-butyl hydroperoxide, clearly showing that defenses against such oxidants are not hypertrophied in the oxygen tolerant line. This contrasts with some earlier publications indicating that increased levels of glutathione (GSH), glutathione peroxidase (GPX) and glutathione reductase (GR) would diminish hyperoxic cell damage (Hoffman et al., 1980; Stevens and Autor, 1980; Rister and Baehner, 1976; Bhandari et al., 2000; Mockett et al., 1999). It is possible (but unknown) that in the early stages of the 2-year period during 
which HeLa-80 cells were being selected for oxygen tolerance some differences in antioxidant defenses appeared. However, the net result of this selection appears to have been a change in mitochondrial metabolism which restricts incidental ROS generation, thereby making adjustments in antioxidant defenses of nugatory import.

This view is supported by other reports that elevated GSH did not protect human carcinoma cells (T47D-H3) against hyperoxia and that increased GPX activity afforded only minor protection (Bilodeau et al., 2002). These authors concluded that GPX overexpression was relatively ineffective because the damaging effects of hyperoxia also involved other types of free radicals which could not be controlled by GSH/GPX (Bilodeau et al., 2002).

\section{Mitochondrial Metabolism is the Focal Point of Hyperoxic Cell Injury}

We have explored the hypothesis that a conspiracy between elevated $\mathrm{O}_{2}$ and cellular respiration leads to the cytostatic and cytocidal effects of hyperoxia. More specifically, we have investigated the possibility that the intracellular production of ROS by mitochondria under conditions of elevated $\mathrm{O}_{2}$ pressures is the most important mechanism of damage. As tests of the importance of hyperoxia-mediated ROS production we employed three models: (i) respiration-deficient $\left(\rho^{\circ}\right)$ HeLa cells lacking mtDNA and respiration, (ii) wild-type HeLa cells were cultured with CCCP (which uncouples mitochondrial metabolism and enhances respiration), and (iii) wild-type HeLa cells cultured in the presence of chloramphenicol (which inhibits mitochondrial inner membrane protein synthesis and suppresses respiration). Although these three strategies 
change mitochondrial function in three different ways, they have one thing in common: all three maneuvers decrease mitochondrial ROS generation and increase tolerance to hyperoxia. As a result, we are able to conclude that interactions between respiring mitochondria and $\mathrm{O}_{2}$ are primarily responsible for hyperoxic cell damage.

$\rho^{0}$ cells require enriched DMEM medium supplemented with glucose, pyruvate and uridine. Pyruvate reacts readily with hydrogen peroxide (in an oxidative decarboxylation reaction) and this could conceivably improve cellular survival in hyperoxic conditions. For that reason, we cultured wild-type HeLa-20 cells in the same enriched medium as the $\rho^{\circ}$ cells as well as conducting other experiments with non- $\rho^{\circ}$ cells cultured with normal DMEM and F-10 media under both $20 \%$ and $80 \%$ oxygen. Regardless of the medium employed, after 5 days, wild-type HeLa-20 cells stopped growing and started dying under $80 \%$ oxygen whether in normal or pyruvatesupplemented medium, clearly indicating that the improved survival and growth of $\rho^{\circ}$ cells was a function of the lack of mitochondrial respiration.

\section{Cytochrome $c$ Oxidase (COX) and ROS Production}

It has been shown that COX somehow modulates ROS production. A $20-30 \%$ reduction in cytochrome $\mathrm{c}$ oxidase has been associated with high levels of superoxide production in calcineurin transgenic mice and the excessive production of $\mathrm{O}_{2}{ }^{-}$evidently contributes to the development of cardiac failure induced by calcineurin adenovirus infection(Sayen et al., 2003). Another recent publication showed that COX inhibition was accompanied by increased ROS production in PC12 pheochromocytoma cells (Yuyama 
et al., 2003). Further indication of the importance of differences in mitochondrial metabolism derives from studies of young versus old animals. Younger animals tend to have more active mitochondria but less electron 'leak'. Interestingly, it has also been reported that COX activity may decline in both older people and patients with neurodegenerative diseases (Boffoli et al., 1994; Bowling and Beal, 1995; Mullerhocker, 1989; Paradies et al., 1993; Rooyackers et al., 1996; Tian et al., 1998).

Several recent reports - as well as our own experimental results - support the view that COX is the rate-limiting step of mitochondrial respiration (Villani and Attardi, 1997; Villani et al., 1998; Villani and Attardi, 2000). In fact, it has been suggested that the relative COX capacity of mammalian cells is normally adjusted to a level only slightly higher than that required to support endogenous respiration (Villani and Attardi, 2000). Further to this point, it has been reported that oxygen modulates COX function and hypoxia will (reversibly) decrease the $\mathrm{V}_{\max }$ of the enzyme (Chandel et al., 1996; Chandel et al., 1997; Semenza, 1999). Oxygen can also affect COX activity by changing the expression of specific subunit isoforms thereby modulating the overall catalytic properties of the enzyme (Allen et al., 1995; Burke and Poyton, 1998; Waterland et al., 1991).

The central importance of COX activity in cell function and survival has been further emphasized by studies in which this activity was inhibited. For example, inhibition of COX, with increased ROS, acted as an initiator of caspase-independent cell death (Yuyama et al., 2003). Changes in COX activity have even been invoked in the 
mechanism of TNF- $\alpha$-induced cell death. In this instance, cell death proceeds following suppression of the activity of respiratory enzymes, presumably COX (Jia et al., 1996). These observations raise an interesting parallel between the toxicities of TNF- $\alpha$ and hyperoxia, and suggest that the oxygen tolerant HeLa-80 cells may as well be resistant to the lethal effects of TNF- $\alpha$.

The Possibility that Increased COX Vb Expression Plays A Major Role in Higher COX

\section{Activity of HeLa-80 Cells}

It has been suggested that $\mathrm{COXVb}$ likely plays a critical role in proper $\mathrm{COX}$ assembly and/or regulation, and consequently in the maintenance of mitochondrial integrity and function (Beauchemin et al., 2001). In the present experiments, we have observed that the oxygen tolerant HeLa-80 cells have 2 3-fold higher $\mathrm{COX} \mathrm{Vb}$ protein expression compared to wild-type HeLa-20 cells. $\mathrm{COX} \mathrm{Vb}$ is an important regulatory subunit of this complex (13 subunit) enzyme. Inhibition of $\mathrm{COX} \mathrm{Vb}$ using siRNA causes a loss $\mathrm{COX}$ activity. The $\mathrm{COX} \mathrm{Vb}$ sequence is the most conserved among the nuclearencoded subunits of COX. COX Vb contains three conserved cysteines in its $\mathrm{C}$-terminus which are reported to bind zinc (Rizzuto et al., 1991). Interestingly, unlike other COX subunits, there are no tissue-specific transcripts for human $\mathrm{COX} \mathrm{Vb}$, and it appears that $\mathrm{COX} \mathrm{Vb}$ may be a single and unique polypeptide existing in all tissues (Zeviani et al., 1988). However, COXVb expression levels vary in different tissues. As might be expected, mitochondria from tissues with higher oxygen consumption such as the heart, kidney, and brain contain higher levels of $\mathrm{COX} \mathrm{Vb}$ mRNA and protein than the liver (Vijayasarathy et al., 1998). 
It has been reported that, in yeast, COX IV (the homologue of human COXVb) was essential for proper COX assembly (Dowhan et al., 1985). Recent publications suggested that $\mathrm{COX} \mathrm{Vb}$ may also play a regulatory role in $\mathrm{COX}$ activity. For instance, Kadenbach reported that COX activity was inhibited by ATP at high intra-mitochondrial ATP/ADP ratios, which requires phosphorylation of $\mathrm{COX} \mathrm{Vb}$ and $\mathrm{COX}$ II by protein kinase A (a cyclic adenosine monophosphate (cAMP)-dependent phosphorylation) (Bender and Kadenbach, 2000). This ATP inhibition was relieved by dephosphorylation of the COX enzyme by protein phosphatase 1 (Bender and Kadenbach, 2000). Thus, if $\mathrm{COXVb}$ is important to the overall $\mathrm{COX}$ activity, $\mathrm{a}>2$-fold higher $\mathrm{COX} \mathrm{Vb}$ expression might contribute to the 2 -fold higher COX activity in oxygen tolerant HeLa-80 cells.

\section{Oxygen Tolerance in HeLa Cells and Rats: A Common Mechanism?}

We have carried out some preliminary investigations of an oxygen tolerant strain of rats bred from a founder which unexpectedly survived for $144 \mathrm{hr}$ in $100 \% \mathrm{O}_{2}$. We have found that isolated hepatic mitochondria from these animals show significantly decreased ROS production under normoxic conditions. Furthermore, the in vivo production of ROS upon exposure to $100 \% \mathrm{O}_{2}$ is also less in the oxygen tolerant rats as judged by (I) the decrease in pulmonary aconitase activity (which probably reflects in situ ROS generation) and (ii) greatly decreased accumulation of nitrotyrosine in the lung following $24 \mathrm{hr}$ under $100 \% \mathrm{O}_{2}$. These rats may have become tolerant to hyperoxia by the same mechanism employed by the HeLa cells - namely, decreased mitochondrial ROS production. 
As was the case with our HeLa-80 cells, there were no differences in antioxidants (such as reduced glutathione (GSH) levels and the enzyme activities of manganese and copper/zinc superoxide dismutases, catalase, glucose-6-phosphate dehydrogenase and glutathione peroxidase) between oxygen tolerant and control rats both under normoxia and following exposure to hyperoxia for $54 \mathrm{hr}$. This prompted us to conduct studies on the mitochondrial function of these rats. Because we had earlier found significantly higher COX activity in our oxygen-tolerant HeLa-80 cells, we measured COX activity in hepatic mitochondria from these animals. The results indicate that the tolerant animals have 2.4 -fold higher COX activity, very similar to that observed in our oxygen tolerant HeLa-80 cells.

Interestingly (and unexpectedly), lung fibroblast cultures derived from these rats were found to be hypersensitive to killing by $\mathrm{H}_{2} \mathrm{O}_{2}$, measured by changes in the metabolically-dependent reduction of the fluorescent dye, Alamar Blue. In the course of these investigations, we inadvertently found that fibroblasts from the tolerant rat cells reduce this dye at a rate $<50 \%$ of wild type fibroblasts when the reduction is expressed per mg protein. As yet, we have no explanation for these unexpected findings which may reflect a global change in cellular redox poise associated with the oxygen tolerance of these unusual rats. These very exciting but preliminary observations suggest that in three instances (HeLa-80 and HeLa-99 cells which were separately selected and the oxygen tolerant rats) oxygen tolerance has been achieved through selection for cells and organisms the mitochondria of which generate substantially less ROS under hyperoxic conditions and by virtue of increased activity of COX. 
The Possibility That Oxygen Tolerance Arises from Enhanced Anti-Apoptotic

\section{$\underline{\text { Mechanisms }}$}

Some earlier reports do support our view that mitochondrial metabolism is crucially involved in hyperoxic cell damage. For example, Yoneda et al. (Yoneda et al., 1995) found that $\rho^{\circ}$ human fibroblasts were resistant to oxygen toxicity. Furthermore, O'Donovan et al. (O'Donovan et al., 2000) report that expression of glutathione reductase selectively targeted to mitochondria could attenuate the cytostatic effects of hyperoxia. However, we were troubled by a recent report from Budinger et al. (Budinger et al., 2002) which concludes that hyperoxic cell death is independent of enhanced generation of ROS but dependent on expression of the pro-apoptotic proteins, Bax or Bak (and it antagonized by Bcl- $\mathrm{X}_{\mathrm{L}}$ ). We cannot explain the discrepancy between our results and these particular investigations. However, we might point out that in this latter work, (i) the tests by which $\rho^{\circ}$ status of the test cells were assured are not mentioned; (ii) the $\rho^{\circ}$ cells were not cloned; (iii) surprisingly, there was no difference in ROS production between wild type and $\rho^{\circ}$ cells under $20 \%$ oxygen and (iv) the necessary control of producing cybrids was not carried out, leaving open the possibility that ethidium-induced mutations affecting nuclear DNA might have influenced the oxygen tolerance of the $\rho^{\circ}$ cells. Furthermore, we consider it unlikely that our present results are explained by significant variations in expression of pro- vs. anti-apoptotic proteins such as Bax and Bak versus Bcl- $\mathrm{X}_{\mathrm{L}}$ and $\mathrm{Bcl}-2$, respectively. This is because we and others have reported that expression of the latter, in particular, is well known to provide significant protection against challenge with exogenous oxidants such as hydrogen peroxide (Zhao et al., 2001) whereas the HeLa- 80 cells are normally sensitive to peroxide killing and the hyperoxia- 
resistant $\rho^{\circ}$ HeLa-20 clones we have developed are, if anything, more susceptible to oxidant killing.

Do Hyperoxia and Radiation Damage Cells through A Common Mechanism?

Whereas there is a clear link between ROS production engendered by both ionizing radiation and hyperoxia, in one sense our observations run counter to a popular hypothesis, originally proposed by Gerschman (1954) (Gerschman et al., 1954) which states that the toxic action of both hyperoxia and $\mathrm{X}$ rays is based on a common mechanism involving the formation of oxidizing free radicals. Contrary to what might be predicted from this hypothesis, the oxygen-resistant HeLa- 80 cells are not cross-resistant to gamma radiation. (Joenje et al., 1985). This implies that cellular properties conferring resistance to killing by hyperoxia do not necessarily contribute to cellular X-ray tolerance. In one way this makes sense: mitochondrial generation of ROS is important in hyperoxic cell damage whereas radiation damage is largely independent of this.

Gerschmann also pointed out that X-irradiation in the presence of hyperoxia had an synergistic effect on cell damage (the so-called 'oxygen enhancement ratio') and that many other agents, such as sulfhydryl containing compounds could cross-protect against both ionizing radiation and oxygen toxicity (Gerschman et al., 1954). Once again, these observations do not conflict with our current findings. There is no question that the generation of ROS by ionizing radiation is increased at higher partial pressures of oxygen, but this increase is passive and quite independent of mitochondrial ROS production. During irradiation, free radicals form throughout the cell. Furthermore, it 
would appear that nuclear DNA is the major lethal target of ionizing radiation. In contrast, under hyperoxic conditions, the excessive ROS primarily come from mitochondria (and, perhaps, some a very small portion ROS may arise from microsomes and other organelles (Hamers, 1985). Therefore, the major hyperoxic damage to cells may involve targets other than nuclear DNA such as cell membranes, proteins and, perhaps, mitochondrial DNA. 


\section{SUMMARY AND CONCLUSIONS}

The aim of the research reported here was to explain the unusual oxygen tolerance of a strain of HeLa cells selected over a prolonged period of exposure to step-wise increases in the partial pressure of oxygen. A secondary aim was to achieve a better understanding of the nature of oxygen toxicity per se.

Surprisingly, we find, as earlier reported by our collaborator Dr. Jeunje (Joenje et al., 1985) no significant differences in oxidant defense parameters nor in the ability of the oxygen tolerant HeLa cells to survive challenge with exogenous oxidants. Rather, the crucial difference appears to reside in the tendency of mitochondria to produce ROS under either normoxic or hyperoxic conditions.

Extensive testing of mitochondrial function in these cells led to the observation that the activity of cytochrome c oxidase - but not of the other components of the mitochondrial electron transport chain - is significantly increased. The net effect of this increase in COX activity appears to be depletion of electron-rich, ROS-generating, intermediates and, thus, diminished ROS production. Further to this point, we find a selective elevation of one sub-unit of $\mathrm{COX}, \mathrm{Vb}$, a known regulator of the overall stability and activity of this complex, 13 sub-unit enzyme. 
Perhaps most excitingly, very recent observations of cells and tissues from an oxygen tolerant strain of rats suggest quite a similar picture: no changes in oxidant defense parameters or in tolerance to exogenous oxidants but (i) diminished mitochondrial ROS production and (ii) similarly exaggerated COX activity.

Overall, these observations suggest that cells and intact animals may adapt genetically to hyperoxia through a similar mechanism: that of limiting mitochondrial ROS generation. These results suggest possible avenues for therapeutic interventions which, by modulating the synthesis of COX components - especially $\mathrm{Vb}$ - may enhance tolerance to hyperoxia and, quite possibly, other stressors commonly encountered in the clinical arena. 


\section{FUTURE INVESTIGATIONS}

The particular importance of $\mathrm{COX} \mathrm{Vb}$ will be investigated using an antisense strategy, specifically, silencer-interference RNA (siRNA). Preliminary experiments indicate that this approach will work; siRNA transfection inhibited COX Vb selectively and COX activity was decreased proportionally to the dose of siRNA tranfected in HeLa80 cells. In further work, we shall: (i) Repeat the siRNA transfection and confirm the inhibitory effect by western blot and real time RT-PCR in both HeLa-20 and HeLa-80

cells. (ii) Measure COX activity and ROS production in both siRNA transfected HeLa-20 and HeLa-80 cells. (iii) Measure oxygen consumption in the absence and presence of CCCP in siRNA transfected HeLa cells. (iv) Determine the duration of the siRNA silencing effects and (v) Expose control and siRNA treated HeLa- 80 cells to $80 \%$ oxygen to determine whether partial silencing of $\mathrm{Vb}$ diminishes oxygen tolerance.

In additional investigations, we will also determine whether $\mathrm{COX} \mathrm{Vb}$ is the critical factor for oxygen tolerance by selectively over-expressing this subunit in wildtype HeLa-20 cells. After confirmation of increased Vb expression, the cells will be challenged with $80 \% \mathrm{O}_{2}$ to determine whether this causes enhanced oxygen tolerance. Since COX Va is closely related to COX Vb (Allen et al., 1995; Waterland et al., 1991), additional investigations of COX Va expression by western blot and real time RT-PCR will be carried out. 
Finally, if the above experiments suggest a critical role for $\mathrm{COX} \mathrm{Vb}$ in the control of mitochondrial metabolism and ROS production, we will explore ways of therapeutically upregulating COX activity. Our first experiments will involve testing the effects of estrogen administration on cells and intact mice. It has been reported that physiologic concentrations of estrogen will increase the expression of COX subunits I-III (Bettini and Maggi, 1992; Chen et al., 1998; Morin et al., 2002; Vanitallie and Dannies, 1988). Furthermore, a very recent report indicates that mitochondria from intact - but not ovarectomized - female rats generate substantially less ROS and, importantly, that ROS production by mitochondria from ovarectomized animals can be suppressed by the administration of estrogen (Borras et al., 2003). If this works as well in intact animals, we will determine whether the administration of estrogen (or other agents which may upregulate COX activity) will enhance tolerance to hyperoxia. 


\section{REFERENCES}

Ackrell, B.A.C., J.J.Maguire, P.R.Dallman, and E.B.Kearney. 1984. Effect of iron-deficiency on succinate-ubiquinone and NADH-ubiquinone oxidoreductases in skeletal-muscle mitochondria. J. Biol. Chem. 259:53-59.

Ahmad, A., S.Ahmad, B.K.Schneider, C.B.Allen, L.Y.Chang, and C.W.White. 2002. Elevated expression of hexokinase II protects human lung epithelial-like A549 cells against oxidative injury. American Journal of Physiology-Lung Cellular and Molecular Physiology 283:L573-L584.

Allen, L.A., X.J.Zhao, W.Caughey, and R.O.Poyton. 1995. Isoforms of yeast cytochrome $\mathrm{c}$ oxidase subunit $\mathrm{V}$ affect the binuclear reaction center and alter the kinetics of interaction with the isoforms of yeast cytochrome c. J. Biol. Chem. 270:110-118.

Alper T, Howard-Flanders P. 1956. Role of oxygen in modifying the radiosensitivity of E. coli B. Nature 178: 978-9.

Alvarez, S, Valdez, LB, Zaobornyj, T, and Boveris, A. 2003. Oxygen dependence of mitochondrial nitric oxide synthase activity. Biochem.Biophys.Res.Commun. 305, 771775.

Amstad, P.A., H.Liu, M.Ichimiya, I.K.Berezesky, B.F.Trump, I.A.Buhimschi, and P.L.Gutierrez. 2001. BCL-2 is involved in preventing oxidant-induced cell death and in decreasing oxygen radical production. Redox Report 6:1-12. 
Anthony, G., A.Reimann, and B.Kadenbach. 1993. Tissue-Specific Regulation of Bovine Heart Cytochrome-C-Oxidase Activity by Adp Via Interaction with Subunit-Via. Proceedings of the National Academy of Sciences of the United States of America 90:1652-1656.

Antunes, F., E.Cadenas, and U.T.Brunk. 2001. Apoptosis induced by exposure to a low steady-state concentration of $\mathrm{H}_{2} \mathrm{O}_{2}$ is a consequence of lysosomal rupture. Biochemical Journal 356:549-555.

Asikainen, T.M., T.T.Huang, E.Taskinen, A.L.Levonen, E.Carlson, R.Lapatto, C.J.Epstein, and K.O.Raivio. 2002. Increased sensitivity of homozygous $\mathrm{SOD}_{2}$ mutant mice to oxygen toxicity. Free Radical Biology and Medicine 32:175-186.

Atamna, H., J.Liu, and B.N.Ames. 2001. Heme deficiency selectively interrupts assembly of mitochondrial complex IV in human fibroblasts. Relevance to aging. J. Biol. Chem. 276:48410-48416.

Ayala-Torres, S., Y.Chen, T.Svoboda, J.Rosenblatt, and B.Van Houten. 2000. Analysis of gene-specific dna damage and repair using quantitative polymerase chain reaction. Methods 22:135-147.

Balla, G., H.S.Jacob, J.Balla, M.Rosenberg, K.Nath, F.Apple, J.W.Eaton, and G.M.Vercellotti. 1992. Ferritin: a cytoprotective antioxidant strategem of endothelium. J. Biol. Chem. 267:18148-18153.

Beauchemin, A.M.J., B.Gottlieb, L.K.Beitel, Y.A.Elhaji, L.Pinsky, and M.A.Trifiro. 2001. Cytochrome $\mathrm{c}$ oxidase subunit $\mathrm{Vb}$ interacts with human androgen receptor: a potential mechanism for neurotoxicity in spinobulbar muscular atrophy. Brain Research Bulletin 56:285-297. 
Bejma, J. and L.L.Ji. 1999. Aging and acute exercise enhance free radical generation in rat skeletal muscle. J. Appl. Physiol 87:465-470.

Bell, L.C., D.J.Richardson, and S.J.Ferguson. 1992. Identification of nitric-oxide reductase-activity in Rhodobacter-capsulatus - the electron-transport pathway can either use or bypass both cytochrome-c2 and the cytochrome-Bc1 complex. Journal of General Microbiology 138:437-443.

Bender, E. and B.Kadenbach. 2000. The allosteric ATP-inhibition of cytochrome c oxidase activity is reversibly switched on by cAMP-dependent phosphorylation. FEBS Letters 466:130-134.

Bettini, E. and A.Maggi. 1992. Estrogen induction of cytochrome-c-oxidase subunit-III in rat hippocampus. Journal of Neurochemistry 58:1923-1929.

Bhandari, V., N.Maulik, and M.Kresch. 2000. Hyperoxia causes an increase in antioxidant enzyme activity in adult and fetal rat type II pneumocytes. Lung 178:53-60.

Bielski BHJ and Shive GG. 1979. Reaction rates of superoxide radicals with the essential amino acids. In: Oxygen free radicals and tissue damage. Ciba Found Symp 65 (new series). Excerpta Medica, Amsterdam.

Bilodeau, J.F., A.Patenaude, B.Piedboeuf, C.Carrier, P.Petrov, R.Faure, and M.E.Mirault. 2002. Glutathione peroxidase-1 expression enhances recovery of human breast carcinoma cells from hyperoxic cell cycle arrest. Free Radical Biology and Medicine 33:1279-1289.

Bindokas, V.P., J.Jordan, C.C.Lee, and R.J.Miller. 1996. Superoxide production in rat hippocampal neurons: selective imaging with hydroethidine. J. Neurosci. 16:13241336. 
Binger C.A.L, Faulkner J.M., and Moore R.L. 1927. Oxygen poisoning in mammals. J. Exp Med. 45:849-864

Birch-Machin, M.A. and D.M.Turnbull. 2001. Assaying mitochondrial respiratory complex activity in mitochondria isolated from human cells and tissues. Method Cell. Biol. 65:97-117.

Bitar, M.S. and B.H.Shapiro. 1987. Aberration of heme and hemoprotein in aged female rats. Mechanisms of Ageing and Development 38:189-197.

Boffoli, D., S.C.Scacco, R.Vergari, G.Solarino, G.Santacroce, and S.Papa. 1994. Decline with age of the respiratory-chain activity in human skeletal-muscle. Biochimica et Biophysica Acta-Molecular Basis of Disease 1226:73-82.

Bonne, G., P.Seibel, S.Possekel, C.Marsac, and B.Kadenbach. 1993. Expression of human cytochrome-c-oxidase subunits during fetal development. European Journal of Biochemistry 217:1099-1107.

Borras, C., J.Sastre, D.Garcia-Sala, A.Lloret, F.V.Pallardo, and J.Vina. 2003. Mitochondria from females exhibit higher antioxidant gene expression and lower oxidative damage than males. Free Radical Biology and Medicine 34:546-552.

Bostek, C.C. 1989. Oxygen toxicity: an introduction. AANA. J. 57:231-237.

Boveris, A. and B.Chance. 1973. Mitochondrial generation of hydrogen-peroxide - general properties and effect of hyperbaric-oxygen. Biochemical Journal 134:707-716.

Boveris, A., N.Oshino, and B.Chance. 1972. The cellular production of hydrogen peroxide. Biochem J 128:617-630.

Bowling, A.C. and M.F.Beal. 1995. Bioenergetic and oxidative stress in neurodegenerative diseases. Life Sciences 56:1151-1171. 
Branicky, R., C.Benard, and S.Hekimi. 2000. Clk-1, mitochondria, and physiological rates. Bioessays 22:48-56.

Brunk, U.T., J.Neuzil, and J.W.Eaton. 2001. Lysosomal involvement in apoptosis. Redox Report 6:91-97.

Budinger, G.R.S., M.Tso, D.S.McClintock, D.A.Dean, J.I.Sznajder, and N.S.Chandel. 2002a. Hyperoxia-induced apoptosis does not require mitochondrial reactive oxygen species and is regulated by Bcl-2 proteins. J. Biol. Chem. 277:1565415660.

Burke, P.A. and R.O.Poyton. 1998. Structure/function of oxygen-regulated isoforms in cytochrome c oxidase. J Exp Biol 201:1163-1175.

Campbell K. 1951. Intensive oxygen therapy as a possible cause for retrolental fibroplasia: a clinical approach. Med J. Austr. ii:48-50

Capaldi, R.A. 1990. Structure and function of cytochrome c oxidase. Annu. Rev. Biochem. 59:569-596.

Capellier, G., P.Beuret, G.Clement, F.Depardieu, C.Ract, J.Regnard, D.Robert, and F.Barale. 1998a. Oxygen tolerance in patients with acute respiratory failure. Intensive Care Medicine 24:422-428.

Capellier, G., T.Jacques, P.Balvay, and F.Barale. 1998b. Inhaled nitric oxide in patients with pulmonary embolism - Reply. Intensive Care Medicine 24:399-400.

Carpente.S, G., Watters, A.E., and R.Usher. 1973. Demyelinative neuropathy in a newborn infant. American Journal of Pathology 70:A77.

Castro, L. and B.A.Freeman. 2001a. Reactive oxygen species in human health and disease. Nutrition 17:161, 163-165. 
Chance, B., H.Sies, and A.Boveris. 1979c. Hydroperoxide metabolism in mammalian organs. Physiol Rev. 59:527-605.

Chandel, N.S., G.R.S.Budinger, S.H.Choe, and P.T.Schumacker. 1997. Cellular respiration during hypoxia - Role of cytochrome oxidase as the oxygen sensor in hepatocytes. J. Biol. Chem. 272:18808-18816.

Chandel, N.S., G.R.S.Budinger, and P.T.Schumacker. 1996. Molecular oxygen modulates cytochrome c oxidase functions. J. Biol. Chem. 271:18672-18677.

Chappell, J.B. 1964. The oxidation of citrate, isocitrate and cis-aconitate by isolated mitochondria. Biochem. J. 90:225-237.

Chen, J., N.Adachi, K.Liu, and T.Arai. 1998. The effects of 17 beta-estradiol on ischemia-induced neuronal damage in the gerbil hippocampus. Neuroscience 87:817-822.

Chomyn, A., S.T.Lai, R.Shakeley, N.Bresolin, G.Scarlato, and G.Attardi. 1994. Platelet-mediated transformation of mtDNA-less human-cells - analysis of phenotypic variability among clones from normal individuals - and complementation behavior of the tRNA(Lys) mutation causing myoclonic epilepsy and ragged-red fibers. American Journal of Human Genetics 54:966-974.

Clark, J.M. and C.J.Lamberts. 1971. Pulmonary oxygen toxicity - review. Pharmacological Reviews 23:37-\&.

Comoroe J.H. Jr., Dripps R.D., Dumke P.R., and Deming M. 1945. Oxygen toxicity. J Am Med Assoc. 128:710-717

Cossarizza, A., D.Ceccarelli, and A.Masini. 1996. Functional heterogeneity of an isolated mitochondrial population revealed by cytofluorometric analysis at the single organelle level. Experimental Cell Research 222:84-94. 
Crosse, V.M. and Evans P.J. 1952. Prevention of retrolental fibroplasia. Arch Ophthalmol. 48:83-87

Cross,A.R. and Jones, O.T.G. 1991. Enzymatic mechanisms of superoxide production. Biochimica et Biophysica Acta 1057:281-298

Croteau, D.L., C.M.J.apRhys, E.K.Hudson, G.L.Dianov, R.G.Hansford, and V.A.Bohr. 1997. An oxidative damage-specific endonuclease from rat liver mitochondria. J. Biol. Chem. 272:27338-27344.

Davermann, D., M.Martinez, J.Mckoy, N.Patel, D.Averbeck, and C.W.Moore. 2002. Impaired mitochondrial function protects against free radical-mediated cell death. Free Radic. Biol. Med. 33:1209-1220.

Das, N., R.L.Levine, W.C.Orr, and R.S.Sohal. 2001. Selectivity of protein oxidative damage during aging in Drosophila melanogaster. Biochemical Journal 360:209-216.

Deneke, S.M. and B.L.Fanburg. 1980. Normobaric oxygen-toxicity of the lung. New England Journal of Medicine 303:76-86.

Deneke, S.M. and B.L.Fanburg. 1982. Oxygen-toxicity of the lung - an update. British Journal of Anaesthesia 54:737-749.

Dewey D. L. 1960. Effect of oxygen and nitric oxide on the radio-sensitivity of human cells in tissue culture. Nature 186:780-782.

Dionisi, O., T.Galeotti, T.Terranova, and A.Azzi. 1975. Superoxide radicals and hydrogen peroxide formation in mitochondria from normal and neoplastic tissues. Biochim. Biophys. Acta 403:292-300. 
Donnelly, M. and I.E.Scheffler. 1976. Energy metabolism in respiration-deficient and wild type Chinese hamster fibroblasts in culture. J. Cell Physiol 89:39-51.

Dowhan, W., C.R.Bibus, and G.Schatz. 1985. The cytoplasmically-made subunit IV is necessary for assembly of cytochrome $\mathrm{c}$ oxidase in yeast. The EMBO Journal 4:179-184.

Elbashir, S.M., J.Martinez, A.Patkaniowska, W.Lendeckel, and T.Tuschl. 2001. Functional anatomy of siRNAs for mediating efficient RNAi in Drosophila melanogaster embryo lysate. The EMBO Journal 20:6877-6888.

Erecinska, M. and D.F.Wilson. 1982. Regulation of cellular-energy metabolism. Journal of Membrane Biology 70:1-14.

Etherington DJ, Silver IA, and Gibbons R. 1979. An in vitro model for the study of collagen degradation during acute inflammation. Life Sci 25:1885-1892.

Fenton, H.J.H. 1894. Oxidation of tartaric acid in presence of iron. J Chem Soc. 65:899-910

Finkel, T. and N.J.Holbrook. 2000. Oxidants, oxidative stress and the biology of ageing. Nature 408:239-247.

Frank, L. and R.J.Roberts. 1978a. Bacterial-endotoxin protection from pulmonary oxygen-toxicity. Pediatric Research 12:560.

Frank, L. and R.J.Roberts. 1978b. Protection from $\mathrm{O}_{2}$ lung toxicity with bacterial lipopolysaccharide (endotoxin). American Review of Respiratory Disease 117:116.

Frank, L., J.Yam, and R.J.Roberts. 1978. Role of endotoxin in protection of adult rats from oxygen-induced lung toxicity. J. Clin. Invest. 61:269-275. 
Freedman, M.L. 1987. Heme and iron-metabolism in aging. Blood Cells 13:227235.

Freeman, B.A. and J.D.Crapo. 1981. Hyperoxia increases oxygen radical production in rat lungs and lung mitochondria. J. Biol. Chem. 256:10986-10992.

Freeman, B.A. and A.K.Tanswell. 1985. Biochemical and cellular aspects of pulmonary oxygen toxicity. Adv. Free Radic. Biol. Med. 1:133-164.

Fuller, K.M., C.F.Duffy, and E.A.Arriaga. 2002. Determination of the cardiolipin content of individual mitochondria by capillary electrophoresis with laser-induced fluorescence detection. Electrophoresis 23:1571-1576.

Gamble, J.T., H.A.Dailey, and G.S.Marks. 2000. N-methylprotoporphyrin is a more potent inhibitor of recombinant human than of recombinant chicken ferrochelatase. Drug Metab Dispos 28:373-375.

Gardner, P.R. and I.Fridovich. 1991. Superoxide sensitivity of the Escherichiacoli aconitase. J. Biol. Chem. 266:19328-19333.

Gardner, P.R., D.D.H.Nguyen, and C.W.White. 1994. Aconitase is a sensitive and critical target of oxygen poisoning in cultured-mammalian-cells and in rat lungs. Proceedings of the National Academy of Sciences of the United States of America 91:12248-12252.

Gasnier, F., R.Rousson, F.Lerme, E.Vaganay, P.Louisot, and O.Gateauroesch. 1993. Use of percoll gradients for isolation of human placenta mitochondria suitable for investigating outer-membrane proteins. Analytical Biochemistry 212:173-178.

Genova, ML., Ventura, B., Giuliano, G., Bovina, C., Formiggini, G., Parenti, CG., and Lenaz, G. 2001. The site of production of superoxide radical in mitochondrial 
Complex I is not a bound ubisemiquinone but presumably iron-sulfur cluster $\mathrm{N}_{2}$. FEBS Lett. 505, 364-368.

Gerschman, R., Gilbert, DL., Nye, SW., Dwyer, P., and Fenn, WO. 1954. Oxygen poisioning and x-irradiation: a mechanism in common. Science 119, 623-626.

Gille, J.J., H.M.Wortelboer, and H.Joenje. 1988. Effect of normobaric hyperoxia on antioxidant defenses of HeLa and CHO cells. Free Radic. Biol. Med. 4:85-91.

Gille, J.J.P. and H.Joenje. 1989. Chromosomal instability and progressive loss of chromosomes in hela-cells during adaptation to hyperoxic growth-conditions. Mutation Research 219:225-230.

Gloster, J.A. and P.Harris. 1962. Observations on an enzymic method for the estimation of pyruvate in blood. Clin. Chim. Acta 7:206-211.

Goijman, S.G. and A.O.Stoppani. 1985. Effects of beta-lapachone, a peroxidegenerating quinone, on macromolecule synthesis and degradation in Trypanosoma cruzi. Arch. Biochem. Biophys. 240:273-280.

Grandjean, F., L.Bremaud, J.Robert, and M.H.Ratinaud. 2002. Alterations in the expression of cytochrome c oxidase subunits in doxorubicin-resistant leukemia K562 cells. Biochemical Pharmacology 63:823-831.

Guidot, D.M. 1996. Endotoxin treatment increases lung mitochondrial scavenging of extramitochondrial superoxide in hyperoxia-exposed rats. Archives of Biochemistry and Biophysics 326:266-270.

Guidot, D.M., J.M.McCord, R.M.Wright, and J.E.Repine. 1993. Absence of electron transport (Rho 0 state) restores growth of a manganese-superoxide dismutase- 
deficient Saccharomyces cerevisiae in hyperoxia. Evidence for electron transport as a major source of superoxide generation in vivo. J. Biol. Chem. 268:26699-26703.

Gutierrez, P.L., R.D.Friedman, and N.R.Bachur. 1982. Biochemical activation of AZQ [3,6-diaziridinyl-2,5-bis(carboethoxyamino)-1,4-benzoquinone] to its free radical species. Cancer Treat. Rep. 66:339-342.

Hafner, R.P. and M.D.Brand. 1988. Hypothyroidism in rats does not lower mitochondrial ADP/O and H+/O ratios. Biochemical Journal 250:477-484.

Hannon, G.J. 2002. RNA interference. Nature 418:244-251.

Hengartner, M.O. 2000. The biochemistry of apoptosis. Nature 407:770-776.

Hansford, R.G , Hogue, B.A., and Mildaziene, V. 1997. Dependence of $\mathrm{H}_{2} \mathrm{O}_{2}$ formation by rat heart mitochondria on substrate availability and donor age. $J$ Bioenerg Biomembr. 29:89-95.

Higuchi, M., B.B.Aggarwal, and E.Yeh. 1997. Activation of CPP32-like protease in tumor necrosis factor-induced apoptosis is dependent on mitochondrial function. $J$. Clin. Invest. 99:1751-1758.

Ho, Y.S., R.Vincent, M.S.Dey, J.W.Slot, and J.D.Crapo. 1998. Transgenic models for the study of lung antioxidant defense: enhanced manganese-containing superoxide dismutase activity gives partial protection to $\mathrm{B} 6 \mathrm{C} 3$ hybrid mice exposed to hyperoxia. Am. J. Respir. Cell Mol. Biol. 18:538-547.

Hoffman, M., J.B.Stevens, and A.P.Autor. 1980. Adaptation to hyperoxia in the neonatal rat - kinetic-parameters of the oxygen-mediated induction of lung superoxide dismutases, catalase and glutathione-peroxidase. Toxicology 16:215-225. 
Ilizarov, A.M., H.C.Koo, J.A.Kazzaz, L.L.Mantell, Y.Li, R.Bhapat, S.Pollack, S.Horowitz, and J.M.Davis. 2001. Overexpression of manganese superoxide dismutase protects lung epithelial cells against oxidant injury. Am. J. Respir. Cell Mol. Biol. 24:436441.

Jackson, R.M., E.S.Helton, L.Viera, and T.Ohman. 1999. Survival, lung injury, and lung protein nitration in heterozygous MnSOD knockout mice in hyperoxia. Experimental Lung Research 25:631-646.

Jamieson, D. 1989. Oxygen-toxicity and reactive oxygen metabolites in mammals. Free Radical Biology and Medicine 7:87-108.

Jarreta, D., J.Orus, A.Barrientos, O.Miro, E.Roig, M.Heras, C.T.Moraes, F.Cardellach, and J.Casademont. 2000. Mitochondrial function in heart muscle from patients with idiopathic dilated cardiomyopathy. Cardiovascular Research 45:860-865.

Jia, L., S.M.Kelsey, M.F.Grahn, X.R.Jiang, and A.C.Newland. 1996. Increased activity and sensitivity of mitochondrial respiratory enzymes to tumor necrosis factor alpha-mediated inhibition is associated with increased cytotoxicity in drug-resistant leukemic cell lines. Blood 87:2401-2410.

Joenje, H. 1983. Oxygen - Our major carcinogen. Medical Hypotheses 12:55-60.

Joenje, H., J.J.Gille, A.B.Oostra, and P.Van der Valk. 1985. Some characteristics of hyperoxia-adapted HeLa cells. A tissue culture model for cellular oxygen tolerance. Lab Invest 52:420-428.

Joenje, H., B.J.van den, and J.van Rijn. 1985. Lack of cross-resistance to Xirradiation in oxygen-resistant mammalian cell lines. J Free Radic Biol Med. 1:307-310. 
Kadenbach, B. and S.Arnold. 1999. A second mechanism of respiratory control. FEBS Letters 447:131-134.

Keller, R.J., N.C.Halmes, J.A.Hinson, and N.R.Pumford. 1993. Immunochemical detection of oxidized proteins. Chemical Research in Toxicology 6:430-433.

Kerbs, H.A. and O.Holzach. 1952. The conversion of citrate into cis-aconitase and isocitrate in the presence of aconitase. Biochem J 52:527-528.

Kessler, R.J., C.A.Tyson, and D.E.Green. 1976. Mechanism of uncoupling in mitochondria - uncouplers as ionophores for cycling cations and protons. Proceedings of the National Academy of Sciences of the United States of America 73:3141-3145.

Kinsey VE, Jacobus JT, Hemphill F. 1956. Retrolental fibroplasia: cooperative study of Retrolental fibroplasia and the use of oxygen. Arch Ophthalmol 56:481-543

Knight, J.A. 1998. Free radicals: Their history and current status in aging and disease. Annals of Clinical and Laboratory Science 28:331-346.

Korshunov, S.S., V.P.Skulachev, and A.A.Starkov. 1997. High protonic potential actuates a mechanism of production of reactive oxygen species in mitochondria. FEBS Letters 416:15-18.

Kruidering, M., B.Van De Water, E.De Heer, G.J.Mulder, and J.F.Nagelkerke. 1997. Cisplatin-induced nephrotoxicity in porcine proximal tubular cells: mitochondrial dysfunction by inhibition of complexes I to IV of the respiratory chain. J Pharmacol Exp Ther 280:638-649.

Laemmli, U.K. 1970. Cleavage of Structural Proteins During Assembly of Head of Bacteriophage-T4. Nature 227:680-\&. 
Lee, I., E.Bender, and B.Kadenbach. 2002. Control of mitochondrial membrane potential and ROS formation by reversible phosphorylation of cytochrome c oxidase. Mol. Cell. Biochem. 234:63-70.

Lee, P.J., J.Alam, G.W.Wiegand, and A.M.K.Choi. 1996. Overexpression of heme oxygenase-1 in human pulmonary epithelial cells results in cell growth arrest and increased resistance to hyperoxia. Proceedings of the National Academy of Sciences of the United States of America 93:10393-10398.

Letellier, T., R.Heinrich, M.Malgat, and J.P.Mazat. 1994. The kinetic basis of threshold effects observed in mitochondrial diseases - a systemic approach. Biochemical Journal 302:171-174.

Letellier, T., M.Malgat, and J.P.Mazat. 1993. Control of oxidativephosphorylation in rat muscle mitochondria - implications for mitochondrial myopathies. Biochimica et Biophysica Acta 1141:58-64.

Levine, R.L., D.Garland, C.N.Oliver, A.Amici, I.Climent, A.G.Lenz, B.W.Ahn, S.Shaltiel, and E.R.Stadtman. 1990. Determination of carbonyl content in oxidatively modified proteins. Methods Enzymol. 186:464-478.

Lightowlers, R., Z.Chrzanowska-Lightowlers, M.Marusich, and R.A.Capaldi. 1991. Subunit function in eukaryote cytochrome $\mathrm{c}$ oxidase. A mutation in the nuclearcoded subunit IV allows assembly but alters the function and stability of yeast cytochrome c oxidase. J. Biol. Chem. 266:7688-7693.

Liu, S.S. 1997. Generating, partitioning, targeting and functioning of superoxide in mitochondria. Bioscience Reports 17:259-272. 
Livak, K.J. and T.D.Schmittgen. 2001. Analysis of relative gene expression data using real-time quantitative PCR and the 2-[Delta][Delta]Ct method. Methods 25:402408.

Mann, V.M., J.M.Cooper, D.Krige, S.E.Daniel, A.H.V.Schapira, and C.D.Marsden. 1992. Brain, Skeletal-muscle and platelet homogenate mitochondrialfunction in parkinsons-disease. Brain 115:333-342.

Masini, A., D.Ceccarellistanzani, and U.Muscatello. 1983. The effect of oligomycin on rat-liver mitochondria respiring in state-4. FEBS Letters 160:137-140.

McCord J.M., Fridovich I. 1969. Superoxide dismutase. An enzymic function for erythrocuprein (hemocuprein). J. Biol. Chem. 244:6049-6055.

Mockett, R.J., R.S.Sohal, and W.C.Orr. 1999. Overexpression of glutathione reductase extends survival in transgenic Drosophila melanogaster under hyperoxia but not normoxia. Faseb Journal 13:1733-1742.

Morin, C., R.Zini, N.Simon, and J.P.Tillement. 2002. Dehydroepiandrosterone and [alpha]-estradiol limit the functional alterations of rat brain mitochondria submitted to different experimental stresses. Neuroscience 115:415-424.

Motterlini R., Foresti R., Intaglietta M., and Winslow R.M.1996. NO-mediated activation of heme oxygenase: endogenous cytoprotection against oxidative stress to endothelium. Am. J. physiol. 270:H107-H114.

Mullerhocker, J. 1989. Cytochrome-c-oxidase deficient cardiomyocytes in the human-heart - an age-related phenomenon - a histochemical ultracytochemical study. American Journal of Pathology 134:1167-1173. 
Nash G, Blennerhassett J.B, and Pontoppidan H. 1967. Pulmonary lesions associated with oxygen therapy and artificial ventilation. New England J. Medicine $276: 368-374$

Nikolaychik, V.V., M.M.Samet, and P.I.Lelkes. 1996. A new method for continual quantitation of viable cells on endothelialized polyurethanes. Journal of Biomaterials Science-Polymer Edition 7:881-891.

Nociari, M.M., A.Shalev, P.Benias, and C.Russo. 1998. A novel one-step, highly sensitive fluorometric assay to evaluate cell-mediated cytotoxicity. Journal of Immunological Methods 213:157-167.

O'Donovan, D.J. and C.J.Fernandes. 2000. Mitochondrial glutathione and oxidative stress: implications for pulmonary oxygen toxicity in premature infants. Mol. Genet. Metab. 71:352-358.

O'Donovan, D.J., J.P.Katkin, T.Tamura, C.V.Smith, and S.E.Welty. 2000. Attenuation of hyperoxia-induced growth inhibition in H441 cells by gene transfer of mitochondrially targeted glutathione reductase. Am. J. Respir. Cell Mol. Biol. 22:732738.

Ojaimi, J., C.L.Masters, C.McLean, K.Opeskin, P.McKelvie, and E.Byrne. 1999a. Irregular distribution of cytochrome c oxidase protein subunits in aging and Alzheimer's disease. Annals of Neurology 46:656-660.

Ojaimi, J., C.L.Masters, K.Opeskin, P.McKelvie, and E.Byrne. 1999 b. Mitochondrial respiratory chain activity in the human brain as a function of age. Mechanisms of Ageing and Development 111:39-47. 
Otterbein, L.E., J.K.Kolls, L.L.Mantell, J.L.Cook, J.Alam, and A.M.K.Choi. 1999a. Exogenous administration of heme oxygenase-1 by gene transfer provides protection against hyperoxia-induced lung injury. J. Clin. Invest. 103:1047-1054.

Otterbein, L.E., L.L.Mantell, and A.M.K.Choi. 1999b. Carbon monoxide provides protection against hyperoxic lung injury. American Journal of Physiology-Lung Cellular and Molecular Physiology 276:L688-L694.

Page, B., M.Page, and C.Noel. 1993. A new fluorometric assay for cytotoxicity measurements in-vitro. International Journal of Oncology 3:473-476.

Paradies, G., F.M.Ruggiero, G.Petrosillo, and E.Quagliariello. 1993. Agedependent decrease in the cytochrome-c-oxidase activity and changes in phospholipids in rat-heart mitochondria. Archives of Gerontology and Geriatrics 16:263-272.

Park, J.I., C.M.Grant, M.J.Davies, and I.W.Dawes. 1998. The cytoplasmic Cu, Zn superoxide dismutase of Saccharomyces Cerevisiae is required for resistance to freezethaw stress. Generation of free radicals during freezing and thawing. J. Biol. Chem. 273:22921-22928.

Patz A, Hoeck LE, de la Cruz E. Studies on the effect of high oxygen administration in retrolental fibroplasia. Nursery observations. Am J. Ophthalmol 1952; $35: 1248-1253$

Poyton, R.O. and C.J.Dagsgaard. 2000. Mitochondrial-nuclear crosstalk is involved in oxygen-regulated gene expression in yeast. Oxygen Sensing: Molecule to Man 475:177-184. 
Rajapakse, N., K.Shimizu, M.Payne, and D.Busija. 2001. Isolation and characterization of intact mitochondria from neonatal rat brain. Brain Research Protocols 8:176-183.

Regan, J.J., B.E.Ramirez, J.R.Winkler, H.B.Gray, and B.G.Malmstrom. 1998. Pathways for electron tunneling in cytochrome c oxidase. Journal of Bioenergetics and Biomembranes 30:35-39.

Rister, M. and R.L.Baehner. 1976. Alteration of superoxide-dismutase, catalase, glutathione peroxidase, and $\mathrm{NAD}(\mathrm{P}) \mathrm{H}$ cytochrome-c reductase in guinea-pig polymorphonuclear leukocytes and alveolar macrophages during hyperoxia. J. Clin. Invest. 58:1174-1184.

Rizzuto, R., D.Sandona, M.Brini, R.A.Capaldi, and R.Bisson. 1991. The most conserved nuclear-encoded polypeptide of cytochrome $\mathrm{c}$ oxidase is the putative zincbinding subunit: primary structure of subunit $V$ from the slime mold Dictyostelium discoideum. Biochimica et Biophysica Acta (BBA) - Gene Structure and Expression 1129:100-104.

Rooyackers, O., D.Adey, P.Ades, and K.á.Nair. 1996. Effect of age on in vivo rates of mitochondrial protein synthesis in humanáskeletalámuscle. PNAS 93:1536415369.

Sanders, S.P., J.L.Zweier, P.Kuppusamy, S.J.Harrison, D.J.P.Bassett, E.W.Gabrielson, and J.T.Sylvester. 1993. Hyperoxic sheep pulmonary microvascular endothelial-cells generate free-radicals via mitochondrial electron-transport. J. Clin. Invest. 91:46-52. 
Sandona, D., S.Gastaldello, R.Rizzuto, and R.Bisson. 1995. Expression of cytochrome c oxidase during growth and development of Dictyostelium. J. Biol. Chem. 270:5587-5593.

Sayen, M.R., A.B.Gustafsson, M.A.Sussman, J.D.Molkentin, and R.A.Gottlieb. 2003. Calcineurin transgenic mice have mitochondrial dysfunction and elevated superoxide production. American Journal of Physiology-Cell Physiology 284:C562C570.

Scotto, A.W., R.W.Rinehart, and D.S.Beattie. 1983. Aging-related decreases in hepatic mitochondrial and cytosolic delta-aminolevulinic-acid synthase during experimental porphyria. Archives of Biochemistry and Biophysics 222:150-157.

Scott, M.D. and J.W.Eaton. 1997. Markers of free radical-mediated tissue injury: Tales of caution and woe. In: FREE RADICAL TOXICOLOGY, K.B. Wallace (ed.), Lippincott-Raven Publishers, Philadelphia, PA. pp. 401-420.

Semenza, G.L. 1999. Perspectives on oxygen sensing. Cell 98:281-284.

Shacter, E., J.A.Williams, M.Lim, and R.L.Levine. 1994. Differential susceptibility of plasma-proteins to oxidative modification - examination by western-blot immunoassay. Free Radical Biology and Medicine 17:429-437.

Smith J.L. 1899. Pathological effects due to increase of oxygen tension in air breathed. J. Physiol. 24:19-35

Smith, P.K., R.I.Krohn, G.T.Hermanson, A.K.Mallia, F.H.Gartner, M.D.Provenzano, E.K.Fujimoto, N.M.Goeke, B.J.Olson, and D.C.Klenk. 1985. Measurement of protein using bicinchoninic acid. Analytical Biochemistry 150:76-85. 
Soloway H.B, Castillo Y, and Martin A.M. Jr. 1968. Adult hyaline membrane disease: relationship to oxygen therapy. Ann Surg. 168:937-945

Steenaart, N.A.E. and G.C.Shore. 1997. Mitochondrial cytochrome c oxidase subunit IV is phosphorylated by an endogenous kinase. FEBS Letters 415:294-298.

Stevens, E.D. 1992. Use of plastic materials in oxygen-measuring systems. Journal of Applied Physiology 72:801-804.

Stevens, J.B. and A.P.Autor. 1980. Proposed mechanism for neonatal rat tolerance to normobaric hyperoxia. Federation Proceedings 39:3138-3143.

Taanman, J.W. 1997. Human cytochrome c oxidase: Structure, function, and deficiency. Journal of Bioenergetics and Biomembranes 29:151-163.

Taanman, J.W., R.E.Hall, C.L.Tang, M.F.Marusich, N.G.Kennaway, and R.A.Capaldi. 1993. Tissue distribution of cytochrome-c-oxidase isoforms in mammals characterization with monoclonal and polyclonal antibodies. Biochimica et Biophysica Acta 1225:95-100.

Tangeras, A. 1986. Effect of decreased ferrochelatase activity on iron and porphyrin content in mitochondria of mice with porphyria induced by griseofulvin. Biochimica et Biophysica Acta 882:77-84.

Tian, L.Q., Q.Y.Cai, and H.C.Wei. 1998. Alterations of antioxidant enzymes and oxidative damage to macromolecules in different organs of rats during aging. Free Radical Biology and Medicine 24:1477-1484.

Towbin, H., T.Staehelin, and J.Gordon. 1979. Electrophoretic transfer of proteins from polyacrylamide gels to nitrocellulose sheets - procedure and some applications. 
Proceedings of the National Academy of Sciences of the United States of America $76: 4350-4354$.

Tsan, M.F., D.Lawrence, and J.E.White. 1991a. Erythrocyte insufflation-induced protection against oxygen-toxicity - role of cytokines. Journal of Applied Physiology $71: 1751-1757$.

Tsan, M.F., C.Y.Lee, and J.E.White. 1991b. Interleukin-1 protects rats against oxygen-toxicity. Journal of Applied Physiology 71:688-697.

Tsan, M.F., J.E.White, P.J.Delvecchio, and J.B.Shaffer. 1992a. Il-6 Enhances TNF-alpha-induced and IL-1-induced increase of mn superoxide-dismutase messengerRNA and $\mathrm{O}_{2}$ tolerance. American Journal of Physiology 263:L22-L26.

Tsan, M.F., J.E.White, and G.H.W.Wong. 1992b. D-factor and growth-hormone enhance tumor necrosis factor-induced increase of mn superoxide-dismutase messengerRNA and oxygen tolerance. Cytokine 4:101-105.

Tsan, M.F., J.E.White, and G.H.W.Wong. 1991c. Differentiation factor and growth-hormone protects rats against oxygen-toxicity. Faseb Journal 5:A890.

Turrens, J.F. 1997. Superoxide production by the mitochondrial respiratory chain. Bioscience Reports 17:3-8.

Turrens, J.F. 2003. Mitochondrial formation of reactive oxygen species. J Physiol. 552:335-344.

Turrens, J.F., A.Alexandre, and A.L.Lehninger. 1985. Ubisemiquinone is the electron donor for superoxide formation by complex III of heart mitochondria. Arch. Biochem. Biophys. 237:408-414. 
Turrens, J.F., B.A.Freeman, J.G.Levitt, and J.D.Crapo. 1982. The effect of hyperoxia on superoxide production by lung sub-mitochondrial particles. Archives of Biochemistry and Biophysics 217:401-410.

Vanitallie, C.M. and P.S.Dannies. 1988. Estrogen induces accumulation of the mitochondrial ribonucleic-acid for subunit-II of cytochrome-oxidase in pituitary-tumor cells. Molecular Endocrinology 2:332-337.

Vijayasarathy, C., I.Biunno, N.Lenka, M.Yang, A.Basu, I.P.Hall, and N.G.Avadhani. 1998. Variations in the subunit content and catalytic activity of the cytochrome c oxidase complex from different tissues and different cardiac compartments. Biochim. Biophys. Acta 1371:71-82.

Vijayasarathy, C., S.Damle, N.Lenka, and N.G.Avadhani. 1999. Tissue variant effects of heme inhibitors on the mouse cytochrome c oxidase gene expression and catalytic activity of the enzyme complex. European Journal of Biochemistry 266:191200.

Vijayasarathy, C., S.Damle, S.K.Prabu, C.M.Otto, and N.G.Avadhani. 2003. Adaptive changes in the expression of nuclear and mitochondrial encoded subunits of cytochrome c oxidase and the catalytic activity during hypoxia. European Journal of Biochemistry 270:871-879.

Villani, G., M.Greco, S.Papa, and G.Attardi. 1998. Low reserve of cytochrome c oxidase capacity in vivo in the respiratory chain of a variety of human cell types. J. Biol. Chem. 273:31829-31836. 
Villani, G. and G.Attardi. 1997. In vivo control of respiration by cytochrome c oxidase in wild-type and mitochondrial DNA mutation-carrying humanácells. PNAS 94:1166-1171.

Villani, G. and G.Attardi. 2000. In vivo control of respiration by cytochrome c oxidase in human cells. Free Radical Biology and Medicine 29:202-210.

Vozzelli, M.A., S.N.Mason, M.H.Whorton, and J.Auten. 2003. Anti-macrophage chemokine treatment prevents neutrophil and macrophage influx in hyperoxia-exposed newborn rat lung. Am J Physiol Lung Cell Mol Physiol00414.

Wan, B., C.Doumen, J.Duszynski, G.Salama, T.C.Vary, and K.F.Lanoue. 1993. Effects of cardiac work on electrical potential gradient across mitochondrial-membrane in perfused rat hearts. American Journal of Physiology 265:H453-H460.

Wanders, R.J.A., A.K.Groen, A.J.Meijer, and J.M.Tager. 1981. Determination of the free-energy difference of the adenine-nucleotide translocator reaction in rat-liver mitochondria using intra-mitochondrial and extra-mitochondrial atp-utilizing reactions. FEBS Letters 132:201-206.

Wong, A., P.Boutis, and S.Hekimi. 1995. Mutations in the clk-1 gene of Caenorhabditis elegans affect developmental and behavioral timing. Genetics 139:12471259.

Waterland, R.A., A.Basu, B.Chance, and R.O.Poyton. 1991. The isoforms of yeast cytochrome $\mathrm{c}$ oxidase subunit $\mathrm{V}$ alter the in vivo kinetic properties of the holoenzyme. J. Biol. Chem. 266:4180-4186.

Weishaupt, A. and B.Kadenbach. 1992. Selective removal of subunit-VIb increases the activity of cytochrome-c-oxidase. Biochemistry 31:11477-11481. 
Williams, A.J., J.Coakley, and J.Christodoulou. 1998. Automated analysis of mitochondrial enzymes in cultured skin fibroblasts. Analytical Biochemistry 259:176180.

Yoneda, M., K.Katsumata, M.Hayakawa, M.Tanaka, and T.Ozawa. 1995. Oxygen stress induces an apoptotic cell-death associated with fragmentation of mitochondrial genome. Biochemical and Biophysical Research Communications 209:723-729.

Yoshikawa, S. 1999. X-ray structure and reaction mechanism of bovine heart cytochrome c oxidase. Biochemical Society Transactions 27:351-362.

Yuyama, K., H.Yamamoto, I.Nishizaki, T.Kato, I.Sora, and T.Yamamoto. 2003. Caspase-independent cell death by low concentrations of nitric oxide in PC12 cells: Involvement of cytochrome c oxidase inhibition and the production of reactive oxygen species in mitochondria. Journal of Neuroscience Research 73:351-363.

Zeviani, M., S.Sakoda, A.A.Sherbany, H.Nakase, R.Rizzuto, C.E.Samitt, S.DiMauro, and E.A.Schon. 1988. Sequence of cDNAs encoding subunit $\mathrm{Vb}$ of human and bovine cytochrome c oxidase. Gene 65:1-11.

Zhang, J.G., M.A.Tirmenstein, F.A.Nicholls-Grzemski, and M.W.Fariss. 2001. Mitochondrial electron transport inhibitors cause lipid peroxidation- dependent and independent cell death: protective role of antioxidants. Arch. Biochem. Biophys. 393:8796.

Zhao, M., F.Antunes, J.W.Eaton, and U.T.Brunk. 2003. Lysosomal enzymes promote mitochondrial oxidant production, cytochrome c release and apoptosis. European Journal of Biochemistry 270:3778-3786. 
Zhao, M., U.T.Brunk, and J.W.Eaton. 2001. Delayed oxidant-induced cell death involves activation of phospholipase A2. FEBS Letters 509:399-404. 


\section{APPENDICES \\ LIST OF ABBREVIATIONS}

\begin{tabular}{|c|c|}
\hline BSA & bovine serum albumin \\
\hline$\beta-G A L$ & $\beta$-galactosidase \\
\hline cAMP & cyclic adenosine monophosphate \\
\hline $\mathrm{CCCP}$ & cyanide m-chlorophenylhydrazone \\
\hline $\mathrm{COX}$ & cytochrome $c$ oxidase \\
\hline $\mathrm{C}_{\mathrm{T}}$ & cycle threshold \\
\hline $\mathrm{DCF}$ & 2',7'-dichlorofluorescin \\
\hline DCFH-DA & dihydrodichlorofluorescein diacetate \\
\hline DCPIP & 2,6-dichlorophenolindophenol \\
\hline DMEM & Dulbecco's Modified Eagle's Medium \\
\hline DNP & 2,4-dinitrophenylhydrazine \\
\hline DTNB & dithionitrobenzoic acid \\
\hline DTT & dithiothreitol \\
\hline EB & ethidium bromide \\
\hline EDTA & ethylenediaminetetraacetic acid \\
\hline EGTA & ethylene glycol-bis (-aminoethyl ether) $N, N, N^{\prime}, N^{\prime}$-tetraacetic acid \\
\hline FBS & fetal bovine serum \\
\hline GR & glutathione reductase \\
\hline
\end{tabular}




\begin{tabular}{|c|c|}
\hline GSH & reduced glutathione \\
\hline GPX & glutathione peroxidase \\
\hline HBSS & Hank's Balanced Salt Solution \\
\hline HeLa-20 & wild-type HeLa cells \\
\hline HeLa-80 & oxygen-tolerant HeLa cells \\
\hline HK II & hexokinase II \\
\hline $\mathrm{H}_{2} \mathrm{O}_{2}$ & hydrogen peroxide \\
\hline $\mathrm{HO}^{\circ}$ & hydroxyl radical \\
\hline $\mathrm{HO}-1$ & heme oxygenase- 1 \\
\hline MnSOD & manganese superoxide dismutase \\
\hline mtDNA & mitochondrial DNA \\
\hline NMP & N-methyl protoporphyrin \\
\hline $\mathrm{O}_{2}$ & oxygen \\
\hline $\mathrm{O}_{2}^{-}$ & superoxide anion \\
\hline$\rho^{\circ}$ cells & cells lacking of mtDNA \\
\hline$\rho^{\circ}$ cybrids & $\rho^{\circ}$ cells with reconstituted mitochondria \\
\hline PBS & phosphate buffered saline \\
\hline PEG & Polyethylene glycol 2000 \\
\hline PMSF & phenylmethylsulfonyl fluoride \\
\hline (RT)-PCR & reverse transcriptase-PCR \\
\hline ROS & reactive oxygen species \\
\hline siRNA & small interfering RNA \\
\hline SOD & superoxide dismutase \\
\hline
\end{tabular}


TCA

Tris- $\mathrm{HCl}$

TTFA

Tween 20 trichloroacetic acid

tris-(hydroxymethyl)aminomethane hydrochloride thenoyltrifluoroacetone

polyoxyethylene-20-sorbitan monolaurate 


\section{CURRICULUM VITAE}

NAME: Jian Li

ADDRESS: 627 S. Preston St. Apt \#5J

Louisville, KY 40202

DOB: Heilongjian, P. R. China - January 9, 1974

EDUCATION \& TRAINING:

M.D., Medicine

Tianjin Medical University, Tianjin, P. R. China

1992-1997

M.S., Pathophysiology

Peking Union Medical College, Beijing, P. R. China

1997-2000

M.S., Pharmacology and Toxicology

University of Louisville, Louisville, Kentucky, USA

2000-2002

PROFESSIONAL EXPERIENCE

Aug. 2000 - Nov. 2003

Graduate Research Fellow, Department of Pharmacology and Toxicology, University of Louisville, Kentucky

Sept. 1997 - July. 2000

Graduate Research Assistant, Department of Pathophysiology, Institute of Basic Medical Science, Peking Union Medical College, Beijing, P.R. China

HONORS AND AWARDS:

Honorable Mention For Outstanding Student Presentation - Ohio Valley Chapter Society of Toxicology, Cincinnati, OH, Nov. 7, 2003. 
SFRBM 2003 Travel Award Winner - Society for Free Radical Biology and Medicine (SFRBM) $10^{\text {th }}$ Annual Meeting, Seattle, Washington, 2003.

Condict Moore Student Research Award $\left(3^{\text {rd }}\right.$ place $)$ - at the $2^{\text {nd }}$ annual University of Louisville Cancer Center retreat, 2003.

Graduate Travel Award Recipient (2003) - Society of Toxicology $42^{\text {nd }}$ Annual Meeting, Salt Lake City, Utah, 2003.

Graduate Student Travel Award - School of Medicine, University of Louisville, 2003.

Condict Moore Best Poster Prize - Molecular Targets Retreat, University of Louisville, Kentucky, 2002

Oral Presentation at Ohio Valley Society of Toxicology 2002 annual meeting, 2002

Graduate Fellow 2001-2002 - IPIBS, University of Louisville

\section{MEMBERSHIP:}

Society of Toxicology

Society for Free Radical Biology and Medicine (SFRBM)

\section{PUBLICATIONS \& ABSTRACTS:}

Li J, Gao XS, Qian M, Eaton JW. Oxygen toxicity: A metabolic disease. Free Radical Biology and Medicine (Manuscript submitted, under review)

Li J, Gao XS, Qian M, Joenje H, Eaton JW. Hyperoxic cell injury: Conspiracy between oxygen and mitochondria. Society for Free Radical Biology and Medicine (SFRBM) $10^{\text {th }}$ Annual Meeting, 2003 (abstract and poster presentation)

Li J, Gao XS, Qian M, Eaton JW. Mitochondrial metabolism: The root of hyperoxic cell damage. Ohio Valley Society of Toxicology 2003 annual meeting, November 7, 2003 (abstract and student poster competition)

Li J, Gao XS, Qian M, Joenje H, Eaton JW. Oxygen toxicity and mitochondrial function. Ohio Valley Society of Toxicology 2003 annual meeting, November 7, 2003 (abstract and student poster competition)

Li J, Gao XS, Qian M, Joenje H, Eaton JW. Mechanism of cellular oxygen toxicity: evidence for mitochondrial respiration as the main subcellular target. Research! Louisville 2003 (abstract and poster) 
Gao XS, Qian MW, Li J, Eaton JW. Cardiac dysfunction in iron overload may arise from cumulative damage to mitochondrial DNA. Ohio Valley Society of Toxicology 2003 annual meeting, November 7, 2003 (abstract and poster)

Li J, Gao XS, Qian M, Joenje H, Eaton JW. Hyperoxic cell injury: Conspiracy between oxygen and mitochondria. Cancer Center Second Annual Retreat, September 17, 2003 (abstract and poster competition)

Gao XS, Qian MW, Li J, Eaton JW. Cardiac dysfunction in iron overload may arise from cumulative damage to mitochondrial DNA. Cancer Center Second Annual Retreat, September 17, 2003 (abstract and poster competition)

Li J, Gao XS, Qian M, Eaton JW. Oxygen toxicity: a metabolic disease. Society of Toxicology 42nd annual meeting, March 9-13, 2003 (abstract and poster)

Li J, Gao XS, Qian M, Eaton JW. Oxygen toxicity: a metabolic disease. Ohio Valley Society of Toxicology 2002 annual meeting, November 2002 (oral presentation and student poster competition)

Li J, Qian M, Gao XS, Eaton JW. Oxygen toxicity: a metabolic disease. Research! Louisville 2002 (abstract and poster)

Li J, Qian M, Gao XS, Eaton JW. Mitochrondrial metabolism and oxygen toxicity. Cancer Center First Annual Retreat, September 18, 2002 (abstract and poster)

Li J, Qian M, Gao XS, Eaton JW. Oxygen toxicity: a metabolic disease. Systems Biology Approaches to Health Care: Mitochondrial Proteomics, NIST, September 2002 (abstract and poster)

Li J, Qian M, Gao XS, Eaton JW. Mitochrondrial metabolism and oxygen toxicity. Systems Biology Approaches to Health Care: Mitochondrial Proteomics, NIST, September 15-17, 2002 (abstract and poster)

Li J, Qian M, Gao XS, Eaton JW. Potential mechanisms of oxygen tolerance in human cells. 3rd International Conference on Oxygen/Nitrogen Radicals: Cell Injury and Disease, June 2002 (abstract and poster)

Li J, Qian M, Eaton JW. Potential mechanisms of oxygen tolerance in human cells. Society of Toxicology 41st annual meeting, p82, March 2002 (abstract and poster)

Li J, Qian M, Eaton JW. Potential mechanisms of oxygen tolerance in human cells. Ohio Valley Society of Toxicology 2001 annual meeting, p9, November 2001 (abstract and student poster competition)

Li J, Eaton JW. Potential mechanisms of oxygen tolerance in human cells. Research! Louisville 2001 
